\title{
Aspectos Práticos Computacionais dos Algoritmos de Simulação MCMC
}

\author{
Ana Cláudia Oliveira de Melo
}

Orientador: Prof. Dr. Marinho Gomes de Andrade Filho

Dissertação apresentada ao Instituto de Ciências Matemáticas e de Computação - ICMC-USP, como parte dos requisitos para obtenção do título de Mestre em Ciências - Área: Ciências de Computação e Matemática Computacional. 
"Produze, a cada momento, uma sementeira de amor, deixando pela estrada percorrida os sinais da esperança e do bem.

Talvez retornes pelo mesmo caminho, realizando uma nova experiência. $E$, se, por acaso, não volveres por ai, aqueles que o irão percorrer te bendirão o labor realizado."

Joana de Angelis

Aos meus pais, que me ensinaram a não desistir, e por toda força e amor que sempre me deram. 
Agradecimentos:

À Deus pela oportunidade de mais essa realização.

Ao amigo, colega e prof. Maninho Gomes de Andrade Filho, pela abertura à discussão e importante orientação no decorrer desse trabalho.

A UFPB, professores do D.E. e demais colegas de trabalho que juntos deram-me a oportunidade e condições possiveis de realizar este mestrado.

Aos amigos Ronei Marcos e Cláudia Lima por todo o apoio e incentivos muito importantes no meu desempenho e concentração.

Aos professores, funcionánios, colegas de pós-graduação e a todos aqueles que de alguma maneira contribuíram para a realização deste trabalho. todos os dias.

Ao Gustavo Alberto Krüger pela paciência, companheinismo, amor e amizade de

A Maria Nilda, por todo o carinho e incentivos durante essa jornada.

Aos irmãos de sangue e de fé, desta e de outras dimensões, que certamente torceram a todo tempo pelo sucesso intelectual e espinitual que certamente me foram exigidos ao longo desta jornada. 


\begin{abstract}
The algorithms of Monte Carlo Markov Chain simulation have application in many areas of statistics, among them we highlight the Bayesian inference problem. The application of these technics however, demands a theoretical analysis of the posterior distribution to assure the convergence. Because of the high complexity level of certain problems, this analysis is not always possible the purpose of this study is to underline this difficulties and present some practical computational aspects that may help in the solution of the Bayesian inference problems. Among them we emphasize sample selection, convergence diagnostics and parameter inference by central limit theorem.
\end{abstract}




\section{Resumo}

Os algoritmos de simulação de Monte Carlo em cadeia de Markov (MCMC) têm aplicações em várias áreas da Estatística, entre elas destacamos os problemas de Inferência Bayesiana. A aplicação destas técnicas no entanto, exige uma análise teórica da distribuição a posteriori para assegurar a convergência. Devido ao alto grau de complexidade de certos problemas, essa análise nem sempre é possível. O objetivo deste estudo é destacar estas dificuldades e apresentar alguns aspectos práticos computacionais que podem auxiliar na solução de problemas de inferência Bayesiana. Entre estes ressaltamos os critérios de seleção de amostras, o uso de técnicas de diagnósticos de convergência e métodos de estimativas. 


\section{SUMÁRIO}

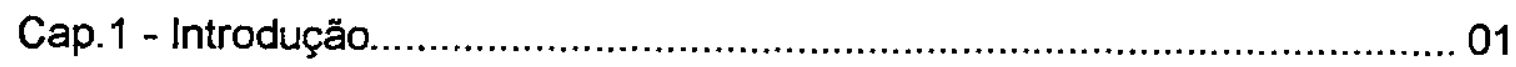

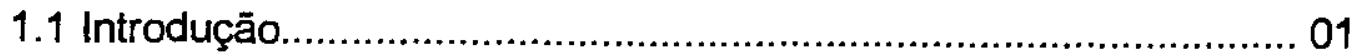

1.2 Apresentaçăo de Alguns Exemplos.............................................. 03

1.2.1 Modelo Hierárquico (Albert, 1996)...................................... 04

1.2.2 Estimando a Média Comum de Populaçōes Normais Independentes (Gregurich and Broemeling, 1997)......................... 06

Cap 2 - Métodos de Simulação de Monte Carlo em Cadeia de Markov............ 09

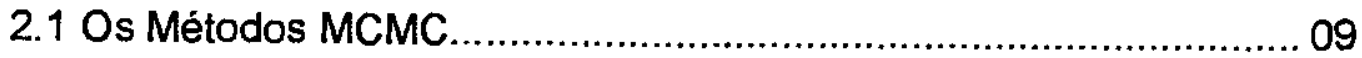

2.2 Algumas Cadeias de Markov.......................................................... 09

2.30 Algoritmo de Metropolis-Hastings.......................................... 11

2.3.1 Cadeia de Passeio Aleatório................................................. 16

2.3.2 Cadeia Independente................................................... 16

2.3.3 Cadeia de Amostragem de Rejeição.................................. 17

2.3.4 Cadeia Autoregressiva................................................... 19

2.4 Condicionamento................................................................... 20

2.50 Amostrador de Gibbs............................................................ 21

2.6 Combinando Estratégias............................................................ 24

$2.7 \mathrm{O}$ Uso do Teorema do Limite Central........................................... 25

Cap 3 - Alguns Resultados Teóricos de Cadeia de Markov............................. 27

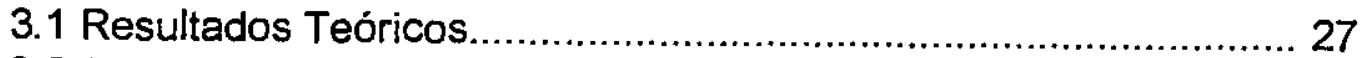

3.2 Convergência de Distribuições....................................................... 28

3.3 Taxas de Convergência............................................................. 31

3.4 Comportamento Limite das Médias........................................... 36

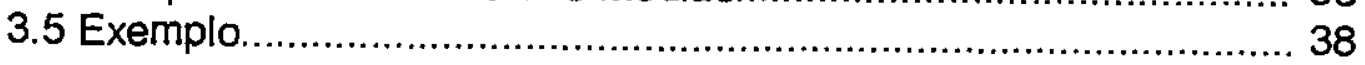

Cap 4 - Implementando os Resultados .................................................. 42

4.1 Formação da Amostra.................................................................. 42

4.2 Determinando o Tamanho da Cadeia........................................ 44

4.3 Redução da Variância................................................................ 45

4.3.1 Reamostragem Ponderada........................................... 45

4.3.2 Condicionando.................................................................. 46

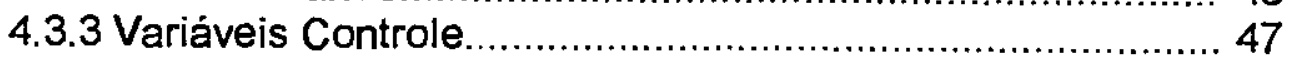


5.1 Convergência em MCMC.......................................................... 48

5.2 Diagnósticos de Convergência MCMC......................................... 49

5.2.1 Gelman e Rubin........................................................ 49

5.2.2 Raftery e Lewis............................................................. 51

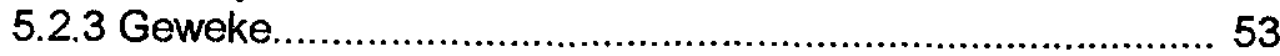

5.2.4 Zellner e Min................................................................. 54

5.2.5. Outros Métodos................................................................. 55

Cap 6 - Alguns Problemas Bayesianos....................................................... 56

6.1 O Primeiro problema................................................................... 56

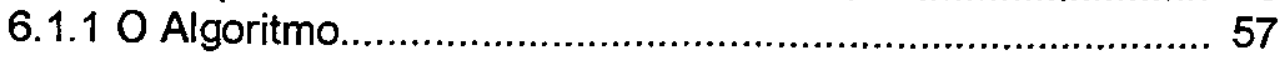

6.1.2 A llustraçăo do algoritmo................................................. 58

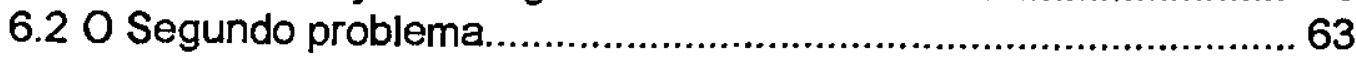

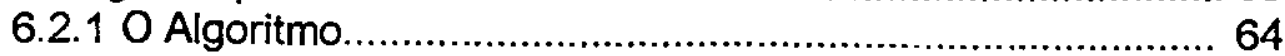

6.2.2 A llustração do algoritmo................................................... 65

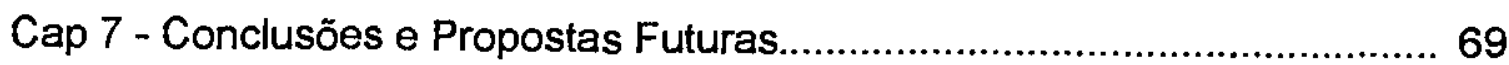

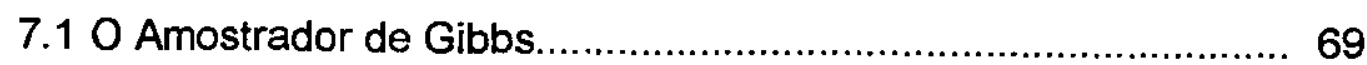

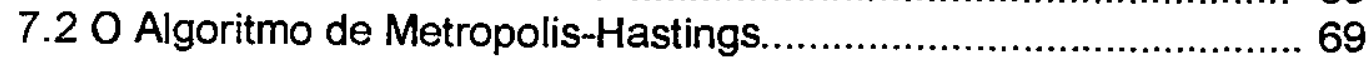

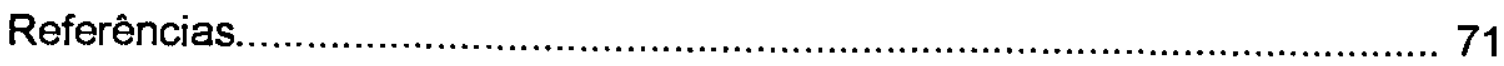

Anexos 


\section{CAPÍTULO 1}

\subsection{Introdução}

Recentemente os estatisticos têm se voltado cada vez mais para os métodos de simulação de Monte Carlo em Cadeia de Markov (MCMC), que surgiram como ferramentas extremamente populares com o intuito de simular distribuições multivariadas fora do padrão. Isto torna-se especialmente verdadeiro no campo da Inferência Bayesiana, a qual exige a resolução de integrais complexas e geralmente de alta dimensão.

A operação de integração executa um papel importante na inferência Bayesiana. Por exemplo, dado uma amostra simples $y$ de uma distribuição com verossimilhança $L(y \mid x)$ e uma densidade a priori para $\boldsymbol{x} \in \mathfrak{R}^{P}$ denotada por $p(\boldsymbol{x})$, de acordo com o teorema de Bayes a posteriori $\pi(x \mid y)$ será dada por:

$$
\pi(x \mid y) \propto L(y \mid x) p(x)
$$

onde a constante de proporcionalidade é dada por:

$$
K=\int L(y \mid x) p(x) d x
$$

Conhecendo-se a distribuição a posteriori, e considerando-se o caso onde $x=\left(x_{1}, x_{2}\right)$ é multivariada, por exemplo, podemos estar interessados na distribuição a posteriori marginal:

$$
\pi\left(x_{1} \mid y\right)=\int \pi\left(x_{1}, x_{2} \mid y\right) d x_{2}
$$


Alternativamente, podemos estar interessados em determinar propriedades importantes sobre os parâmetros, tais como o valor esperado a posteriori

$$
E\{\theta(x) \mid y\}=\int \theta(x) \pi(x \mid y) d x
$$

Entretanto a resolução desta integral e de funções de alta dimensão é em geral complexa e de estrema importância na estatística Bayesiana, seja no cálculo da constante normalizadora na expressão (1.1), na distribuição marginal na equação (1.2) ou no cálculo da esperança na equação (1.3)

Geralmente, a resolução direta destas integrais não é possível e, tradicionalmente empregaríamos o uso da integração numérica ou técnicas de aproximação analítica [ver Smith 1991]. Entretanto, encontramos nos métodos de simulação de Monte Carlo em Cadeia de Markov a alternativa de amostrarmos diretamente da posteriori, obtendo estimativas amostrais de quantidades de interesse, performando desse modo a integração implícita.

A idéia da amostragem através dos métodos de MCMC, foi inicialmente introduzida por Metropolis, Rosenbluth, Rosenbluth, Teller, e Teller (1953) como um método para simulação eficiente dos niveis de energia dos átomos na estrutura cristalina e subseqüentemente adaptado e generalizado por Hastings (1970) enfocando problemas estatísticos. A idéia é extremamente simples. Suponha que temos uma distribuição $\pi(x)$ qualquer, $x \in E \subseteq \mathfrak{R}^{p}$, da qual conhecemos apenas a constante multiplicativa. Geralmente nos referimos a essa distribuição como a distribuição alvo ou de equilibrio. Se $\pi$ é suficientemente complexa de modo que não possamos amostrar diretamente dela, um método indireto de obtermos a amostra de $\pi$ é construindo uma cadeia de Markov aperiódica e irredutível com espaço de estados $E$, e cuja a distribuição estacionária (ou invariante) é $\pi(x)$. Então se simulamos uma longa cadeia de acordo com essa estrutura descrita acima, os valores simulados são considerados uma amostra dependente da distribuição de equilibrio e estes podem ser usados para sumarizar importantes caracteristicas de $\pi$, sobe as quais é possível fazer inferências.

Sob certas condições de regularidade dadas em Roberts e Smith (1994) por exemplo, a trajetória da amostra da cadeia de Markov imita uma amostra aleatória de $\pi$. Dadas realizações $\left\{X^{(n)}: n=0,1, \ldots\right\}$ de uma cadeia, resultados tipicamente assintóticos concluem que a 
distribuição dos estados desta cadeia no tempo $t$ converge para $\pi$ com $N \rightarrow \infty$, e a consistência da média ergódica, para alguma função escalar $\theta$,

$$
\frac{1}{N} \sum_{n=1}^{N} \theta\left(X^{(n)}\right) \stackrel{N \rightarrow \infty}{\longrightarrow} E_{n}\{\theta(X)\} \quad \text { quase certamente. }
$$

Importantes resultados de implementação são associados aos métodos MCMC. Estes incluem muitos outros como a escolha do núcleo de transição da cadeia, o número de cadeias a serem executadas, o tamanho da cadeia, a escolha dos valores iniciais, etc.

Este trabalho tem como objetivo, analisar os aspectos do uso dos métodos MCMC na Inferência Bayesiana. Na próxima seção deste capítulo faremos uma breve introdução sobre alguns problemas de Inferência Bayesiana, e para estes vamos observar a necessidade da simulação das amostras através dos métodos MCMC para o cálculo dos estimadores dos parâmetros de interesse. No capítulo dois, descreveremos os métodos de simulação MCMC, assim como alguns dos algoritmos mais usados. O capítulo três aborda alguns resultados teóricos da cadeia de Markov importantes no estudo na convergência dos algoritmos MCMC. No capítulo quatro ressaltamos alguns tópicos sobre aspectos práticos na implementação dos algoritmos e obtenção dos resultados. No capítulo cinco discutimos sobre o problema da convergência e abordamos alguns dos diagnósticos de convergência mais utilizados. $\mathrm{O}$ capítulo seis apresenta possíveis soluções para os problemas apresentados ao longo dos capítulos anteriores utilizando os métodos de simulação MCMC. O capítulo sete lista as propostas futuras para este trabalho.

\subsection{Apresentação de alguns exemplos}

Apresentaremos nesta subseção, alguns exemplos para os quais observaremos que em decorrência da necessidade de uma análise Bayesiana completa em modelos mais complexos, tais como, o modelo hierárquico ou até mesmo um modelo que envolva muitos parâmetros, as dificuldades com respeito a obtenção das distribuições marginais através da integração analítica torna-se bastante dificil, quando não impossível. Para estes exemplos apresentaremos no capítulo seis possíveis soluções utilizando os métodos de simulação MCMC. 


\subsubsection{Modelo Hierárquico (Albert, 1996)}

\section{A Densidade dos dados}

Considere um modelo hierárquico permutável Bayesiano onde $X$ é uma variável aleatória com distribuição de Bernoulli e $P(x \in A)=p$, ou seja, $p$ é o parâmetro de interesse deste estudo. Definimos agora:

$$
\mu_{i}=\frac{1}{n_{i}} \sum_{j=1}^{n_{i}} x_{i j}, i=1, \ldots, N \Rightarrow\left(n_{i}, \mu_{i}\right) \sim \operatorname{Bin}\left(p_{i}, n_{i}\right) \Rightarrow n_{i}, \mu_{i}=\sum_{j=1}^{n_{i}} x_{i j}
$$

assim, $P\left(Y_{i}=n_{i} \mu_{i}\right) \propto p^{n_{i} \mu_{i}}(1-p)^{n_{i}-n_{i} \mu_{i}}$. Usando agora a seguinte transformação:

$$
\theta_{i}=\log \left(\frac{p_{i}}{1-p_{i}}\right) \Rightarrow p_{i}=\frac{e^{\theta_{i}}}{1+e^{\theta_{i}}}
$$

Seja $Y=\left(\mu_{1} n_{1}, \cdots, \mu_{N} n_{N}\right)$, teremos que $f\left(\mu_{1} n_{1}, \ldots, \mu_{N} n_{N}\right) \propto \prod_{i=1}^{N} e^{n_{t} \mu_{t} \theta_{1}}\left(1+e^{\theta_{l}}\right)^{-n_{1}}$, ou seja:

$$
f(\boldsymbol{Y} \mid \boldsymbol{\theta}) \propto \prod_{i=1}^{N} e^{\eta_{\mu_{1} \theta_{i}}}\left(1+e^{\theta_{t}}\right)^{-n_{t}}, \quad \boldsymbol{\theta}=\left(\theta_{1}, \theta_{2}, \ldots, \theta_{N}\right)
$$

\section{A Priori para $\theta$}

Supondo $\theta_{1} \sim N\left(m, \tau^{2}\right)$ e fazendo a seguinte transformação: $\lambda_{1}=m$ e $\lambda_{2}=\log \tau^{2}$, a priori para $\theta$ será dada por:

$$
g\left(\theta \mid \lambda_{1}, \lambda_{2}\right) \propto \prod_{i=1}^{N} e^{-\lambda_{2} / 2} \exp \left\{\frac{-\left(\theta_{1}-\lambda_{1}\right)^{2}}{2 e^{\lambda_{2}}}\right\}
$$




\section{A Priori para os Hiper-parâmetros $\lambda_{1}$ e $\lambda_{2}$}

Considerando que $\lambda_{1}$ e $\lambda_{2}$ são variáveis aleatórias, supomos:

$$
\lambda_{1} \sim N\left(\delta_{1}, \gamma_{1}\right) \text { e } \quad \lambda_{2} \sim N\left(\delta_{2}, \gamma_{2}\right)
$$

ou seja, $\lambda_{1}$ e $\lambda_{2}$ são independentes. Então a priori para $\lambda_{1}$ e $\lambda_{2}$, será dada por:

$$
h\left(\lambda_{1}, \lambda_{2}\right) \propto \exp \left\{-\frac{\left(\lambda_{1}-\delta_{1}\right)^{2}}{2 \gamma_{1}}\right\} \exp \left\{-\frac{\left(\lambda_{2}-\delta_{2}\right)^{2}}{2 \gamma_{2}}\right\}
$$

\section{A Distribuição a Posteriori Conjunta}

Como estamos tratando de um modelo hierárquico, a posteriori para $\theta$ é dada, de acordo com o Teorema de Bayes, por:

$$
\pi\left(\boldsymbol{\theta}, \lambda_{1}, \lambda_{2} \mid \boldsymbol{Y}\right) \propto f(\boldsymbol{\theta} \mid \boldsymbol{Y}) g\left(\boldsymbol{\theta} \mid \lambda_{1}, \lambda_{2}\right) h\left(\lambda_{1}, \lambda_{2}\right)
$$

ou seja,

$$
\pi\left(\theta, \lambda_{1}, \lambda_{2} \mid \boldsymbol{Y}\right) \propto \prod_{i=1}^{N} e^{\eta_{1} \theta_{1} \mu_{1}}\left(1+e^{\theta_{i}}\right)^{-n_{1}} e^{-\lambda_{2} / 2} e^{-\frac{\left(\theta_{1}-\lambda_{1}\right)^{2}}{2 e^{2}}} e^{-\frac{\left(\lambda_{1}-\delta_{1}\right)^{2}}{2 \gamma_{1}}} e^{-\frac{\left(\lambda_{2}-\delta_{2}\right)^{2}}{2 \gamma_{2}}}
$$

As Condicionais para os Parâmetros $\theta$ e $\lambda=\left(\lambda_{1}, \lambda_{2}\right)$

A partir da equação (1.7) podemos construir as distribuições condicionais $\pi(\theta \mid \lambda, Y)$ e $\pi(\lambda \mid \boldsymbol{\theta}, \mathbf{Y})$. 


$$
\begin{aligned}
& \pi(\theta \mid \lambda, Y) \propto N\left(\lambda_{1}, e^{\lambda_{2}} I_{N}\right) \Psi_{1}(\theta), \text { onde: } \Psi_{1}(\theta) \propto \prod_{i=1}^{N} e^{n_{t} \theta_{1} \mu_{1}}\left(1+e^{\theta_{t}}\right)^{-n_{l}} \\
& \pi(\lambda \mid \theta, Y) \propto N(\delta, \Sigma) \Psi(\theta, \lambda) \quad, \text { onde: } \Psi_{2}(\theta, \lambda) \propto \prod_{i=1}^{N} e^{-\lambda_{2} / 2} \exp \left\{-\frac{\left(\theta_{l}-\lambda_{1}\right)^{2}}{2 e^{\lambda_{2}}}\right\}
\end{aligned}
$$

Observamos então que, devido a complexidade do modelo hierárquico, a integração da equação (1.7) para os cálculos dos parâmetros de interesse para inferências é de dificil solução, entretanto este problema foi resolvido por simulação MCMC a partir da simulação amostral das condicionais dadas nas equações (1.8) e (1.9) para gerar amostras da distribuição de equilibrio $\pi\left(\theta, \lambda_{1}, \lambda_{2}\right)$.

\subsubsection{Estimando a média comum de populaçōes normais independentes (Gregurich \& Broemeling, 1997)}

\section{A Densidade dos dados}

Considere $k$ populações independentes e normalmente distribuídas, $N\left(\theta, \tau_{i}^{-1}\right)$ para $\mathrm{i}=1$. 2. .... $k$ onde os parâmetros, $\tau_{1}, \tau_{2}, \ldots, \tau_{\mathrm{k}}$ são desconhecidos e $\theta$ é uma média comum desconhecida. Suponha que $X_{i j}$ representa o conjunto de observações de $k$ amostras independentes e $j=1,2, \ldots, n_{i}$. Então a densidade conjunta da variável amostral é:

$$
f\left(X_{i j} \mid \theta, \tau_{1}, \tau_{2}, \ldots, \tau_{\mathrm{k}}\right) \propto \prod_{i=1}^{\mathrm{k}} \tau_{i}^{n_{1} / 2} \exp \left\{\frac{-\tau_{i}}{2}\left[\left(n_{i}-1\right) S_{i}^{2}+n_{i}\left(\theta-\bar{X}_{i}\right)^{2}\right]\right\}
$$

onde $\quad S_{i}^{2}=\sum_{j=1}^{n_{t}}\left(x_{i j}-\bar{X}_{i}\right)^{2} /\left(n_{i}-1\right)$ e $\bar{X}_{t}=\sum_{j=1}^{n_{i}} x_{i j} / n_{i}$

obs: $\quad \sum_{j=1}^{n_{i}}\left(x_{i j}-\theta\right)^{2}=\left(n_{i}-1\right) S_{i}^{2}+n_{i}\left(\theta-\bar{X}_{i}\right)^{2} \quad$ e $\quad \tau_{i}=1 / \sigma_{i}^{2}$ 


\section{A Priori não informativa para os parâmetros $\theta$ e $\tau_{1}, \tau_{2}, \ldots, \tau_{k}$}

Lembrando que, a priori não informativa é usada quando dispomos de pouca, ou mesmo de nenhuma informação a priori.

$$
\pi\left(\theta, \tau_{1}, \tau_{2}, \ldots, \tau_{k}\right) \propto \prod_{i=1}^{k} 1 / \tau_{\mathfrak{i}}, \quad i=1,2, \ldots, k \quad \theta \in \Re \quad e \quad \tau_{i}>0
$$

\section{A Distribuição a Posteriori Conjunta}

E a partir do produto das equações 1.10 e 1.11 obtemos a distribuição a posteriori conjunta dos parâmetros de acordo com a equação a seguir

$$
\pi\left(\theta, \tau_{1}, \tau_{2}, \ldots, \tau_{\mathrm{k}} \mid X_{i j}\right) \propto \prod_{i=1}^{\mathrm{k}} \tau_{i}^{\left(n_{i} / 2\right)-1} \exp \left\{\frac{-\tau_{i}}{2}\left[\left(n_{i}-1\right) S_{i}^{2}+\left(\theta-\bar{X}_{i}\right)^{2}\right]\right\}
$$

\section{As Condicionais para os parâmetros $\theta \quad e \quad \tau_{\mathrm{i}}$}

Teremos então as seguintes condicionais:

$$
\begin{aligned}
& \pi\left(\theta \mid \tau_{1}, \tau_{2}, \ldots, \tau_{k}\right) \sim N\left[\left(\sum_{i=1}^{k} n_{i} \tau_{i} \bar{X}_{i} / \sum_{i=1}^{k} n_{i} \tau_{i}\right),\left(\sum_{i=1}^{k} n_{i} \tau_{i}\right)^{-1}\right] \\
& \pi\left(\tau_{i} \mid \theta\right) \sim \operatorname{Gama}\left[n_{i} / 2 ;\left(\left(n_{i}-1\right) S_{i}^{2}+n_{i}\left(\theta-\bar{X}_{i}\right)^{2}\right) / 2\right]
\end{aligned}
$$

Do mesmo modo que no exemplo 1.2. I observamos as dificuldades de obtenção dos parâmetros de interesse via integração da equação 1.12. Esse problema será tratado no capitulo 6 usando-se algoritmo MCMC. 
Observamos então que, a integração da equação da densidade a posteriori conjunta nos dois exemplos, para as estimativas dos parâmetros de interesse da inferência, é de dificil solução devido a sua complexidade e ou o número de parâmetros envolvidos. Porém este problema pode ser resolvido por simulação MCMC a partir da simulação amostral das distribuiç̃oes condicionais para cada um dos parâmetros, como será mostrado no capítulo 6 .

Para aplicarmos os métodos de simulação MCMC é necessário, entretanto, um conhecimento teórico do seu mecanismo de funcionamento para que essa ferramenta não se torne mais um problema. Todavia para um usuário aplicado, geralmente não fica claro quais os resultados teóricos que são relevantes para o seu problema. Este trabalho descreve nos capítulos seguintes algumas implicações práticas dos vários resultados teóricos sobre MCMC. No entanto, algumas sugestões feitas neste trabalho não são estritamente implicadas pela teoria, mesmo porque os resultados teóricos não podem responder todas questões sobre o uso de MCMC. Algumas sugestões são intuitivas e baseadas em experiências. 


\section{CAPÍTULO 2}

\section{Métodos de Simulação de Monte Carlo em Cadeia de Markov (MCMC)}

\subsection{Os Métodos MСмC}

Os métodos MCMC consistem numa familia de algoritmos iterativos usados para gerar amostras de distribuições multivariadas. Os algoritmos MCMC, tais como o Metropolis-Hastings (Metropolis at al, 1953; Hastings, 1970) e Gibbs Sampler (Geman e Geman, 1984; Gelfand e Smith, 1990) têm se tornado uma ferramenta extremamente popular na área da estatística [ver por exemplo as recentes revisões Smith e Roberts, 1993; Chib e Greenberg, 1995; Casella e George, 1992]. Além das muitas aplicações, constata-se um progresso substancial nos aspectos teóricos desses algoritmos. Na seção 2.2 a seguir, faremos uma breve revisão da teoria da cadeia de Markov e nas seções subsequentes apresentaremos alguns desses importantes algoritmos.

\subsection{Algumas Cadeias de Markov}

Uma Cadeia de Markov com distribuição invariante $\pi$ é uma seqüência de valores da v.a. $\left\{X^{(n)} ; n \geq 0\right\} X^{(n)} \in \mathfrak{R}^{q}$, tal que o núcleo de transição $P$ que denota a probabilidade de mudança de um estado atual $X^{(n)}$ para um estado $X^{(n+1}$, é definido por:

$$
P\left(X^{(n)}, A\right)=P\left\{X^{(n+1)} \in A \mid X^{(0)}, \ldots, X^{(n)}\right\}, A \in \mathfrak{R}^{q}
$$

e satisfaz a seguinte condição:

$$
\pi(A)=\int \pi(d x) P(x, A)
$$


para toda medida do conjunto $A$.

A distribuição de $X^{(0)}$ é a distribuição inicial da cadeia. A distribuição condicional de $X^{(n)}$ dado $X^{(0)}$ é escrita como:

$$
P\left\{X^{(n)} \in A \mid X^{(0)}\right\}=P^{n}\left(X^{(0)}, A\right)
$$

onde $P^{n}$ denota a $n$-ésima iteração do núcleo $P$.

A distribuição invariante $\pi$ é uma distribuição de equilibrio para a cadeia se para todo $x$

$$
\lim _{n \rightarrow \infty} P^{n}(x, A)=\pi(A)
$$

para toda medida do conjunto $A$.

Uma cadeia de Markov com distribuição invariante $\pi$ é irredutível se, para algum estado inicial, existe uma probabilidade positiva de transitar para qualquer conjunto ao qual $\pi$ atribui uma probabilidade positiva. Uma cadeia é periódica se as visitas aos espaços de estados ocorrem espaçadamente com uma certa regularidade, de outro modo a cadeia é aperiódica. Se a cadeia tem distribuição invariante $\pi$ e esta é irredutível e aperiódica, então $\pi$ é a única distribuição invariante e é também a distribuição de equilibrio da cadeia.

Quando o processo de Markov atinge uma distribuição de equilíbrio $\pi$, tal que em equilibrio $\pi\left(X^{(n)}\right)=\pi\left(X^{(n+1)}\right)$, então dizemos que a cadeia satisfaz a propriedade de reversibilidade

$$
\pi(x) P(x, y)=\pi(y) P(y, x)
$$

Este conceito significa dizer que, se estamos na estacionariedade, a cadeia de Markov tem a mesma chance de estando em $x$, saltar para $y$ que de estando em $y$, saltar para $x$.

Desta maneira para gerar amostras da distribuição de equilíbrio $\pi$, nós realizamos uma cadeia de Markov com núcleo de transição $P(x ;)$ satisfazendo a condição de reversibilidade (2.2), até a cadeia atingir a distribuição de equilíbrio.

Resultados mais teóricos sobre estas e outras características mais importantes da cadeia de Markov serão vistos no capítulo 3. 


\subsection{O Algoritmo de Metropolis-Hastings (M-H)}

O algoritmo de Metropolis foi originalmente introduzido por Metropolis et al (1953) para calcular propriedades das substâncias compostas da interação individual das moléculas. Uma variação deste algoritmo foi proposta por Baker (1965). Uma generalização foi introduzida por Hastings (1970) e estudada futuramente por Peskun (1973). O algoritmo de Metropolis forma a base dos algoritmos simulados (Kirkpatrick et al., 1983). Na reconstrução dos problemas de Inferência Bayesiana discreta considerados por Geman e Geman (1984), o amostrador de Gibbs pode ser visto como um caso especial da versão Barker's do algoritmo de Metropolis.

O Algoritmo de Metropolis-Hastings se propõe a gerar valores de uma variável aleatória com densidade $\pi(x)$, quando essa não é padronizada, ou seja, quando não sabemos gerar diretamente de $\pi(x)$. Para isso, o algoritmo utiliza um núcleo de geração que denotamos pela densidade condicional $q(x, y)$ da qual sabemos gerar valores que serão candidatos a valores de $\pi(x)$.

A base teórica deste algoritmo consiste em interpretar a seqüência gerada $x_{1}, x_{2}, \ldots$, como uma trajetória de um processo de Markov com densidade de probabilidade de transição $q(x, y)$ e distribuição de probabilidade denotada por $Q(y, A)=P(x \in A \mid Y=y)$. Portanto a densidade geradora de candidatos satisfaz a seguinte condição:

$$
\int q(x, y) d y=1
$$

Esta densidade pode ser interpretada da seguinte maneira: quando um processo está no ponto $x$ e no estágio $n$, para o processo passar para o estágio $n+l$ a densidade $(q(x, y))$ gera um valor $y$. Se $q(x, y)$ satisfaz a condição de reversibilidade (2.2) para todo $(x, y)$, ou seja:

$$
q(x, y) \pi(x)=q(y, x) \pi(y)
$$

então encontramos um núcleo de transição satisfatório e todos os pontos serão aceitos. Entretanto podemos encontrar que para algum $(x, y)$ : 


$$
q(x, y) \pi(x) \geq q(y, x) \pi(y)
$$

neste caso, o processo move-se de $x$ para $y$ mais freqüentemente que de $y$ para $x$. Para corrigir esta condição, nós reduzimos o número de movimentos de $x$ para $y$ através da introdução de uma probabilidade $\alpha(x, y)<1$, denominada probabilidade de movimento. Desta maneira, temos que, se o movimento é feito, então $X^{(n+1)}=y$; caso contrário $X^{(n+1)}=X^{(n)}$. Devemos definir $\alpha(y, x)$ como sendo seu valor limite, por tratar-se de uma probabilidade este valor será 1. Para obtermos reversibilidade necessitamos então que:

$$
q(x, y) \pi(x) \alpha(x, y)=q(y, x) \pi(y)
$$

dai temos que, se $\pi(x) q(x, y)>0$, então:

$$
\alpha(x, y)=\pi(y) q(y, x) / \pi(x) q(x, y) .
$$

Se a desigualdade em (2.4) ocorre de maneira inversa, estabelecemos $\alpha(x, y)=1$. As probabilidades $\alpha(x, y)$ e $\alpha(y, x)$ são introduzidas para garantir que os dois lados de (2.4) estão balanceados e assim, a condição de reversibilidade é satisfeita. Resumindo, a probabilidade de movimento pode ser determinada por:

$$
\alpha(x, y)=\min \left[1, \frac{\pi(y) q(y, x)}{\pi(x) q(x, y)}\right], \text { se } \pi(x) q(x, y)>0
$$

note que se (2.3) conserva-se, então $\alpha(x, y)=1$ sempre, e o candidato $y$ é sempre aceito. Para ver que (2.6) satisfaz a reversibilidade, considere $x$ e $y$ como dois pontos da distribuição de equilibrio $\pi(\cdot)$, tais que, $\pi(y) q(y, x) \geq \pi(x) q(x, y)$, os quais resultam em $\alpha(x, y)=1$. Então a densidade de probabilidade de uma transição de $x$ para $y$ é:

$$
\pi(x) P(x, y)=\pi(x) q(x, y) \alpha(x, y)=\pi(x) q(x, y) .
$$


Considere agora a densidade de probabilidade de uma transição de $y$ para $x$ :

$$
\begin{aligned}
\pi(y) P(y, x) & =\pi(y) q(y, x) \alpha(y, x) \\
& =\pi(y) q(y, x) \frac{\pi(x) q(x, y)}{\pi(y) q(y, x)} \\
& =\pi(x) q(x, y)
\end{aligned}
$$

que implica que $\pi(x) P(x, y)=\pi(y) P(y, x)$, portanto a reversibilidade conserva-se.

Uma observação importante é que a constante de normalização de $\pi(\cdot)$ pode ser ignorada, pois esta desaparecerá no cálculo da razão entre $\pi(y) / \pi(x)$.

$\mathrm{O}$ algoritmo computacional de $\mathrm{M}-\mathrm{H}$ é muito simples, consiste em:

$\mathrm{I}^{\mathbf{2}}$ ) Inicializamos $\mathrm{o}$ contador de iterações da cadeia $n \leftarrow 1$ onde $n=1, \ldots, N$ e arbitraremos valores iniciais para os parâmetros de interesse.

$2^{2}$ ) Geramos um ponto $y$ de acordo com a densidade geradora de candidatos $q\left(x^{(n)}, y\right)$ e geramos u de uma distribuição uniforme $[0,1]$.

$3^{\circ}$ ) Atualizamos $x^{(n)}$ por $x^{(n+1)}=y$ com probabilidade:

$$
\alpha\left(x^{(n)}, y\right)=\min \left[1, \frac{\pi(y) q\left(y, x^{(n)}\right)}{\pi\left(x^{(n)}\right) q\left(x^{(n)}, y\right)}\right]
$$

ou seja: se $u \leq \alpha\left(x^{(n)}, y\right)$

$$
\text { faça } x^{(n+1)}=y
$$

caso contrário

$$
x^{(n+1)}=x^{(n)} .
$$

fim.

$4^{\text {e }}$ ) Atualizamos o contador de iterações $(n \leftarrow n+1)$ e voltamos ao $2^{9}$ procedimento até que a convergência do processo seja diagnosticada. 
Como em qualquer algoritmo de simulação MCMC os resultados $\left\{x^{(l)}, x^{(2)}, \ldots, x^{(N)}\right\}$ só podem ser considerados uma amostra da densidade $\pi(x)$, após a cadeia ter passado pela fase transitória e o efeito do estado inicial fixado ter se tomado tão pequeno que pode ser ignorado. De fato essa convergência para a distribuição invariante ocorre sob as condições de regularidade. Essas condições de regularidade são irredutibilidade e aperiodicidade [ver Smith e Roberts, 1993]. Essas condições significam que se $x$ e $y$ estão no domínio de $\pi(\cdot)$, é possivel mover-se de $x$ para $d y$ (onde $d y$ é um conjunto do espaço de estados de medida não nula) em um número finito de iterações com probabilidade diferente de zero e o número de movimentos necessários para mover-se de $x$ para $d y$ não precisa ser um múltiplo de algum inteiro. Essas condições são usualmente satisfeitas se $q(x, y)$ tem uma densidade positiva com o mesmo suporte que $\pi(\cdot)$ e quando $q(x, y)$ tem um suporte restrito (por exemplo, uma densidade uniforme centrada no ponto corrente em uma largura finita).

Se definimos a densidade de um núcleo de Metropolis como:

$$
p(x, y)= \begin{cases}q(x, y) \alpha(x, y), & \text { se } x \neq y \\ 0, & \text { se } x=y\end{cases}
$$

e estabelecemos

$$
r(x)=1-\int p(x, y) \mu(d y)
$$

então, o núcleo de Metropolis $P$ pode ser escrito como

$$
P(x, d y)=p(x, y) \mu(d y)+r(x) \delta_{x}(d y)
$$

onde $\delta_{x}$ denota um ponto de massa em $x$. O valor $r(x)$ nos dá a probabilidade do algoritmo permanecer em $x$. Visto que $P$ satisfaz a condição de reversibilidade

$$
\pi(x) p(x, y)=\pi(y) p(y, x)
$$

segue que $\pi$ é uma distribuição invariante para $P$. Para algum conjunto mensurável $A$, 


$$
\begin{aligned}
\int P(x, A) \pi(d x) & =\int\left[\int_{A} p(x, y) \mu(d y)\right] \pi(x) \mu(d x)+\int r(x) \delta_{x}(A) \pi(x) \mu(d x) \\
& =\int_{A}\left[\int p(x, y) \pi(x) \mu(d x)\right] \mu(d y)+\int_{A} r(x) \pi(x) \mu(d x) \\
& =\int_{A}\left[\int p(y, x) \pi(y) \mu(d x)\right] \mu(d y)+\int_{A} r(x) p(x) \mu(d x) \\
& =\int_{A}(1-r(y)) \pi(y) \mu(d y)+\int_{A} r(x) \pi(x) \mu(d x) \\
& =\int_{A} \pi(y) \mu(d y) .
\end{aligned}
$$

Para $P$ ser irredutivel é necessário que $Q$ seja irredutível, mas isto não é suficiente: a irredutibilidade de $P$ depende de $Q$ e $\pi$. Se $P$ é irredutível e $\pi(\{x: r(x)>0\})>0$, então, pelos resultados de Nummelin (1984, seção 2.4), o núcleo de Metropolis é aperiódico.

$\mathrm{O}$ algoritmo original de Metropolis assume $q(x, y)=q(y, x)$. Neste caso, a probabilidade de aceitação é simplificada para:

$$
\alpha(x, y)=\min \{\pi(y) / \pi(x), 1\}
$$

Barker (1965) e Hastings (1970) consideram algumas formas alternativas da probabilidade de aceitação, mas resultados de Peskun (1973) mostram que a forma dada aqui é ótima entre uma faixa regularmente larga de escolhas. A razão principal é que esta forma rejeita passos candidatos menos freqüentemente que outras formas. Hastings sugere monitoração da rejeição.

O algoritmo de Metropolis é muito geral, permitindo uma variedade de casos especiais baseado na escolha de um núcleo de transição diferente. As subseções seguintes dão alguns exemplos dos núcleos de Metropolis que são proveitosos para examinar a distribuição a posteriori. 


\subsubsection{Cadeia de Passeio Aleatório}

Suponha $E=R^{k}, \mu$ é uma medida de Lebesgue, e $f$ é uma densidade em $E$. Se $Y$ é gerado pelo sorteio de $Z$ independentemente de $f$ e estabelecendo $Y=x+Z$, então $q(x, y)=f(y-x)$. Portanto, o núcleo $Q$ da cadeia de Metropolis é um passeio aleatório. Uma escolha natural para a distribuição de incremento inclui uma distribuição uniforme em formato de um disco, uma densidade normal ou talvez uma distribuição $t$ multivariada. A matriz escala para $f$ pode ser obtida como uma constante $c$ multiplicada pela informação inversa na moda a posteriori. Escolher um bom tamanho para o passo (step), ainda permanece como um problema em aberto, mas, $c=1$ e $c=1 / 2$ parece ser um número razoável em um bom número de exemplos de trabalhos.

Se a densidade de incremento $f$ é simétrica em relação a origem, então, $q$ é simétrica e a forma simples da probabilidade de aceitação pode ser usada. O algoritmo dado por Müller (1991) corresponde a uma cadeia de Metropolis do tipo passeio aleatório com uma densidade $f$ de incremento que é simétrica em relação à origem.

Se a densidade $f$ é estritamente positiva em $R^{k}$, então, o núcleo de Metropolis do tipo passeio aleatório é irredutível e aperiódico. Se $f$ é não estritamente positivo, em toda parte, mas é estritamente positivo na vizinhança da origem, então, a condição suficiente para o núcleo de Metropolis ser irredutível e aperiódico é que $E^{+}$seja aberto e conectado.

\subsubsection{Cadeia Independente}

O candidato $Y$ também pode ser escolhido de uma densidade fixada $f$. Esta opção é discutida em Hastings (1970, seção 2.5). Neste caso, $q(x, y)=f(y)$ e a probabilidade de aceitação $\alpha(x, y)$ pode ser escrita como:

$$
\alpha(x, y)=\min \{w(y) / w(x), 1\}
$$

onde $w(x)=\pi(x) / f(x)$ 
A importância desta função peso $w$ que será usada na amostragem đar-se-á se as observações foram geradas da densiđade $f$.

A cadeia de Metropolis independente está intimamente ligada à importância đo correspondente processo de amostragem. Valores candidatos com baixo peso são raramente aceitos. Por outro lado, valores candidatos com pesos altos são usualmente aceitos, e o processo permaneceria usualmente nestes pontos por vários passos, portanto, teremos nesta amostra a repetição destes pontos com peso alto. Portanto, é importante para a amostragem a escolha đo $f$ para prođuzir uma função peso que é limitađa e tão perto đe uma constante quanto possivel. Se a função peso é constante, então, o algoritmo de Metropolis nunca rejeitará os valores candiđatos, e a cadeia produzirá uma amostra independente e identicamente distribuída (i.i.d). de $\pi$. Entretanto, a melhor escolha de $f$ para um núcleo de Metropolis independente ainda permanece uma questão em aberto.

Um núcleo de Metropolis independente é irredutível e aperiódico se e somente se $f \dot{e}$ positiva e bem próxima a $\pi$ em toda parte de $E^{+}$.

Para alguns problemas, esta pode ser uma densidade natural $f$ para usar na cadeia independente, mas pode ser dificil ou impossível para amostrarmos diretamente de $f$. Geyer (1991) sugere construir uma cađeia auxiliar $Y^{(n)}$ com distribuição de equilíbrio $f$ e permutando os estado de $X^{(n)}$ e $Y^{(n)}$ da cadeia com probabilidade de aceitação de Metropolis dada por:

$$
\min \left\{\frac{\pi(y) f(x)}{\pi(x) f(y)}, 1\right\}
$$

A cadeia resultante bivariada $\left(X^{(n)}, Y^{(n)}\right)$ tem uma distribuição invariante com densidade proporcional a $\pi(x) f(y)$.

\subsubsection{Cadeia de Amostragem de Rejeição}

Um caso especial interessante de núcleo de Metropolis independente ocorre se a amostragem de $f$ usa amostragem de rejeição. Amostragem đe rejeição é a base đe vários 
algoritmos para gerar variáveis de distribuições padrão univariadas. Este método tem também sido sugerido para ser usado com o amostrador de Gibbs em casos onde não é possível amostrar diretamente da distribuição condicional direta.

$\mathrm{Na}$ tentativa para usar amostragem de rejeição para amostrar diretamente de $\pi$, usamos a densidade $h$ e a constante $c$, tal que, esperançosamente, $\pi(x) \leq \operatorname{ch}(x)$ para todo $x$. Pares $(Z, U)$ são gerados; gerando $Z$ de $h$ e $U$ uniformemente no intervalo $[0, c h(Z)]$ ate um par satisfazendo $U<\pi(Z)$ é obtido. Ao final temos então a densidade:

$$
f(x) \propto \pi(x) \wedge \operatorname{ch}(x)
$$

Ou seja, $f(x)$ é proporcional ao mínimo entre $\pi(x) e \operatorname{ch}(x)$.

Se temos na verdade $\pi(x) \leq \operatorname{ch}(x)$, então, $f$ é proporcional a $\pi$ e obtemos uma amostra independente e identicamente distribuída de $\pi$. Mas, é muito dificil assegurar que $c$ é grande o bastante para $c h$ dominar $\pi$, se a escolha de $c$ é excessivamente grande, obteremos um algoritmo ineficiente com muitas rejeições. E até mesmo sem uma análise extensiva das caldas de $h$ e $\pi$ não podemos estar certos que $c h$ domina $\pi$.

No entanto esta é a grande dificuldade deste algoritmo. Usando este esquema de rejeição para conduzir uma cadeia de Metropolis independente, obtemos uma solução simples. Se definimos $C=\{x: \pi(x) \leq \operatorname{ch}(x)\}$, então a probabilidade de aceitação é:

$$
\alpha(x, y)= \begin{cases}1 & \text { para } x \in C \\ \frac{\operatorname{ch}(x)}{\pi(x)} & \text { para } x \notin C, y \in C \\ \min \left\{\frac{\pi(y) h(x)}{\pi(x) h(y)}, 1\right\} & \text { para } x \notin C, y \notin C\end{cases}
$$

Portanto, o algoritmo rejeitará ocasionalmente o valor candidato quando a cadeia estiver no ponto $x \notin C$. Repete-se o ponto $x$ na trajetória da amostra e compensa-se, portanto, a deficiência no envelopamento em $x$. 
A dependência é introduzida para maquiar esta deficiência e assegura que $\pi$ é a distribuição invariante da cadeia de Markov. Se o envelope é de fato adequado, então, os candidatos não são rejeitados e a cadeia produz uma seqüência i.i.d de $\pi$.

A visita ao conjunto $C$ forma um processo de renovação que pode ser usado para uma análise regenerativa da cadeia de amostragem de rejeição.

\subsubsection{Cadeia Autoregressiva}

Se $E=R^{k}, \mu$ é uma medida de Lebesgue e $f$ é uma densidade em $E$ com respeito a $\mu$, então, uma estratégia intermediária entre um passeio aleatório e um núcleo independente $\dot{\mathrm{e}}$ obtido pela geração de $Z$ a partir de $f$, e definindo o valor candidato por $Y=a+b(x-a)+Z$. Aqui $a \in R^{k}$ é um vetor fixo e $b$ é qualquer constante real ou uma matriz $k \times k$. Portanto:

$$
q(x, y)=f(y-a-b(x-a))
$$

e para $b=1$ este reduz-se ao núcleo do passeio aleatório. Para $a=0$ e $b=0$ produzimos um núcleo independente.

Se $0<b<1$, então esta estratégia reduz-se ao estado corrente em direção ao ponto $a$ adicionando antes o incremento $Z$.

Nesta estratégia autoregressiva é também possivel termos $b<0$. Se $b=-1$, então o estado corrente é refletido sobre o ponto $a$ adicionando antes o incremento $Z$. Isto é usado para introduzir correlação negativa entre os estados sucessivos na cadeia e reduzirá freqüuentemente a variância das estimativas da esperança das funções lineares.

A estratégia da reflexão pode ser obtida para um limite usando uma densidade de incremento degenerada e concentrada na origem. Isto corresponde a gerar um candidato para exatamente o reflexo do estado corrente $x$ sobre o ponto $a$ para produzir $y=2 a-x$. Este candidato é, então, aceito com probabilidade 


$$
\alpha(x, y)=\min \left\{\frac{\pi(2 a-x)}{\pi(x)}, 1\right\}
$$

Visto que a densidade geradora de candidatos não é absolutamente contínua com respeito à medida de Lebesgue, a medida dominante para $\pi$, este núcleo limitante não satisfaz a definição do núcleo de Metropolis dado acima. Apesar disso, temos a distribuição invariante $\pi$ que é obviamente periódica e não irredutivel e, entretanto, não pode ser usado sozinho. Mas, isto pode ser útil em misturas ou com ciclos de outros núcleos, como discutido a seguir.

Estratégias que usam reflexo sobre o ponto $a$ são mais efetivas quando a densidade $\pi$ é aproximadamente simétrica a $a$.

\subsection{Condicionamento}

Uma boa maneira para construir uma cadeia de Markov com distribuição invariante $\pi$ é usando a distribuição condicional. Suponha que $X$ tem distribuição $\pi, f$ é uma função definida em $E$ (espaço de estados) e $Y=f(X)$. Se:

$$
Q(y, A)=P\{X \in A \mid Y=y\}
$$

então $P(x, A)=Q(f(x), A)$ é um núcleo de transição com distribuição invariante $\pi$. Visto que $P(x,$.$) assume toda a massa no conjunto f^{-1}(\{f(x)\}), P$ não seria tipicamente irredutivel. Mas, se escolhermos algumas funções apropriadas $f_{1}, \ldots, f_{m}$, e a partir destas construirmos os correspondentes núcleos condicionais $P_{1}, \ldots, P_{m}$, tais que usando estes núcleos na ordem, produziremos o núcleo de interesse $P=P_{1} P_{2}, \ldots, P_{m}$ que será irredutível e terá distribuição invariante $\pi$. Esta é a estratégia usada no amostrador Gibbs de Gelfand e Smith (1990). Se $E$ é um subconjunto de um espaço e $x \in E$ pode ser escrito como $x=\left(x_{1}, x_{2}, \ldots, x_{m}\right)$, então o amostrador Gibbs usa a função:

$$
f_{i}(x)=f_{i}\left(x_{1}, \ldots, x_{m}\right)=\left(x_{1}, \ldots, x_{i-1}, x_{i+1}, \ldots, x_{m}\right) \quad \text { para } i=1, \ldots, m .
$$


O núcleo obtido pelo condicionamento em $Y$ produz $X_{n+1}$ pela amostragem da distribuição condicional $X \mid Y=f\left(X_{n}\right)$. Em particular, um núcleo que aplica um dos métodos descritos a seguir para a distribuição condicional $X \mid Y=y$ produz um núcleo com distribuição invariante $\pi$. Em resumo, um único núcleo deste tipo é usualmente não irredutivel, mas o produto de alguns destes produzirá um núcleo irredutivel.

Podemos no entanto apresentar um exemplo de que mesmo procedendo desta forma podemos ter cadeias que não são irredutíveis, ou seja se $P_{1}$ e $P_{2}$ são $\pi$-irredutiveis, aperiódicas e ambas têm distribuição estacionária $\pi$. Não implica necessariamente que $P_{1}, P_{2}$ seja irredutivel. Veja o seguinte exemplo: Seja $X=\{1,2,3\}$ e supondo que $P_{1}(1,2)=P_{1}(2,3)=P_{2}(1,3)=P_{2}(2,1)=1 \quad \operatorname{com} P_{i}(3, i)=P_{i}(3,3)=1 / 2 \quad i=1,2$; temos:

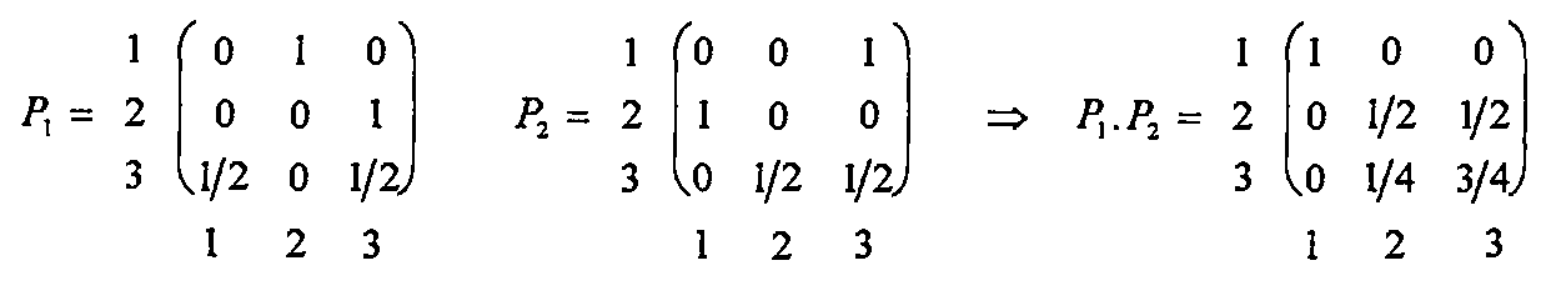

Portanto $P_{1} \cdot P_{2}$ não é irredutivel, notamos que o estado 1 da cadeia com núcleo $P_{1} \cdot P_{2}$ é absorvente. Assim nunca será visitado se partimos dos estados 2 ou 3. Portanto uma implicação prática é que quando consideramos diferentes algoritmos MCMC, é importante verificar se a cadeia de Markov é irredutível e aperiódica. Por exemplo se $\pi(\cdot)$ é uma densidade contínua com respeito a uma medida de Lebesgue e se o suporte de $\pi(\cdot)$ é conexo então o amostrador de Gibbs resultante é sempre irredutivel (Roberts e Smith, 1994).

\subsection{O Amostrador de Gibbs}

O Amostrador de Gibbs é essencialmente um esquema iterativo de amostragem de uma cadeia de Markov cujo núcleo de transição é formado pelas distribuições condicionais completas, ou seja, temos aqui um caso especial do algoritmo Metropolis-Hastings. No algoritmo $\mathrm{M}-\mathrm{H}$ a 
probabilidade de movimento, foi dada por (2.6) no caso do amostrador de Gibbs imagine que no $n$-ésimo, $X$ é um vetor com $r$ elementos:

$$
X=\left(X_{1}, X_{2}, \ldots, X_{1}, \ldots, X_{r}\right)
$$

Definimos agora:

$$
X_{-i}=\left(X_{1}, \ldots, X_{i-1}, X_{i+1}, \ldots, X_{r}\right)
$$

e note que em geral:

$$
Y=\left(Y_{i}, X_{-i}\right), \quad Y_{-i}=X_{-i} \text { e } X=\left(X_{i}, X_{-i}\right)
$$

Agora, se em (2.6) usamos como densidade candidata a distribuição condicional completa, temos:

$$
\begin{aligned}
& q(y, x)=\pi\left(X_{i} \mid Y_{-i}\right) \\
& q(x, y)=\pi\left(Y_{i} \mid X_{-i}\right)
\end{aligned}
$$

e substituindo na razão em (2.6) o termo para $\alpha(x, y)$ torna-se:

$$
\frac{\pi(y) \pi\left(X_{i} \mid Y_{-i}\right)}{\pi(x) \pi\left(Y_{i} \mid X_{-i}\right)}=\frac{\pi(y) \pi\left(X_{i} \mid X_{-i}\right)}{\pi(x) \pi\left(Y_{i} \mid X_{-i}\right)}=\frac{\pi(y) \pi\left(X_{i}, X_{-i}\right) \pi\left(X_{-i}\right)}{\pi(x) \pi\left(Y_{i}, X_{-i}\right) \pi\left(X_{-i}\right)}=1
$$

Ou seja, como no amostrador de Gibbs, os candidatos são amostrados diretamente da distribuição "condicional completa" $\pi\left(Y_{i} \mid X_{-i}\right)$ então $\left(x_{i}^{(n+1)}=y_{i}\right)$ serão sempre aceitos. Numa notação clara o núcleo de transição do amostrador de Gibbs é dado por:

$$
\prod_{i=1}^{r} \pi\left(X_{i}^{(n+1)} \mid X_{j}^{(n)}, j>i, X_{j}^{(n+1)}, j<i\right)
$$

Mostraremos agora que o amostrador de Gibbs satisfaz (2.1) e que repetidas amostragens da distribuição condicional completa geram amostras da distribuição conjunta na convergência:

Esboçamos o argumento para o caso onde $X=\left(X_{1}, X_{2}\right)$, e como anteriormente, definimos $Y_{i}$ como sendo o candidato de $X_{i}, i=1,2$. O movimento é de $X=\left(X_{1}, X_{2}\right)$ para 
$Y=\left(Y_{1}, Y_{2}\right)$. Este movimento será feito em dois estágios e o núcleo de transição é portanto $P(X, Y)=\pi\left(Y_{1} \mid X_{2}\right) \pi\left(Y_{2} \mid Y_{1}\right)$.

Se amostrarmos sucessivamente $\pi\left(Y_{1} \mid X_{2}\right)$ e $\pi\left(Y_{2} \mid Y_{1}\right)$, obteremos um ponto da distribuição de $Y_{1}$ e $Y_{2}$. Note que amostrar de $\pi\left(Y_{1} \mid X_{2}\right)$ e de $\pi\left(Y_{2} \mid Y_{1}\right)$ é amostrar da distribuição condicional completa.

Assim mostrar que o amostrador de Gibbs gera amostras da distribuição conjunta, é mostrar que a seguinte condição é satisfeita:

$$
\iint \pi\left(Y_{1} \mid X_{2}\right) \pi\left(Y_{2} \mid Y_{1}\right) \pi\left(X_{1}, X_{2}\right) d X_{1} d X_{2}=\pi\left(Y_{1}, Y_{2}\right)
$$

(note que os primeiros dois termos na integral representam o núcleo de transição). Integrando inicialmente com respeito a $X_{1}$ e em seguida com respeito a $X_{2}$ teremos:

$$
\begin{aligned}
\int \pi\left(Y_{1} \mid X_{2}\right) \pi\left(Y_{2} \mid Y_{1}\right) \pi\left(X_{2}\right) d X_{2} & =\int \pi\left(Y_{1}, X_{2}\right) \pi\left(Y_{2} \mid Y_{1}\right) d X_{2} \\
& =\pi\left(Y_{1}\right) \pi\left(Y_{2} \mid Y_{1}\right) \\
& =\pi\left(Y_{1}, Y_{2}\right)
\end{aligned}
$$

o que mostra que (2.9) é satisfeita.

$\mathrm{O}$ algoritmo amostrador de Gibbs é mais simples ainda que o algoritmo de MetropolisHastings.

Considere o vetor de parâmetros $\theta=\left(\theta_{1}, \theta_{2}\right)$. Seja a distribuição a posteriori $p\left(\theta_{1}, \theta_{2} \mid y\right)$ e as condicionais $p\left(\theta_{1} \mid \theta_{2}, \mathrm{y}\right), p\left(\theta_{2} \mid \theta_{1}, \mathrm{y}\right)$. Assumimos que os valores iniciais são fornecidos por $\left(\theta_{1}^{(0)}, \theta_{2}^{(0)}\right)$. A implementação do amostrador de Gibbs consiste das iterações do seguinte algoritmo.

$\left.1^{2}\right)$ Inicializamos o contador de iterações da cadeia $(n \leftarrow 1)$, onde $n=1, \ldots, N$ e arbitraremos valores iniciais para os parâmetros de interesse $\theta=\left(\theta_{3}^{(0)}, \theta_{2}^{(0)}\right)$. 
$\left.2^{\circ}\right)$ Geramos respectivamente

$$
\theta_{1}^{(n)} \sim p\left(\theta_{1} \mid \theta_{2}^{(n-1)}, \mathrm{y}\right) \quad \text { e } \quad \theta_{2}^{(n)} \sim p\left(\theta_{2} \mid \theta_{1}^{(n)}, \mathrm{y}\right) .
$$

$\left.3^{2}\right)$ Atualizamos o contador de iterações $(n \leftarrow n+1)$, e voltamos ao $2^{q}$ procedimento até a convergência do processo seja diagnosticada.

Dentro do contexto Bayesiano, esses algoritmos são utilizados para gerar amostras da distribuição a posteriori dos parâmetros que deseja-se fazer inferência. Esse tipo de abordagem vem dando um grande impulso a área de inferência Bayesiana, pois permite analisar parâmetros de modelos bastante complexos, cujo tratamento analítico é praticamente impossível. Uma das grandes dificuldades dos métodos de MCMC é verificar a convergência da amostra gerada para assegurar que estamos gerando da distribuição desejada.

\subsection{Combinando estratégias}

Os métodos esboçados acima podem ser usados na forma pura, ou eles podem ser combinados em estratégias hibridas. Uma maneira para formar uma estratégia hibrida é usando o condicionante, como descrito na seção 2.4 , e então, aplica uma estratégia mais básica para a distribuiçāo condicional. Duas outras formas básicas das estratégias híbridas são misturas e ciclos. Suponha que $P_{1}, \ldots, P_{m}$ são núcleos de Markov com distribuição $\pi$. Na mistura, probabilidades positivas $\alpha_{1}, \ldots, \alpha_{m}$ são especificadas, e em cada passo, um dos núcleos é selecionado de acordo com estas probabilidades. Num ciclo, cada núcleo é usado por sua vez, e quando o último é usado, o ciclo é reiniciado.

Misturas e ciclos podem ser usados de várias maneiras. Por exemplo, um amostrador de Gibbs pode ser combinado com passos ocasionais de uma cadeia independente numa mistura ou ciclo para reiniciar o amostrador de Gibbs e, portanto, reduz as correlações quando a distribuição de equilibrio é preservada. Como outro exemplo, suponha $\theta$ dividido em dois componentes $\left(\theta_{1}, \theta_{2}\right)$ e amostrar diretamente de $\left(\theta_{1} \mid \theta_{2}\right)$ é possivel, mas amostrar de $\left(\theta_{2} \mid \theta_{1}\right)$ não é possivel. 
Então, o passo Gibbs para $\left(\theta_{1} \mid \theta_{2}\right)$ pode ser combinado com o passo de Metropolis dado por $\left(\theta_{2} \mid \theta_{1}\right)$ numa mistura ou num ciclo.

Se um dos núcleos na mistura é irredutível e aperiódico, então, é fảcil ver que o núcleo da mistura é irredutível e aperiódico também. Se um dos núcleos é irredutível e aperiódico, então, o núcleo do ciclo também é freqüentemente irredutivel e aperiódico, mas estes são apenas contra exemplos simples que mostram que na afirmação geral para este efeito isto pode ser feito. Em geral, irredutibilidade e aperiodicidade de um ciclo precisa ser verificado para cada caso a menos que um destes núcleos tenha alguma estrutura especial. [veja a Proposição 4 no capítulo 3 a seguir].

Misturas também podem ser construidas por seleção de acordo com uma distribuição fixada de uma familia de funções de transição indexadas por um parâmetro geral

\subsection{O Uso do Teorema do Limite Central}

A metodologia MCMC consiste basicamente na substituição da expressão analítica da densidade de interesse, por uma amostra gerada a partir desta densidade.

Amostras da cadeia podem ser obtidas pela integração de Monte Carlo. Uma integral

$$
\mu=\int g(x) d P(x)
$$

pode ser aproximada pela média da função sobre a cadeia.

$$
\hat{\mu}_{n}=\frac{1}{n} \sum_{i=1}^{n} g\left(x_{i}\right)
$$

Em situações ótimas, $\hat{\mu}_{\mathrm{n}} \rightarrow \mu$ quase certamente (significado para quase todas as trajetórias amostrais da simulação de Monte Carlo), e pelo Teorema do Limite Central: 


$$
\sqrt{n}\left(\hat{\mu}_{n}-\mu\right) \stackrel{D}{\rightarrow} N\left(0, \sigma^{2}\right)
$$

obtemos o tamanho do erro de Monte Carlo. A variância $\sigma^{2}$ é teoricamente dificil de calcular, mas ela pode ser estimada da própria cadeia de Markov por métodos de séries temporais padronizadas, com pode ser visto em Hastings (1970).

$\mathrm{Na}$ inferência Bayesiana existem casos nos quais calcular uma densidade é tarefa dificil, devido a uma matemática intratável, ou ainda, onde a densidade desejada é obtida analiticamente mas expressa sob uma forma "aproximada", não padronizada e de dificil normalização. A grande vantagem destes métodos é a possibilidade de gerar, a partir de algoritmos computacionais simples, amostras de uma densidade da qual não se sabe gerar diretamente.

Apesar de recentes avanços nesta teoria dos algoritmos MCMC, a prática tem permanecido um tanto controvertida, pois questões como: o número de iterações a serem executadas até a convergência para a distribuição a posteriori conjunta e o número de interações a serem coletadas para obter estimativas precisas da posteriori desejada, são questões ainda muito discutidas na implementação destes algoritmos. Os cinco principais problemas da simulação MCMC são os seguintes:

1. A escolha da densidade, da qual, vamos gerar a amostra;

2. O comprimento do periodo de aquecimento, ou seja, o quanto do início da simulação será desprezado. Este item vem abordar o problema da convergência do processo. No capítulo cinco adiante, serão discutidos os principais critérios de convergência utilizados atualmente;

3. O tamanho da amostra que devemos coletar, para obtermos estimativas precisas;

4. Os possiveis estimadores ou métodos para estimar os parâmetros de interesse;

5. O erro de estimação devido a simulação (neste caso está incluido as dificuldades para construir intervalos de confiança do estimador devido às correlações entre os valores gerados que afetam a estimativa da variância dos parâmetros).

Neste trabalho estamos interessados em vários aspectos práticos para contornar cada uma dessas dificuldades. As alternativas de solução para cada uma dessas dificuldades serão ilustradas com exemplos de inferência Bayesiana. 


\section{Capítulo 3 \\ Alguns Resultados Teóricos \\ de Cadeia de Markov}

\subsection{Resultados Teóricos}

Esta seção apresenta alguns resultados da teoria geral do espaço de estados da Cadeia de Markov (CM) de forma a estabelecer propriedades da CM construida para ter uma distribuição invariante específica. O desenvolvimento desta seção é baseada primariamente em Nummelin (1984).

Para iniciar, precisamos de algumas notações e definições. Seja $\lambda$ uma $\sigma$-álgebra contável em $E$. Um núcleo de transição (de Markov) em $(E, \lambda)$ é uma função $P: E \times \lambda \rightarrow[0,1]$ tal que:

i) Para algum $A$ fixado $A \in \lambda$, a função $P(\cdot, A)$ é mensurável.

ii) Para algum $x$ fixado $x \in E$, a função $P(x, \cdot)$ é uma medida de probabilidade em $(E, \lambda)$.

Probabilidades para uma $\mathrm{CM}$ com núcleo de transição $P$ iniciada em $x$ está denotada por $P_{x}$

Se $v$ é uma probabilidade, $P$ é uma função de transição em $(E, \lambda)$ e $h$ é uma função real $\lambda$-mensurável, então, $v P, P h e$ uh são definidas como:

$$
\begin{aligned}
& (v P)(A)=\int P(x, A) v(d x) \\
& (P h)(x)=\int h(y) P(x, d y) \quad e \\
& \text { wh }=\int h(y) v(x, d y)
\end{aligned}
$$

para todo $x \in E$ e $A \in \lambda$ Um valor real não negativo da função $h$ é chamado harmônico para $P$ se $h=P h$.

Segundo Nummelin, a norma da variação total de uma medida limitada simbolizada para $\lambda$ em $(E, \lambda)$ é definida como: 


$$
\|\lambda\|=\sup _{A \in \lambda} \lambda(A)-\inf _{A \in \lambda} \lambda(A)
$$

A variação total da distância de duas medidas tais $\lambda_{1}$ e $\lambda_{2}$ é $\left\|\lambda_{1}-\lambda_{2}\right\|$. Outra definição da distância da variação total pode diferir para um ou dois fatores.

A notação $\left\{A_{n}\right.$ i.o. $\}$ significa que a seqüência $A_{n}$ ocorre freqüentemente e infinitamente, isto é, $\sum 1_{A n}=\infty$.

Para um espaço de estados geral, irredutibilidade é definida com respeito a uma medida $\sigma$ finita $\varphi$. Um núcleo de transição $P$ em $(E, \lambda)$ é $\varphi$-irredutível se $\varphi(E)>0$ e para cada $x \in E$ e cada $A \in \lambda$ com $\varphi(A)>0$ existe um inteiro $n=n(x, A) \geq 1$ tal que $P^{n}(x, A)>0$. Para nossa proposta, é natural termos $\varphi=\pi$ (distribuição de equilíbrio da $\mathrm{CM}$ ). A notação usual de irredutibilidade para um espaço de estados discretos corresponde à irredutibilidade com respeito à medida enumerável.

Um núcleo de transiçāo $P \pi$-irredutivel é periódico se existe um inteiro $d \geq 2$ e uma seqüência $\left\{E_{0}, E_{1}, \ldots, E_{d-1}\right\}$ de $d$ conjuntos disjuntos não vazios em $\lambda$ tal que para todo $i=0,1, \ldots, d-1$ e todo $x \in E_{i}$

$$
P\left(x, E_{j}\right)=1 \quad \text { para } j=i+1(\bmod d)
$$

De outra forma o núcleo é aperiódico.

\subsection{Convergência de Distribuições}

Um conceito crucial na teoria do espaço de estados da CM é "recorrência". Este conceito é também crucial na teoria da convergência do espaço de estados da cadeia geral. Uma definição geral da "recorrência" é dada em Nummelin (1984; definição 3.5). Uma definição que é suficiente para o presente contexto é como segue. 
Uma cadeia $\pi$-irredutivel $X_{n}$ com distribuição invariante $\pi$ é recorrente se para cada $B \operatorname{com} \pi(\mathrm{B})>0$ :

$$
\begin{aligned}
& P_{x}\left\{X^{(n)} \in B \text { i.o. }\right\}>0 \text { para todo } x \\
& P_{x}\left\{X^{(n)} \in B \text { i.o. }\right\}=1 \text { para quase todo } x
\end{aligned}
$$

A cadeia é Harris recorrente se $P_{x}\left\{X_{n} \in B\right.$ i.o. $\}=1$ para todo $x$. Suponha uma cadeia $P \pi$ irredutivel e que $\pi$ é uma distribuição invariante para a cadeia, então, $P$ é recorrente (Teorema 3.6 parte (i) e a Proposição 3.9 parte (iv) de Nummelin (1984)).

Pelo Corolário 5.2 de Nummelin (1984), uma cadeia $\pi$-irredutível recorrente tem uma medida invariante que é única a menos de uma constante multiplicativa.

A cadeia é chamada positiva recorrente se a massa total destas medidas é finita; de outro modo é "recorrente nula". Portanto, se $P$ é $\pi$-irredutível e $\pi$ é uma distribuição de probabilidade invariante para $P$, então, $P$ é positiva recorrente e $\pi$ é uma distribuição invariante única. Se $P$ é também aperiódica, então, o Teorema 3.7 parte (i) e a Proposição 6.3 de Nummelin (1984) mostra que a probabilidade de transição converge para $\pi$. Isto é sumarizado no seguinte teorema:

Teorema 1 (Tierney 1994): Suponha $P \pi$-irredutivel e $\pi P=\pi$. Então, $P$ é positiva recorrente e $\pi$ é a distribuição invariante única de $P$. Se $P$ é também aperiódica, então, para quase todo $x$.

$$
\left\|P^{n}(x, \cdot)-\pi\right\| \rightarrow 0
$$

com $\|$ denotando a variação da distância total. Se $P$ é Harris Recorrente, então, a convergência ocorre para todo $x$.

Athreya at al (1992) apresenta uma prova deste resultado. No entanto este resultado não fornece qualquer informação sobre a taxa de convergência, estas são suposições mínimas. De fato, as suposições são essencialmente necessária e suficientes para que: 


$$
\left\|P^{n}(x,)-\pi\right\| \rightarrow 0
$$

para todo $x$. Portanto é necessário que a cadeia seja $\pi$-irredutivel, aperiódica e Harris recorrente positiva com distribuição invariante $\pi$.

Podemos observar que, em nossas aplicações não é dificil verificar que a cadeia é Harris recorrente.

O resultado básico, o qual segue do Teorema 3.6 parte (i) e Teorema 3.8 de Nummelin (1984), é o seguinte teorema:

Teorema 2 (Tierney 1994): Se P é recorrente, então, $P$ é Harris Recorrente se e somente se toda função harmônica limitada é uma constante.

Uma condição que é satisfeita pela maioria das amostras de Gibbs irredutiveis é dada pelo seguinte corolário:

Corolário 1 (Tierney 1994): Suponha $P \pi$-irredutivel e $\pi P=\pi$. Se $P(x, \cdot)$ é absollttamente contínua com respeito a $\pi$, para todo $x$, então, $P$ é Harris recorrente.

Prova: Seja $h$ uma função harmônica limitada para $P$. A suposição implica que $P$ é recorrente; assim, pela proposição 3.13 de Nummelin (1984), $h=\pi h$ em quase todo ponto. Então continuidade absoluta, implica que $(P h)(x)=\pi h$, para todo $x$. Portanto, $h=\pi h$, ou seja $h$ é constante.

Para um núcleo Metropolis definido como acima, não é necessário nenhuma condição adicional.

Corolário 2 (Tierney 1994): Suponha $P$ um núcleo Metropolis $\pi$-irredutivel. Então, $P \dot{e}$ Harris recorrente.

Prova: Seja $h$ uma função harmônica limitada por $P$. Visto que a suposição implica que $P$ é recorrente, $h=\pi h$ em toda parte, como na prova anterior. Suponha $x \in E^{+}$, seja $p(x, y)$ denotando 
a densidade do núcleo Metropolis, e seja $r(x)$ a probabilidade que uma cadeia, partindo de $x$ permaneça em $x$. Agora $\int_{A} \pi(\mathrm{y}) \mu(\mathrm{dy})=0$ implica $\int_{A} p(x, y) \mu(d y)=0$ para $x \in E^{+}$.

Assim,

$$
\int p(x, y) h(y) \mu(d y)=(1-r(x)) r h .
$$

Portanto,

$$
\int P(x, d y) h(y)=(1-r(x)) \pi h+r(x) h(x)=h(x),
$$

e isto implica que $(1-r(x))(h(x)-\pi h)=0$ para todo $x \in E^{+}$.

Desde que $\pi$ não seja concentrada em um único ponto, $\pi$-irredutibilidade implica que $r(x)<1$ para todo $x$. Portanto, $h(x)=\pi h$ para todo $x \in E^{+}$. Finalmente, se $x \notin E^{+}$, então, por restrições impostas em $Q \quad(Q(x, A)=P(y \in A \mid X=x))$ e a definição de $\alpha(x, y)$, temos $Q\left(x, E^{+}\right)=1$ e $\alpha(x, y)=1$ e, portanto, $h(x)=(P h)(x)=\pi h$. Assim, $h \equiv \pi h$, isto é, $h$ é constante.

\subsection{Taxas de Convergência}

Uma CM é chamada ergódica se esta é Harris recorrente positiva e aperiódica. Várias formas de ergodicidade forte que nos fornece informações sobre a taxa de convergência no Teorema 1 , podem ser verificadas.

Uma forma fraca de ergodicidade mais forte que ergodicidade simples é chamada de ergodicidade de grau 2. Se $S_{B}$ denota o tempo de visita ao conjunto $B$, então, uma cadeia ergódica com distribuição invariante $\pi$ é ergódica de grau dois se:

$$
\int_{B} \pi(d x) E_{x}\left[S_{B}^{2}\right]<\infty
$$

para todo $B \in \bar{\lambda} \operatorname{com} \pi(B)>0$ (Nummelin, 1984; definição 5.5). Para tal cadeia: 


$$
n\left\|P^{n}(x,)-\pi\right\| \rightarrow 0
$$

para quase todo $x$ (Nummelin, 1984; Corolário 6.9).

Ergodicidade de grau dois é tipicamente muito dificil de se verificar na prática.

Ergodicidade geométrica e uniforme são duas formas fortes de ergodicidade. Uma cadeia de Markov ergódica com distribuição invariante $\pi$ é geometricamente ergódica se existe uma função real não negativa $M \operatorname{com} \pi|M|<\infty$ e uma constante positiva $r<1$, tal que:

$$
\left\|P^{n}(x ;)-\pi\right\| \leq M(x) r^{n}
$$

para todo $x$. A cadeia é uniformemente ergódica se há uma constante positiva $M$ e uma constante positiva $r<1$, tal que:

$$
\sup _{x \in E}\left\|P^{n}(x ;)-\pi\right\| \leq M r^{n}
$$

Ergodicidade uniforme implica em ergodicidade geométrica que implica em ergodicidade de grau dois.

Para se verificar mais facilmente as condições suficientes de ergodicidade geométrica e uniforme, precisamos ter a noção da condição de minorização e de conjunto pequeno. Um núcleo $P$ $\pi$-irredutivel satisfaz a condição de minorização $M(m, \beta, C, \gamma)$, para um inteiro $m \geq 1$, uma constante $\beta>0$, um conjunto $C \in \lambda$, e uma medida de probabilidade $\gamma$ em $\lambda$ se $\pi(C)>0$ e

$$
\beta \gamma(\cdot) \leq P^{m}(x ;) \quad \text { paratodo } x \in C .
$$

Um conjunto $C$ é um conjunto pequeno para $P$ se $P$ satisfaz uma condição de minorização $M(m, \beta, C, \gamma)$ para algum $m, \beta$ e $\gamma$. Na teoria geral, conjuntos pequenos representam papel similar para estados individuais na teoria de cadeias de Markov com espaço de estado discreto.

A seguinte condição é suficiente para assegurar ergodicidade geométrica e pode algumas vezes também ser usada para verificar ergodicidade uniforme: 
Proposição 1 (Tierney 1994): Suponha $X_{n}$ ergódica e que existe uma função real " $\mathrm{g}$ " não negativa $\lambda$-mensurável, um conjunto pequeno $C$, uma constante $r>1$, e um inteiro $m \geq 1$ tal que:

$$
\sup _{x \in C^{c}} E\left[g\left(X_{n+m}\right)-g\left(X_{n}\right) \mid X_{n}=x\right]=\sup _{C^{c}}\left(r P^{m} g-g\right)<0
$$

$e$

$$
\sup _{x \in C} E\left[g\left(X_{n+m}\right) ; X_{n+m} \in C^{C} \mid X_{n}=x\right]=\sup _{c} P^{m}\left(1_{C^{c}} g\right)<\infty
$$

então, $X_{n}$ é geometricamente ergódica. Se $g$ é limitada, então, $X_{n}$ é uniformemente ergódica.

Prova: Visto que $\left\|P^{n}(x)-,\pi\right\|$ é não crescente em " $n$ ", uma cadeia aperiódica $X_{n}$ é geometricamente ergódica se $Y_{n}=X_{n m}$ é geometricamente ergódica para algum inteiro $m \geq 1$. Assim, é suficiente para considerar o caso $m=1$. Para este caso, a Proposição 5.21 e o Teorema 6.14 parte (iii) de Nummelin (1984) mostra que a hipótese da proposição implica em ergodicidade geométrica. Finalmente, a prova do Teorema I em Chan (1989) (ver também Teorema 3.1 e a seguinte nota em Chan (1993)) mostra que sobre estas hipóteses existem constantes $a$ e $b$ e uma constante positiva $\rho<1$ tal que:

$$
\left\|P^{n}(x, \cdot)-\pi\right\| \leq(a+b g(x)) P^{n}
$$

Assim, se $g$ é limitada, então, $X_{n}$ é uniformemente ergódica.

Esta condição pode algumas vezes ser usada para verificar ergodicidade geométrica ou uniforme dos amostradores Gibbs tomando $C$ limitado com $\pi(x)$ positivo em $C$, e tomando " $g$ " dependendo apenas em uma das coordenadas. Chan (1993) dá corolários para este resultado com condições suficientes que podem ser fáceis de verificar, e mostra como usar estes resultados para verificar ergodicidade geométrica dos amostradores Gibbs em alguns exemplos.

Uma condição alternativa para ergodicidade geométrica de um núcleo de Gibbs é dado por Schervish e Carlin (1992). Notas seguindo prova do seu Corolário 1 mostram que a condição de quadrado integrável implica em ergodicidade geométrica como é definido aqui. 
Para ergodicidade uniforme, uma condição simples suficiente e necessária é disponível (Nummelin, 1984; Teorema 6.15):

Proposição 2 (Tierney 1994): Um micleo de transição $P$ é uniformemente ergódico se e somente se o espaço de estados $E$ é pequeno. Além disso, se $P$ satisfaz a condição de minorização $M(m, \beta, E, \gamma)$, então, a taxa de convergência $r$ satisfaz $r^{m} \leq(1-\beta)$.

Prova: Esta segue do Teorema 6.15 de Nummelin (1984), junto com a observação que uma condição de minorização $M(m, \beta, E, \gamma)$ para $P$ implica que $P$ é $\gamma$-irredutivel, que as condições $M(k, \beta, E, \gamma)$ conserva-se para todo $K \geq m$ e, portanto, que $P$ é aperiódica. A taxa resultante segue das notas após o Teorema 6.15 de Nummelin e a representação da distribuição invariante dada no Corolário 5.2 de Nummelin.

Roberts e Polson (1990) dão condições para ergodicidade uniforme baseada na continuidade e compactação. Em adição, eles dão uma versão do teorema precedente baseado na condição de minorização com $m=1$.

Para um núcleo Metropolis, o corolário segue dando uma condição suficiente para ergodicidade uniforme que pode freqüentemente ser assegurada truncando $\pi$ para um conjunto compacto apropriado:

Corolário 3 (Tierney 1994): Um mícleo Metropolis com $\mu\left(E^{+}\right)<\infty$ e $q$ e $\pi$ limitados fora do zero em $E^{+}$satisfaz uma condição de minorização $M(1, \beta, E, \gamma)$ com $\gamma$ proporcional a restriçăo de $\mu$ para $E^{+}$, e é uniformemente ergódico.

Condições fracas são possiveis.

Para um núcleo Metropolis independente, uma condição suficiente para ergodicidade uniforme pode ser dada em termos da função peso. 
Corolário 4 (Tierney 1994): Um mucleo Metropolis independente com densidade $f$ e função peso limitada $w=\pi / f$ satisfaz uma condição de minorização $M(1, \beta, E, \pi) \operatorname{com} \beta=(\sup w)^{-1} e, \dot{e}$ portanto, uniformemente ergódico. A taxka de convergência $r$ satisfaz:

$$
r \leq(1-\beta)=\left(1-(\sup w)^{-1}\right)
$$

Sob certas condições, podemos inferir taxas de convergência de misturas ou ciclos de núcleos de seus componentes. Para misturas, se um núcleo é uniformemente ergódico, então, a mistura é:

Proposição 3 (Tierney 1994): Suponha $P_{1}$ e $P_{2}$ tendo distribuição invariante $\pi$ e $P_{1}$ é uniformemente ergódico. Então, para $0<\alpha<1$ o núcleo $\alpha P_{1}+(1-\alpha) P_{2}$ é ergódico.

Prova: Visto que $P_{1}$ é uniformemente ergódico e satisfaz a condição de minorização $M(m, \beta, E, \gamma)$ para algum $m, \beta$ e $\gamma$. Assim:

$$
\left(\alpha P_{1}+(1-\alpha) P_{2}\right)^{m}(x, \cdot) \geq \alpha^{m} P_{1}^{m}(x, \cdot) \geq \alpha^{m} \beta \gamma(\cdot)
$$

para todo $x$. Assim $\alpha P_{1}+(1-\alpha) P_{2}$ satisfaz a condição de minorização $M(m, \beta, E, \gamma)$ e é uniformemente ergódico.

Para combinações cíclicas, hipóteses fortes parecem ser necessárias:

Proposição 4 (Tierney 1994): Suponha $P_{1}$ e $P_{2}$ tendo distribuição invariante $\pi$ e ass.suma que $P_{1}$ satisfaz a condição de minorização $M(1, \beta, E, \gamma)$ para algum $\beta$ e $\gamma$. Então, $P_{1} P_{2}$ e $P_{2} P_{1}$ são uniformemente ergódicos.

Prova: Desde que $P_{1}(x, \cdot) \geq \beta \gamma(\cdot)$ para todo $x$,

$$
P_{1} P_{2}(x, \cdot) \geq \beta\left(\gamma P_{2}\right)(\cdot)
$$


Assim $P_{1} P_{2}$ satisfaz a condição de minorização $M\left(1, \beta, E, \gamma P_{2}\right)$ e é portanto uniformemente ergódico. Similarmente:

$$
P_{1} P_{2}(x, \cdot) \geq \beta \gamma(\cdot)
$$

e $P_{2} P_{1}$ satisfaz a condição de minorização $M(1, \beta, E, \gamma)$.

Visto que um núcleo independente com função peso limitada $w=\pi / f$ satisfaz a condição de minorização $M(1, \beta, E, \gamma)$, alguma mistura ou ciclo contendo tal núcleo é uniformemente ergódico. Portanto, alguma estratégia pode ser feita uniformemente ergódica inserindo passos de partidas periódicos ou aleatórios usando uma distribuição de partida $f$ com caldas suficientemente largas.

\subsection{Comportamento Limite das Médias}

Suponha usarmos uma única e longa execução (de uma cadeia) para estimarmos a esperança $\pi f$ da função real $\pi$-integrável para a média amostral

$$
\bar{f}_{n}=\frac{1}{n} \sum_{i=1}^{n} f\left(X_{i}\right)
$$

O comportamento limite desta média é descrito pela Lei dos Grande Números e o Teorema do Limite Central.

A Lei dos Grandes Números pode ser obtida do teorema ergódico ou o teorema de ChaconOrnstein. O seguinte teorema é um corolário para o Teorema 3.6 no Capítulo 4 do Revuz (1975). 
Teorema 3 (Tierney 1994): Suponha $X_{n}$ ergódico com distribuição de equilibrio $\pi, f$ uma função real e $\pi|f|<\infty$. Então, para alguma distribuição inicial, $\bar{f}_{n} \rightarrow \pi f$ quase certamente.

A Lei dos Grandes Números conserva-se para alguma cadeia ergódica e não necessita de condição alguma na taxa de convergência para a distribuição estacionária. O Teorema do Limite Central utilizado necessita de algumas suposições na taxa de convergência. $O$ seguinte Teorema do Limite Central é dado no Corolário 7.3 de Nummelin (1984).

Teorema 4 (Tierney 1994): Suponha $X_{n}$ ergódico de grau 2 com distribuição de equilibrio $\pi$ e, suponha f real e limitada. Então, existe um mimero real $\sigma(f)$ tal que a distribuição de

$$
\sqrt{n}\left(\bar{f}_{n}-\pi f\right)
$$

converge fracamente para uma distribuição normal com média zero e variância $\sigma(f)^{2}$ para alguma distribuição inicial.

A suposição do limitante em $f$ pode ser removida se a cadeia é uniformemente ergódica:

Teorema 5 (Tierney 1994): Suponha $X_{n}$ uniformemente ergódico com distribuição de equilibrio $\pi$ e, suponha f real e $\pi\left(f^{2}\right)<\infty$. Então, existe um mimero real $\sigma(f)$ tal que a distribuição de

$$
\sqrt{n}\left(\bar{f}_{n}-\pi f\right)
$$

converge fracamente para uma distribuição normal com média zero e variância $\sigma(f)^{2}$ para alguma distribuição inicial. 
Isto segue do item (ii) no Corolário 4.2 do Cogburn (1970). A suposição que a cadeia è uniformemente ergódica implica, na terminologia de Cogburn, que o estado de espaço inteiro é uniforme.

As condições nestes teoremas precisam ser fortes. Nummelin (1984; Teorema 7.6) dá uma condição fraca, mas é iniciada em termos da esperança relacionada ao tempo de visita a conjuntos com probabilidade $\pi$-positiva e parecem um tanto dificil para verificar diretamente. Kipnis e Varadhan (1986) dão um Teorema do Limite Central para Cadeia de Markov reversível que necessita somente de uma variância limitada finita; Tóth (1986) estende seus resultados para cadeia não reversível, mas tem, além disso, outra condição que não é fácil para verificar ou interpretar.

Como uma nota final, a suposição de ergodicidade nos teoremas desta subseção implica que as cadeias são aperiódicas.

Para uma cadeia não geometricamente ergódica o teorema do limite central pode falhar facilmente como mostra o exemplo a seguir.

\subsection{Exemplo}

Uma característica da cadeia de $\mathrm{M}-\mathrm{H}$ é que existe uma probabilidade de rejeição do movimento da cadeia. Se $x \in X e A(x)$ é a probabilidade de se mover partindo de $x$, calculada por:

$$
A(x)=1-P(x,\{x\})
$$

Se $A(x)$ é muito pequeno para muitos valores de $x \in X$, o algoritmo tende a ficar estagnado em um estado particular $x$. Portanto $A(\cdot)$ afeta a convergência da cadeia de Markov. Roberts (1997) mostra que se $A(\cdot)$ não é maior que zero então a cadeia de Markov converge com uma taxa sub-geométrica. Ou seja, se a região com baixa taxa de aceitação é grande, então o teorema do limite central não é válido para uma média ergódica de funçð̃es da cadeia. Se: 


$$
A(x) \rightarrow \text { monotonicamente para zero e } \quad \lim _{x \rightarrow \infty}\left|\frac{\pi(x)}{A^{\prime}(x)}\right|=\infty
$$

então o teorema do limite central não é válido. Como mostra o exemplo que segue:

Considere uma amostra independente com $X=\mathfrak{R}^{+}, \pi(\cdot)=\operatorname{Exp}(1)$ e $Q(x, \cdot)=\operatorname{Exp}(k)$, vemos que, para algum $k>2$ a cadeia é não geometricamente ergódica, ou seja o teorema do limite central neste caso é falho. Para verificarmos temos que:

$$
q(x, y)=k e^{-k y} \quad \text { e } \quad \pi(y)=e^{-y}
$$

então,

$$
\alpha(x, y)=\frac{\pi(y) q(y, x)}{\pi(x) q(x, y)}=e^{-(1-k) y} e^{(k-1) x}
$$

Temos ainda que a probabilidade da cadeia permanecer em $x$ é dada por:

$$
\begin{aligned}
P(x,\{x\}) & =\int_{0}^{x}[1-\alpha(x, y)] g(x, y) d y \\
& =\int_{0}^{x} k e^{-k y}\left[1-e^{-(1-k) y} e^{-(k-1) x}\right] d y \\
& =1-e^{-k x}-k\left(e^{-(k-1) x}+e^{-k x}\right)
\end{aligned}
$$

onde $P(x, y)=q(x, y) \alpha(x, y), \quad y \neq x$. Calculando portanto $A(x)$ :

$$
\begin{aligned}
A(x) & =1-P(x,\{x\}) \\
& =k e^{-(k-1) x}-(k-1) e^{-k x}
\end{aligned}
$$

Temos que se $k>2$, então : 


$$
\lim _{x \rightarrow \infty} A(x) \rightarrow 0 \quad \text { e } \quad \lim _{x \rightarrow \infty}\left|\frac{\pi(x)}{A^{\prime}(x)}\right| \rightarrow \infty,
$$

ou seja, a cadeia converge com uma taxa sub-geométrica, o quê implicará na falha do teorema do limite central.

Para tornar essa idéia mais concreta consideramos dois possiveis valores para $k$, fizemos $k=0,9$ e $k=5$, ou seja, temos dois diferentes núcleos de transição $P_{1}$ e $P_{2}$ respectivamente. Claramente nenhuma escolha é particularmente efetiva para representar $\pi$.

$O$ seguinte experimento foi realizado a partir de $P_{1}$ e $P_{2}$ para estimar o efeito final destes dois algoritmos em suas correspondentes estimativas ergódicas. Para cada um dos núcleos foram geradas 150 cadeias com 20.000 iterações cada uma e em cada caso o algoritmo foi inicializado com $X^{(0)}=1$, que é a média dos valores de $\pi$. Na figura 1 podemos observar a densidade estimada das médias ergódicas para os núcleos $P_{1}$ e $P_{2}$ respectivamente.

É possivel ver através da figura (3.1) a seguir que, $P_{1}$ converge um tanto lentamente, mas após uma longa geração de valores, a estimativa obtida é ergódica, distribuida aproximadamente em torno do 1 , com uma variância pequena. Por outro lado $P_{2}$, após o mesmo número de iterações de $P_{1}$, parece convergir para valores abaixo de 1 . O efeito disto é que a estimativa ergódica da média para $P_{2}$ ficou consideravelmente abaixo de 1 e a curva dạ distribuição com uma assimetria positiva bastante acentuada. 

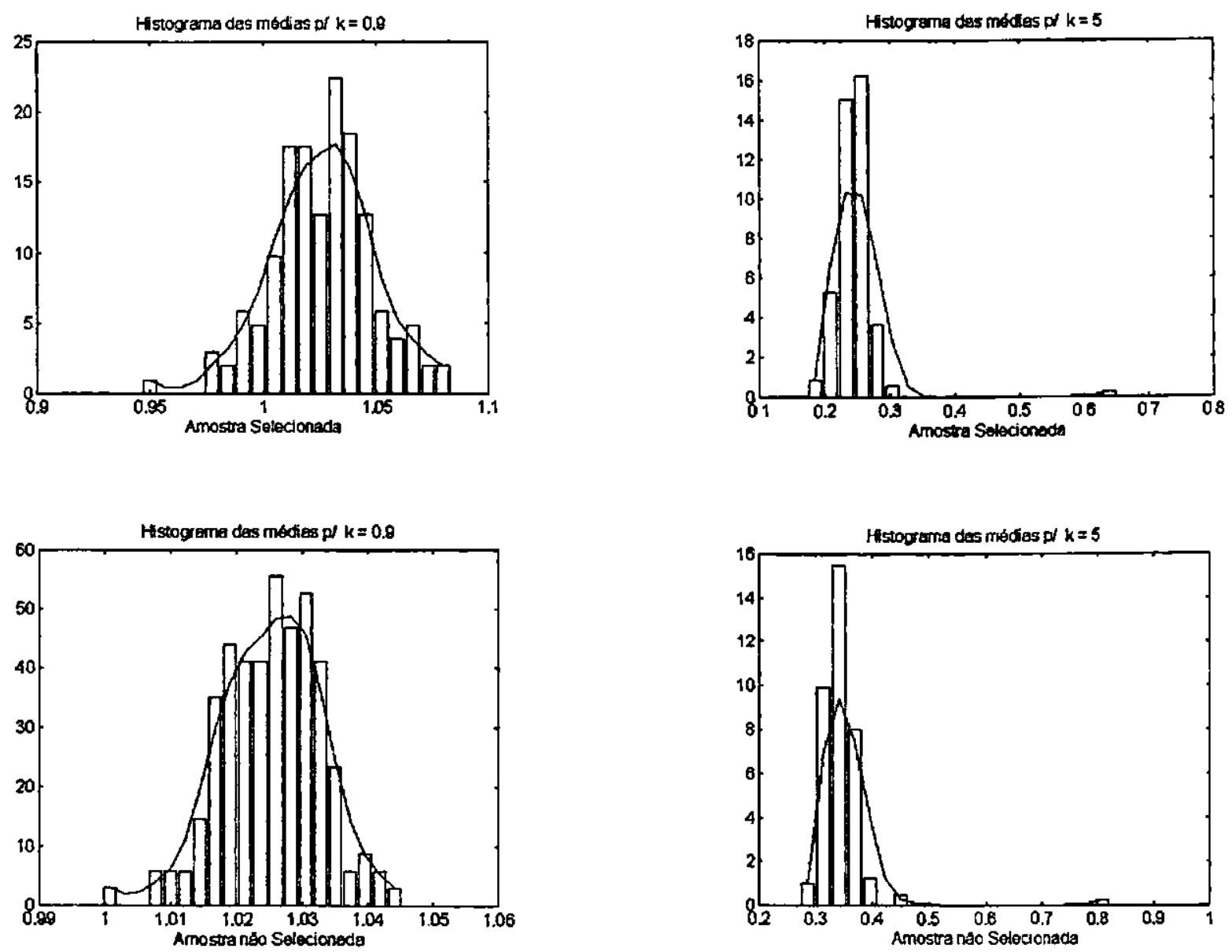

Figura 3.1: Histogramas dos valores selecionados e não selecionados, gerados para $P_{1}$ e $P_{2}$ $(k=0,9$ e $\quad k=5)$ respectivamente

Resultados gerais sobre amostras independentes (ver Smith e Tierney 1996) implicam que, de fato, $P_{2}$ não é geometricamente ergódica enquanto $P_{1}$ embora tenha uma convergência um tanto lenta tem uma taxa de convergência de $\rho=0,99$. De fato, de Roberts e Rosenthal (1997a) o teorema do limite central conserva-se para $P_{1}$ enquanto de Roberts (1996) o teorema do limite central não conserva-se para $P_{2}$.

Logo, de acordo com o exemplo visto, percebemos que é de extrema importância que o algoritmo MCMC escolhido seja geometricamente ergódico. 


\section{Capítulo 4}

\section{Implementando os Resultados}

Para examinar as propriedades teóricas da cadeia de Markov, discutiremos aqui alguns tópicos sobre aspectos práticos na implementação dos algoritmos e obtenção dos resultados que precisam ser consideradas antes de usar tal cadeia para examinar a distribuição a posteriori.

\subsection{Formação da Amostra}

Discutiremos aqui duas diferentes maneiras de usar a cadeia de Markov para amostrar de uma distribuição a posteriori. Na primeira a cadeia de Markov pode ser usada para gerar $m$ cadeias independentes de tamanho $n$, de uma distribuição a posteriori, e após o período de aquecimento ou pré-convergência coletamos os estados de cada uma das cadeias de maneira aleatória. $\mathrm{O}$ tamanho da cadeia deve ser grande o bastante para assegurar que a cadeia alcançou a distribuição de equilibrio, ou seja convergiu. A segunda maneira consiste em usar uma única e longa cadeia . A experiência e a avaliação teórica na literatura de simulação é a favor da segunda maneira, ou seja, de uma cadeia única e longa. A maior desvantagem no uso de múltiplas cadeias é que é virtualmente impossivel dizer o quanto uma cadeia é longa o bastante para que a mesma atinja o equilibrio. Até mesmo quando usamos cadeias longas é dificil determinar o quanto da cadeia foi afetada pelo valor inicial. A segunda desvantagem no uso de múltiplas cadeias é que existe um desperdicio muito grande dos valores gerados, pois menos da metade dos $m n$ valores gerados são aproveitados. Com uma única cadeia de tamanho $m n$ descartaremos apenas uma pequena fração dos valores inicias possibilitando desta forma o uso de praticamente a maioria dos valores gerados.

Uma dificuldade que surge da dependência no uso de uma única cadeia é que a variância dos estimadores são dificeis de ser obtidas. Entretanto a literatura de simulação oferece algumas alternativas tais como o uso do agrupamento de médias e a análise de séries temporais (Bratley et al., 1987, Chapter 3; Ripley, 1987, Chapter 6) para auxiliar no cálculo desta variância. 
$\mathrm{Na}$ análise de séries temporais podemos estimar a variância de Monte Carlo usando dados de apenas uma cadeia. Considere uma amostra de tamanho $n$ (possivelmente correlacionada) de uma cadeia de Gibbs $x_{1}, x_{2}, \ldots, x_{n}$. Os valores $X$ 's seriam amostras representantes de uma distribuição marginal a posteriori de valores aditivos genéricos, de variâncias aditivas ou mais geralmente de funções de amostras de Gibbs $x_{i}, g\left(x_{i}\right)$. O estimador $\hat{\mu}$ da média é dado por:

$$
\hat{\mu}=n^{-1} \sum_{i=1}^{n} g\left(x_{i}\right)
$$

O estimador da variância de Monte Carlo de $\hat{\mu}, \hat{\sigma}^{2}(\hat{\mu})$, baseado em séries temporais é obtido como segue:

$$
\hat{\sigma}^{2}(\hat{\mu})=n^{-1}\left[\hat{\gamma}(0)+2 \sum_{i=1}^{2 \delta+1} \gamma(i)\right], \quad \text { e } \quad \hat{\gamma}(t)=n^{-1} \sum_{i=1}^{n-t}\left[\left(g\left(x_{i}\right)-\hat{\mu}\right)\left(g\left(x_{i+t}\right)-\hat{\mu}\right)\right]
$$

onde $\hat{\gamma}(t)$ é o estimador da autocovariancia de lag-t, $\delta$ é escolhido tal que é o maior inteiro satisfazendo $[\hat{\gamma}(2 \delta)+\hat{\gamma}(2 \delta+1)]>0, \delta=0,1, \ldots$. Se os valores são independentes $\sigma^{2}(\hat{\mu})=\gamma(0) / n$. Note que a função $g\left(x_{i}\right)$ pode ser $g\left(x_{i}\right)=x_{i}, g\left(x_{i}\right)=I\left(x_{i} \leq x\right)$ ou alguma outra função dos dados. Uma idéia do efeito da autocorrelação na quantidade de informação na cadeia pode ser obtida calculando um tamanho efetivo da cadeia como $\hat{\Psi}=\gamma(0) / \hat{\sigma}^{2}(\hat{\mu})$. Quando os valores da cadeia de Gibbs são independentes, $\hat{\Psi}=n$, e o tamanho efetivo (verdadeiro) e atual são iguais.

De alguma maneira essas alternativas podem ser úteis para que obtenhamos uma amostra independente aproximada da posteriori. Usando cadeias múltiplas isso pode ser obtido coletando todos os $r$-́simos valores ao longo da amostra. O número $r$ de pontos a serem pulados em ordem produzirá independência aproximada que pode usualmente ser escolhido muito menor que o número $n$ de valores para alcançar o equilibrio aproximado, visto que uma quantidade pequena de correlação é usualmente muito menos sério que o viés nas estimativas das médias. 


\subsection{Determinando o Tamanho da Cadeia}

Outra consideração importante é o tamanho total da amostra ou o tamanho da cadeia necessário para obtermos estimativas precisas. Para uma amostra independente e identicamente distribuída (i.i.d.) de tamanho $n$ de uma distribuição a posteriori $\pi$, o desvio padrão da amostra da média da função $f(\theta)$ é $\sigma / \sqrt{n}$, onde $\sigma$ é o desvio padrão a posteriori de $f(\theta)$. Se a estimativa preliminar de $\sigma$ é utilizável , talvez de uma análise assintótica, então isso pode ser usado para estimar o tamanho da amostra que seria necessária para uma amostragem i.i.d.. Na amostragem dependente, os valores são geralmente correlacionados daí a necessidade de obtermos um tamanho de amostra grande. Se as séries podem ser aproximadas por um modelo regressivo de primeira ordem, então o desvio padrão assintótico da amostra de médias será:

$$
\frac{\sigma}{\sqrt{n}} \sqrt{\frac{1+\rho}{1-\rho}}
$$

onde $\sigma$ é o desvio padrão a posteriori de $f(\theta)$ e $\rho$ é a autocorrelação da série $f\left(X_{n}\right)$. Uma suposição grosseira para $\rho$ pode ser portanto usada para ajustar o tamanho da amostra para dependência na série.

Ao invés de fixar um tamanho para a amostra, é possivel também usar regras seqüenciais ou um agrupo de regras seqüenciais para determinar quando parar a amostragem. Visto que a informação a priori dos valores da média e desvio padrão a posteriori é freqüentemente utilizada então os métodos Bayesianos seqüenciais tornam-se uma escolha natural para uma análise inicial. $O$ agrupamento de médias pode ser usado de forma razoável para assegurar uma suposição de normalidade por grupo de médias.

Uma opção intermediária é determinar o tamanho da amostra baseada numa cadeia piloto. Raftery e Lewis (1992) sugerem uma possivel aproximação. 


\subsection{Redução da Variância}

Para qualquer método de simulação, as técnicas de redução da variância podem com freqüência reduzir significativamente o tamanho da amostra necessária para obtermos precisão nas estimativas. Métodos de redução da variância tais como reamostragem ponderada, condicionamento, variáveis controle e variáveis comum podem ser usadas com qualquer método de cadeia de Markov.

\subsubsection{Reamostragem Ponderada}

A Reamostragem ponderada pode ser usada como um método de redução de variância para construir uma cadeia de Markov com distribuição de equilíbrio $\pi^{\prime}$ ao invés de $\pi$ resultando então numa amostra ponderada com pesos de importância apropriados (Hastings, 1970, Section 2.5). Para reduzir a variância de uma estimativa da esperança de $\pi f$, a densidade $\pi^{\prime}(x)$ seria escolhida para ser aproximadamente proporcional a $\pi(x)|f(x)|$.

Reamostragem ponderađa é também útil se é fácil construir uma cadeia com distribuição de equilibrio $\pi^{\prime}$, ou se uma amostra de uma tal cadeia já está disponivel. Por exemplo, esta aproximação pode ser usada para estimar esperanças para uma distribuição a priori não-conjugada com uma amostra Gibbs de uma distribuição priori conjugada mas similar.

Usar amostra comum com pesos de importância é particularmente útil para comparar as esperanças de duas distribuições similares, correspondendo talvez a duas distribuições a priori diferentes ou a eliminação de algumas observações. As correlações positivas resultam numa maneira de usar a mesma série para estimar as duas esperanças o que reduziria a variância da diferença estimada. Isso pode ser visto como o uso de variáveis comuns.

Em algumas aplicações da reamostragem ponderada, funções peso ilimitadas seriam usadas com atenção. 


\subsubsection{Condicionando}

Suponha uma cadeia de Markov ergódica produzindo pares da forma $\left(X^{(n)}, Y^{(n)}\right)$. O $X$ limite da distribuição de equilibrio é $\pi$, e a esperança condicional $h\left(Y^{(n)}\right)=E\left[f\left(X^{(n)}\right) \mid Y^{(n)}\right]$ pode ser utilizada. Então a amostra de médias da esperança condicional $h\left(Y^{(n)}\right)$ convergirá para a esperança $\pi f$. Para uma sequêencia de pares i.i.d. a média das esperanças condicionais tem menor variäncia que a média das séries $f\left(X^{(n)}\right)$. Vai depender da estrutura das correlações se essa forma de condicionar leva a uma redução na variância para uma série dependente. Uma condição suficiente é que as correlações nas séries $h\left(Y^{(n)}\right)$ não são tão grandes quanto nas séries $f\left(Y^{(n)}\right)$. Liu et al.(1991, Teorema 4.1) mostra que essa condição influencia na amostra aleatória de Gibbs, para a qual a coordenada a ser atualizada é selecionada independentemente conforme a uma distribuição fixada em cada passo.

Condicionar é particularmente útil para calcular esperanças ou densidades marginais das coordenadas limites no amostrador de Gibbs, desde que as suposições necessárias para o amostrador implique que as médias condicionais ou densidades de parâmetros, dado o resto, sejam usualmente úteis. Neste caso as variáveis $Y^{(n)}$ consistem de todas as variáveis da sequêencia $X^{(n)}$ do amostradas pelo Gibbs exceto a de interesse. Gelfand e Smith (1990) referem-se a esse condicionamento como uma Rao-Blackvellization.

Os pares $\left(X^{(n)}, Y^{(n)}\right)$ podem ser construidos usando as esperanças condicionais $h\left(Y^{(n)}\right)$ para facilitar. Em alguns casos essas esperanças são úteis na forma fechada, em outros elas podem ser aproximadas usando métodos assintóticos ou integração numérica de dimensão inferior. Um método geral para construir uma cadeia $\left(X^{(n)}, Y^{(n)}\right)$ é começar com uma cadeia $Y^{(n)}$ com distribuiçāo invariante $\pi$ e outro núcleo de Markov $R$ com distribuição invariante $\pi$. As componentes $X^{(n)}$ serão então geradas da distribuição $R\left(Y^{(n)}, \cdot\right)$.

A cadeia $\left(X^{(n)}, Y^{(n)}\right)$ pode também ser composta obtendo $X^{(n)}$ de uma cadeia com distribuição invariante $\pi$ e obtendo $Y^{(n)}$ consistindo de $X^{(n-1)}$ e algumas das variáveis usadas para 
gerar $X^{(n)}$ de $X^{(n-1)}$. A esperança condicional é calculada por uma integral unidimensional $h\left(Y^{(n)}\right)$. Se essa integral é avaliada numericamente então pode ser necessário um número maior de valores da densidade a posteriori. O número de valores pode ser reduzido significativamente pela substituição da integral numérica pela esperança condicional de uma grade finita com a distribuição condicional isto é uma distribuição invariante.

As cadeias aumentadas $\left(X^{(n)}, Y^{(n)}\right)$ usadas para condicionar, também são cadeias de Markov com distribuição invariante conhecida. Suas propriedades podem entretanto ser derivadas dos resultados do capítulo 3.

\subsubsection{Variáveis Controle}

Uma maneira para introduzir a variável controle no método da cadeia de Markov usar a amostra com importância nos pesos para calcular estimativas da aproximação normal, e para dar precisão aos erros nessas estimativas. Outra aproximação, descrita por Schmeiser e Chen (199l), é para calcular estimativas da aproximação normal usando variáveis comuns, por exemplo para transformar as variáveis usadas para gerar um valor candidato no algoritmo de Metropolis para uma variável normal apropriada. 


\section{CAPÍTULO 5}

\section{Diagnósticos de Convergência}

\subsection{Convergência em MCMC}

Apesar dos algoritmos MCMC permitirem uma grande expansão das classes dos modelos candidatos para um dado problema, eles também sofrem de uma enorme, bem conhecida e séria desvantagem: a convergência dos processos. Os algoritmos na convergência, produzem uma amostra da distribuição de interesse, e o nosso problema é saber até que ponto é razoável acreditar que a amostra gerada é verdadeiramente representativa em relação a distribuição de interesse. Um fator de grande relevância para esta dúvida é que a natureza do algoritmo de Markov gera valores de amostra que serão, geralmente, correlacionados entre si, o que atrapalha o algoritmo na sua tentativa de extrair uma amostra da distribuição de interesse e na determinação da Variância de Monte Carlo, a qual influenciará diretamente nas estimativas das características do modelo que são calculadas com base nos valores gerados. Grande parte dos trabalhos aplicados, têm demonstrado que estas correlações, muitas vezes altas, existentes entre os valores gerados, não são incomuns e são causadas por exemplo, por uma escolha deficiente de parâmetros ou talvez por uma reparametrização.

Os esforços para encontrar uma solução para o problema de determinar a convergência de algoritmos MCMC têm se concentrado em duas áreas. A primeira é teórica, na qual o núcleo de transição da cadeia de Markov é analisado numa tentativa de pré-determinar um número de iterações que irão indicar a convergência na distância da variação total dentro de uma tolerância específica para uma distribuição estacionária verdadeira. Entretanto, quase todos os trabalhos realizados utilizando os métodos MCMC estão baseados na segunda abordagem para o problema da convergência: utilizando-se ferramentas denominadas de diagnósticos de convergência ao resultado produzido pelo algoritmo. Tentativas anteriores deste tipo feitas por estatísticos, envolveram comparações entre a distribuição empírica dos resultados produzidos em iterações consecutivas (ou próximas à consecutiva) e a respectiva convergência, quando a diferença entre as duas fosse, de alguma forma, passivel de ser negada. Este procedimento conduz a amostras que utilizam um grande número de cadeias paralelas independentes para obter estimativas sobre os momentos simples, quantil e densidade. 


\subsection{Diagnósticos de Convergência MCMC}

Nessa seção, serão apresentados um Método de Séries Temporais e alguns diagnósticos de convergência baseados em propriedades estatísticas da(s) cadeia(s) de Markov considerada(s) como indicadores da convergência dos processos. Abordaremos entretanto os diagnósticos de convergència mais utilizados como o de Gelman e Rubin (1992b), Raftery e Lewis (1992), Geweke (1992).

\subsubsection{Gelman e Rubin}

O método de Gelman e Rubin (1992b) sugere que a convergência pode ser verificada a partir da utilização de várias cadeias em paralelo começando de diferentes pontos. Com isso evita-se que as cadeias se concentrem em regióes em tomo de uma moda local, no caso de multimodalidade da posteriori. Além disso em alguns casos convergência lenta pode levar à percepção errônea de convergência quando se está utilizando uma única cadeia. Exemplos ilustrativos dessa situação são fornecidos em Gelman e Rubin (1992a) e Gelman (1995). Após a indicação de convergência, todas as cadeias devem apresentar o mesmo comportamento qualitativo e quantitativo, entretanto se analisarmos apenas uma cadeia a indicação da convergência pode ser problemática.

Um indício de forte convergência é a verificação visual de similaridade entre as trajetórias das cadeias após algumas iterações. Gelman e Rubin (1992a) desenvolveram essa idéia e propuseram alguns métodos formais para a detecção de convergência além dessa verificação visual. Esse método é baseado nas técnicas de análise de variância e indica a convergência do processo apenas quando a variância entre as cadeias for bem menor que a variância dentro da cadeia ou, equivalentemente, quando os histogramas das cadeias misturadas forem similares aos histogramas de cada uma das cadeias isoladas.

As cadeias são inicializadas em pontos que devem ser sobredispersos em relação à distribuição a posteriori. O número de cadeias deve ser grande mas não necessariamente muito maior que um. Para componentes continuas, pode se proceder uma busca de moda(s) e respectiva(s) curvaturas na(s) moda(s) e gerar pontos iniciais a partir de uma (mistura de ) 
distribuição(ões) $t$-Student. No casso de multimodalidade é recomendável utilizar pelo menos uma cadeia a partir de cada moda.

Considerando $m$ cadeias paralelas e uma função real $t(\theta)$, tem-se $m$ trajetórias $\left\{\mathrm{t}_{1}^{(j)}, t_{2}^{(j)}\right.$, $\left.\ldots, t_{m}^{(i)}\right\}, j=1, \ldots, n$ para $t$. Portanto podemos obter a variância entre as cadeias $(E)$ dada por:

$$
E=\frac{n}{m-1} \sum_{i=1}^{m}\left(\bar{t}_{i}-\bar{t}\right)^{2}
$$

onde: $\bar{t}_{i}$ representa as médias das observações da cadeia $i$ dada por: $\bar{t}_{i}=\frac{1}{n} \sum_{j=1}^{n} t_{i}^{(j)}, i=1, \ldots, m$;

$\bar{t}$ é a média geral dada por, $\bar{t}=\frac{1}{m} \sum_{i=1}^{m} \bar{t}_{i}, i=1, \ldots, m e$

$S_{i}^{2}$ nos fornece a variância dentro da cadeia $i$ dada por, $S_{i}^{2}=\frac{1}{n-1} \cdot \sum_{j=1}^{n}\left(t_{i}^{(f)}-\bar{t}_{i}\right)$.

Note que $E=n W$, onde $W=\frac{1}{m-1} \sum_{i=1}^{m}\left(\vec{t}_{i}-\bar{t}\right)^{2}$ é o estimador não viciado das variâncias entre as cadeias. E a média das variâncias dentro das cadeias $(D)$ é dada por:

$$
D=\frac{1}{m(n-1)} \sum_{i=1}^{m} \sum_{j=1}^{n}\left(t_{i}^{(j)}-\bar{t}_{i}\right)^{2}
$$

Sob convergência, todos os $m n$ valores são gerados da distribuição a posteriori conjunta e a variância de $t$ pode ser estimada de forma não-viciada por $\hat{\mathrm{V}}=(1-1 / n) \mathrm{D}+(1 / n) \mathrm{E}$.

Se as cadeias ainda não tiverem convergido, então essa estimativa é maior que $\hat{V}$, pois os valores iniciais ainda estarão influenciando e eles foram escolhidos com dispersão maior do que a da distribuição de equilibrio. Por outro lado, $D$ fornece estimativas menores que $\hat{\mathrm{V}}$ pois uma cadeia só não terá coberto toda a variabilidade de $t(\theta)$. Um indicador de convergência é dado pela redução potencial da escala

$$
\sqrt{R}=\sqrt{\left(\frac{\hat{V}}{D}\right) \cdot \frac{d f+3}{d f+1}}
$$


onde: $\quad d f=2(\hat{V})^{2} / \operatorname{Var}(\hat{V}) \mathrm{e}$

$$
\begin{aligned}
\operatorname{Var}(\hat{V}) \cong & \left(\frac{n-1}{n}\right)^{2} \cdot \frac{1}{m} \cdot \operatorname{Var}\left(S_{i}^{2}\right)+\left(\frac{m+1}{m n}\right) \cdot \frac{2}{m-1} \cdot E^{2}+ \\
& 2 \cdot \frac{(m+1)(n-1)}{m n^{2}} \cdot \frac{n}{m} \cdot\left[\operatorname{Cov}\left(S_{i}^{2}, \bar{t}_{i}^{2}\right)-2 \bar{t} \operatorname{Cov}\left(S_{i}^{2}, \bar{t}_{i}\right)\right]
\end{aligned}
$$

que é sempre maior que 1. A medida que $\boldsymbol{n}$ cresce, ambos os estimadores acabarão convergindo para a variância de $t$ e $R$ convergirá para 1 . Logo, $R$ pode ser usado como indicador de convergência pela avaliação de sua proximidade a 1. Gelman(1995) sugere aceitar convergência quando o valor de $R$ calculado para todas as funções de $t$ de interesse for da ordem de 1,1 a 1,2 . Podemos tomar $t(\theta)=-2 \log \pi(\theta)$ e assim monitorar também a convergência da posteriori. Quando a convergência está assegurada, utiliza-se os valores gerados após o período de aquecimento para inferência.

Embora tenha sido criado para as amostras de Gibbs, o método de Gelman e Rubin pode ser aplicado a qualquer algoritmo MCMC. Sua abordagem enfatiza a redução da variação da tendência estimada.

$\mathrm{O}$ método de Gelman e Rubin tem recebido um grande número de críticas, devido a formulação dos estimadores $E$ e $D$. Aqueles que defendem a utilização de uma única e longa cadeia consideram bastante ineficiente utilizar múltiplas cadeias e descartar um substancial número de iterações anteriores de cada uma.

\subsubsection{Raftery e Lewis}

O método de Raftery e Lewis (1992) tem por objetivo detectar a convergência para a distribuição estacionária e fornecer uma maneira de limitar a variância das estimativas dos quantis dos parâmetros via amostrador de Gibbs. Mais especificamente, o método requer o fornecimento dos valores $M, N$, e $k$ onde $M$ determina o número de iterações que devem ser descartados, $N$ é o numero de iterações que serão processadas e $k$ é o tamanho do espaçamento que será dado entre os valores, para garantir independência na amostra coletada que deve ser usada nos procedimentos de inferência. 
Esses valores são escolhidos de forma a garantir que um determinado quantil $u$ de uma determinada função $t(\theta)$ seja estimado com uma precisão pré-especificada. Por exemplo queremos obter $q=P(t(\theta) \leq u \mid$ dados $)=0,025$ então $u$ será o limite inferior de intervalos de confiança simétricos de $95 \%$ a posteriori para $t(\theta)$. Esse nível de confiança é devido ao processo amostral sendo utilizado para a estimação de $u$ e não deve ser confundido com a incerteza a posteriori a respeito de $\theta$ expressa por $\pi$.

A abordagem é baseada na teoria da formação de uma nova cadeia de 0's e l's dada por $Z^{(j)}=I\left(t^{(j)} \leq u\right)$ onde $t^{(j)}$ é o valor gerado de $t$ na $j$-ésima iteração do amostrador de Gibbs para $\theta$. Entretanto apesar de $Z^{(j)}$ decorrer de uma cadeia de Markov ela não é uma cadeia de Markov. Apesar disso é razoável supor que as dependências entre os estados decaem rapidamente com a distância e novas cadeias $Z_{k}^{(j)}$ podem ser construídas tomando os valores de $Z^{(j)}$ a cada $k$ iterações. $O$ valor de $k$ é escolhido de forma que o modelo de Markov seja preferido ao modelo de Markov de segunda ordem, isto é, com dependências em dois estágios passados. Toma-se $k$ como o menor valor para o qual a dependência em apenas um estágio passado é preferida segundo algum critério estatístico.

Uma vez escolhido $k$, passa-se a trabalhar com o processo a $k$ iterações assim construído e a seguir, determina-se $M=m k$ usando resultados de cadeias de Markov com dois estágios. Esse valor é escolhido de forma a garantir que a probabilidade de que, em um determinado estágio, a cadeia esteja suficientemente próxima da probabilidade de equilibrio. Finalmente, escolhe-se $N=n k$ de forma a garantir que a estimativa de $q$ estará próxima de $q$ de acordo com a probabilidade de cobertura especificada. Note que $q$ é estimado por $\bar{Z}_{k, n}=(1 / n) \sum_{j=1}^{n} Z_{k}^{(m+j)}$. Usando as propriedades assintóticas de $\bar{Z}_{k, n}$ chega-se ao valor de $N$.

Assim, basta especificar o quantil, a tolerância em sua estimação, a probabilidade com que vai ser permitida essa tolerância e o nível de proximidade da cadeia a dois estados de sua distribuição de equilibrio. Para se ter uma idèia das ordens de grandeza envolvidas, no caso mais favorável de $k=1$ e supondo que se deseja estimar o quantil 0,025 com erro máximo de 0,0125 a um nivel de $95 \%$ de confiança obtém-se $N=n=600$.

Raftery e Lewis (1995) sugere que esse diagnóstico seja utilizado para todas as quantidades de interesse com $q=0,025$ e $q=0,975$, eles enfatizam ainda que é muito útil a habilidade para apontar a precisão da estimativa dos quantis, uma vez que eles estão no coração 
da estimativa de densidade e fornecem, ainda, estimativas robustas para o centro e a dispersão da distribuição. Alguns críticos chamam a atenção para fato de que o método pode produzir estimativas variáveis do número de iterações necessárias, fornecendo diferentes cadeias iniciais para o mesmo problema. É ainda, de alguma maneira, impossível que esta convergência possa ser "rediagnosticada" para cada quantil de interesse.

\subsubsection{Geweke}

Geweke (1992) recomenda a utilização de métodos de análise espectral para calcular a convergência da amostra de Gibbs quando o objetivo da análise é estimar a média de alguma função $t$ de parâmetros $\theta$ sendo simulados. Se os valores de $t\left(\theta^{(j)}\right)$ são computados após cada iteração da amostra de Gibbs, a seqüência resultante pode ser considerada como uma série temporal. O método de Geweke parte do principio de que a natureza do processo MCMC e da função $t$ implica na existência de uma densidade espectral $S_{t}(\omega)$ para esta série temporal que não contém descontinuidade na freqüência zero. Se esta premissa se cumpre, então para a estimativa de $E[t(\theta)]$ baseado em $N$ iterações da amostra de Gibbs, é dada por:

$$
\bar{t}_{N}=\frac{\sum_{i=1}^{N} t\left(\theta^{(i)}\right)}{N},
$$

cuja variância assintótica estimada é $\hat{S}_{t}(0) / N$. A raiz quadrada desta variância assintótica pode ser usada para estimar o erro padrão da média. Geweke refere-se a esta estimativa como "erro numérico padrão". (NSE - numeric standard error).

O diagnóstico de convergência de Geweke sugere que após um número $N$ de iterações suficientemente longo, calcule-se a média $\bar{t}_{n_{a}}$, baseado nas primeiras $n_{A}$ iterações e $\bar{t}_{n_{b}}$, baseado nas últimas $n_{b}$ iterações, e os respectivos estimadores das variâncias assintóticas $\hat{S}_{t}^{a}(0)$ e $\hat{S}_{t}^{b}(0)$. Se as razões $n_{a} / N$ e $n_{b} / N$ são fixos e $n_{a}+n_{b}<N$, utilizando-se o teorema do limite central temos que se $N \rightarrow \infty$

$$
\frac{\bar{t}_{n_{a}}-\bar{t}_{n_{b}}}{\left(\hat{S}_{t}^{a}(0) / n_{a}\right)+\left(\hat{S}_{t}^{b}(0) / n_{b}\right)} \rightarrow N(0,1)
$$


ou seja, a distribuição deste diagnóstico aproxima-se de uma normal padrão à medida em que $N$ tende ao infinito. Assim um teste de hipóteses pode ser construído, e se a diferença padronizada entre as médias for muito grande, isto indicará na não convergência do processo. Geweke sugeriu utilizar $n_{A}=0,1 N$ e $n_{B}=0,5 N$.

O método de Geweke tenta lidar com a tendência e a variância. A exemplo do diagnóstico de convergência de Gelman e Rubin, o de Geweke é essencialmente univariado mas se $t(\theta)$ for considerado (-2) vezes o logaritmo da densidade posteriori $(t(\theta)=-2 \log \pi(\theta))$, então isto também pode ser usado para investigar a convergência da posterior conjunta. Isto exige, apenas, uma cadeia simples de amostras e pode ser aplicado com qualquer método MCMC.

As desvantagens do método de Geweke incluem sua sensibilidade na especificação da janela espectral. Além disso, embora seu diagnóstico seja quantitativo, Geweke não especifica um procedimento para aplicá-lo, Ao contrário, deixa isso a cargo da experiência e da escolha subjetiva do estatístico.

\subsubsection{Zellner e Min}

Suponha que $\theta$ possa ser dividido em dois componentes $\theta_{1}$ e $\theta_{2}$. Logo, $\pi(\theta)=\pi\left(\theta_{l} \mid \theta_{2}\right) \pi$ $\left(\theta_{2}\right)=\pi\left(\theta_{2} \mid \theta_{1}\right) \pi\left(\theta_{1}\right)$, para todo valor de $\theta$. Em geral, as condicionais são fáceis de se obter mas as marginais não. Por isso, elas são estimadas usando o amostrador de Gibbs. Sejam $\hat{\pi}\left(\theta_{1}\right)$ as estimativas de $\pi\left(\theta_{i}\right), \mathrm{i}=1,2$.

Zellner e Min (1995) propõem dois critérios para verificação da convergência do amostrador de Gibbs. O critério da diferença é baseado na estatística:

$$
\hat{\eta}=\pi\left(\theta_{1} \mid \theta_{2}\right) \hat{\pi}\left(\theta_{2}\right)-\pi\left(\theta_{2} \mid \theta_{1}\right) \hat{\pi}\left(\theta_{1}\right)
$$

Se a cadeia tiver convergido, para qualquer valor de $\theta, \hat{\eta}$ será próximo de zero.

O critério da razão é baseado nas estatísticas: 


$$
\hat{\xi}_{1}=\frac{\pi\left(\theta_{2} \mid \theta_{1}\right) \hat{\pi}\left(\theta_{1}\right)}{\pi\left(\theta_{2}^{\prime} \mid \theta_{1}^{\prime}\right) \hat{\pi}\left(\theta_{1}^{\prime}\right)} \quad \text { e } \quad \hat{\xi}_{2}=\frac{\pi\left(\theta_{1} \mid \theta_{2}\right) \hat{\pi}^{\prime}\left(\theta_{2}\right)}{\pi\left(\theta_{1}^{\prime} \mid \theta_{2}^{\prime}\right) \hat{\pi}\left(\theta_{2}^{\prime}\right)}
$$

onde $\theta^{\prime}=\left(\theta_{1}^{\prime}, \theta_{2}^{\prime}\right)$ é um outro valor considerado para $\theta$. Tanto $\hat{\xi}_{1}$ quanto $\hat{\xi}_{2}$ são estimativas de $\xi=\pi(\theta) / \pi\left(\theta^{\prime}\right)$. Portanto, se a cadeia tiver convergido, $\hat{\xi}_{1}$ e $\hat{\xi}_{2}$ estarão próximos. Além disso, se eles estiverem próximos de $\xi$ então a convergência se deu para a distribuição de equilibrio correta. Zellner e Min (1995) apresentam a inferência para os critérios acima e discutem a sua utilização prática.

As duas principais desvantagens do critério de Zellner e Min é primeiro, que uma grade de discretização deve ser arbitrada para se avaliar as estatísticas ( $\hat{\eta}$ ou $\hat{\xi}_{1}$ e $\hat{\xi}_{2}$ ) e tanto a amplitude dessa grade como sua discretização podem afetar o desempenho do critério. A outra desvantagem é que esse critério só aplica-se ao algoritmo amostrador de Gibbs, não se aplica ao Metrópolis-Hasting pois é necessário determinar a constante normalizadora da densidade conjunta.

\subsubsection{Outros Métodos}

Existem outros métodos tais como, os métodos de Garren e Smith (1993), Johnson (1994), Liu, Liu e Rubin (1992), Mikland, Tiermey e Yu (1995), Ritter e Tanner (1992), Roberts (1992), Yu (1994), Yu e Mykland (1994). Em princípio portanto são superiores aos métodos usados acima. Sua complexidade prática entretanto contrabalança suas virtudes teóricas. 


\section{CAPÍTULO 6 \\ Alguns Problemas Bayesianos}

Neste capitulo trataremos dos dois problemas introduzidos no capítulo 1 para os quais observamos a necessidade da simulação das amostras através dos métodos MCMC para o cálculo dos estimadores dos parâmetros de interesse.

\subsection{O Primeiro Problema}

No primeiro exemplo consideramos um modelo hierárquico permutável, para o qual as variáveis aleatórias independentes $y_{1}, \ldots, y_{5}$ são observadas, cada $y_{i}=n_{i} \mu_{i}, i=1,2, \ldots, 5$, tem densidade amostral, $f\left(y_{i} \mid \theta_{i}\right)$ binomial dada pela equação (1.4):

$$
f(\boldsymbol{Y} \mid \boldsymbol{\theta}) \propto \prod_{i=1}^{5} e^{n_{1} \mu_{i} \theta_{1}}\left(1+e^{\theta_{l}}\right)^{-n_{t}}, \quad \boldsymbol{\theta}=\left(\theta_{1}, \theta_{2}, \ldots, \theta_{5}\right)
$$

onde $\boldsymbol{Y}=\left(y_{1}, \ldots, y_{5}\right)$ e os $\theta_{i}$ 's são parâmetros comuns desconhecidos. Para modelar a priori para $\boldsymbol{\theta}$ acreditamos que a amostragem das médias $\theta_{1}, \ldots, \theta_{5}$ são permutáveis e supomos $\theta_{i} \sim N\left(m, \tau_{1}\right)$. Por tratar-se de um modelo hierárquico a especificação da priori foi dividida em dois estágios, são eles:

$1^{\circ}$ Estágio: definição da priori para o parâmetro de interesse dada pela equação (1.5)

$$
g\left(\theta \mid \lambda_{1}, \lambda_{2}\right) \propto \prod_{i=1}^{5} e^{-\lambda_{2} / 2} \exp \left\{\frac{-\left(\theta_{1}-\lambda_{1}\right)^{2}}{2 e^{\lambda_{2}}}\right\} \text { onde } \lambda_{1}=m \text { e } \lambda_{2}=\log \tau^{2}
$$

$2^{\circ}$ Estágio: definição da priori dos hiperparâmetros do $1^{2}$ estágio dada pela equação (1.6)

$$
h(\lambda) \propto \exp \left\{-\frac{\left(\lambda_{1}-\delta_{1}\right)^{2}}{2 \gamma_{1}}\right\} \exp \left\{-\frac{\left(\lambda_{2}-\delta_{2}\right)^{2}}{2 \gamma_{2}}\right\} \quad \text { onde } \lambda=\left(\lambda_{1}, \lambda_{2}\right)
$$


Obtivemos assim um modelo hierárquico permutável, para o qual a densidade conjunta a posteriori de $(\theta, \lambda)$ é dada pela equação (1.7) a qual é resultado do produto das três equações acima citadas

$$
\pi\left(\theta, \lambda_{1}, \lambda_{2} \mid \boldsymbol{Y}\right) \propto \prod_{i=1}^{s} e^{n \theta_{1} \mu_{4}}\left(1+e^{\theta_{1}}\right)^{-n_{1}} e^{-\lambda_{2} / 2} e^{-\frac{\left(\theta_{1}-\lambda_{1}\right)^{2}}{2 e^{\lambda_{2}}}} e^{-\frac{\left(\lambda_{1}-\delta_{1}\right)^{2}}{2 \gamma_{1}}} e^{-\frac{\left(\lambda_{2}-\delta_{2}\right)^{2}}{2 \gamma_{2}}}
$$

E a partir desta equação construímos as distribuições condicionais $\pi(\theta \mid \lambda, Y)$ e $\pi(\lambda \mid \theta, Y)$ como segue:

$$
\begin{array}{ll}
\pi(\boldsymbol{\theta} \mid \lambda, \boldsymbol{Y}) \propto N\left(\lambda_{1}, e^{\lambda_{2}} \mathbf{I}_{N}\right) \Psi_{1}(\boldsymbol{\theta}) \quad, \text { onde: } \Psi_{1}(\boldsymbol{\theta}) \propto \prod_{i=1}^{5} e^{\eta_{1} \theta_{i} \mu_{i}}\left(1+e^{\theta_{i}}\right)^{-n_{l}} \\
\pi(\lambda \mid \boldsymbol{\theta}, \boldsymbol{Y}) \propto N(\delta, \Sigma) \Psi(\boldsymbol{\theta}, \lambda) \quad, \text { onde: } \Psi_{2}(\boldsymbol{\theta}, \lambda) \propto \prod_{i=1}^{5} e^{-\lambda_{2} / 2} \exp \left\{-\frac{\left(\theta_{i}-\lambda_{1}\right)^{2}}{2 e^{\lambda_{2}}}\right\}
\end{array}
$$

Visto que, as expressões das condicionais não são totalmente conhecidas, optaremos por simular a amostra a partir do algoritmo de M-H. Nosso objetivo neste exemplo é observar como critérios de amostragens tais como, seleção de amostras distanciadas por um passo $k$, pode afetar a correlação dos valores gerados e portanto a variância das estimativas.

\subsubsection{O Algoritmo}

$1^{0}$ Passo: Inicializamos o contador de iterações $j \leftarrow 1$ e arbitraremos valores iniciais para os parâmetros $\left(\boldsymbol{\theta}^{(0)}, \lambda^{(0)}\right)$.

$2^{0}$ Passo: Geramos um novo par $\left(\boldsymbol{\theta}^{(t)}, \lambda^{(1)}\right)$ de acordo com suas respectivas condicionais:

$$
\begin{aligned}
& \pi\left(\boldsymbol{\lambda}^{(\prime \prime} \mid \boldsymbol{\theta}, \boldsymbol{Y}\right) \propto N(\boldsymbol{\delta}, \Sigma) \Psi_{2}\left(\boldsymbol{\theta}^{(j-l)}, \boldsymbol{\lambda}^{(j-l)}\right) \\
& \pi\left(\boldsymbol{\theta}^{\prime \prime} \mid \boldsymbol{\lambda}, \boldsymbol{Y}\right) \propto N\left(\lambda_{I}^{(j)}, e^{\lambda_{2}} \mathbf{I}_{\mathrm{N}}\right) \Psi_{1}\left(\boldsymbol{\theta}^{(j-l)}\right)
\end{aligned}
$$


$3^{2}$ Passo: Calculamos a probabilidade de aceitação do novo valor da iteração $j$ por:

.Para o valor $\lambda^{(j)}$ gerado:

Fazemos $p_{1}=\min \left[1, \frac{\Psi_{2}\left(\theta^{(j)}, \lambda^{(j)}\right)}{\Psi_{2}\left(\theta^{(-1)}, \lambda^{(-i)}\right)}\right]$;

Geramos $u \sim U[0,1]$;

Aplicamos então a seguinte regra:

$$
\begin{aligned}
& \lambda^{(j)}=\lambda^{(j)} \text { gerado, se } p_{1} \leq u \\
& \lambda^{(j)}=\lambda^{(j-1)} \text {, se caso contrário. }
\end{aligned}
$$

Para o valor $\theta^{(1)}$ gerado:

Fazemos $p_{2}=\min \left[1, \frac{\Psi_{1}\left(\theta^{(j)}\right)}{\Psi_{1}\left(\theta^{(-1)}\right)}\right]$;

Geramos $u \sim U[0,1]$;

Aplicamos então a seguinte regra:

$$
\begin{aligned}
& \theta^{(j)}=\theta^{(j)} \text { gerado, se } p_{2} \leq u \\
& \theta^{(j)}=\theta^{(j-1)}, \text { se caso contrário. }
\end{aligned}
$$

40 Passo: Atualizamos o contador de iterações $(j \leftarrow j+1)$ e voltamos a o passo 2 até a convergência do processo.

\subsubsection{A llustração do Algoritmo}

Vamos ilustrar o uso deste algoritmo utilizando o seguinte conjunto de dados binomiais e valores iniciais para os hiperparâmetros, sugeridos por Albert (1994):

\begin{tabular}{c|ccccc}
\hline Tamanho da amostra $\left(n_{i}\right)$ & 05 & 10 & 15 & 20 & 25 \\
\hline$y_{1}=n_{i} \mu_{i}$ & 1,0 & 0,9 & 0,8 & 0,5 & 0,8 \\
\hline
\end{tabular}

Tabela 6.1: Conjunto de valores binomiais

\begin{tabular}{l|c|c}
\hline Hiperparâmetros & $\gamma=\left(\gamma_{1}, \gamma_{2}\right)$ & $\delta=\left(\delta_{1}, \delta_{2}\right)$ \\
\hline Valores Iniciais & $(1,1)$ & $(0,0)$ \\
\hline
\end{tabular}

Tabela 6.2: Valores iniciais dos hiperparámetros 
Para um número de iterações igual a 10.000 , dos quais selecionamos uma amostra de tamanho 500. As figuras (6.1 e 6.2) mostradas a seguir nos dá a análise gráfica dos resultados simulados para o parâmetro $p_{4}$, resultante da seguinte transformação:

$$
p_{i}=\frac{e^{\theta}}{1+e^{Q_{1}}}, \quad i=1, \ldots, 5
$$

Na figura (6.1) a seguir, os dois gráficos sumarizam a distribuição marginal a posteriori do parâmetro através do histograma (a esquerda) e a distribuição acumulada dos valores simulados (a direita).
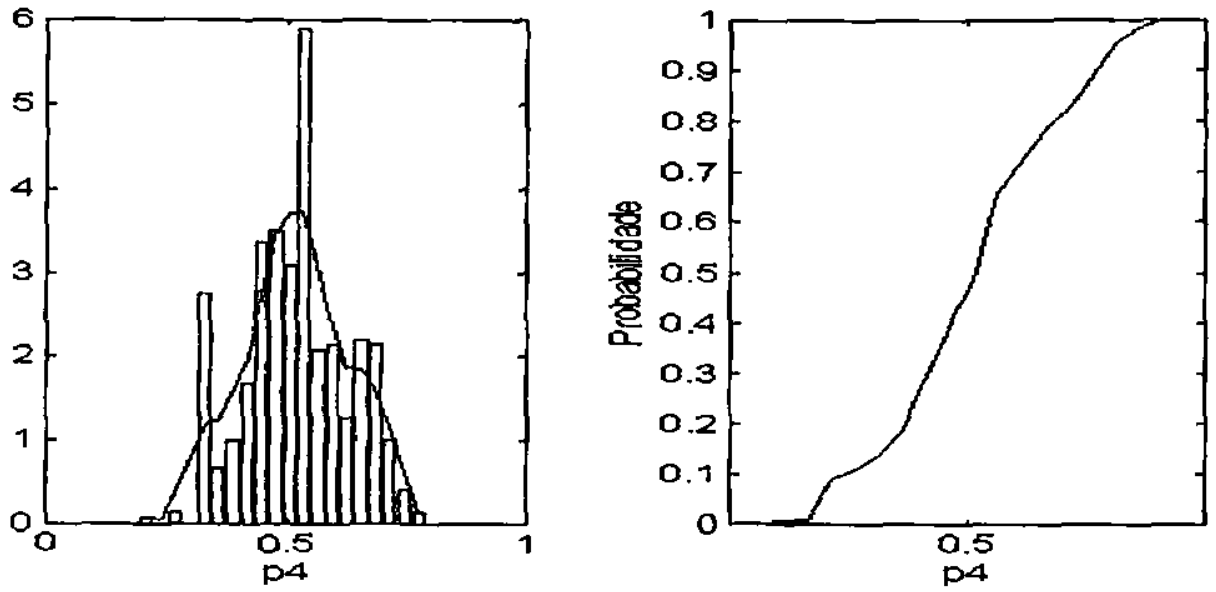

Figura 6.1: Histograma e gráfico da distribuiçăo acumulada do parâmetro $\mathrm{p}_{4}$

A figura (6.2) a seguir nos mostra o gráfico da seqüência de iterações e o gráfico das correlações entre os valores selecionados. Podemos ver que o segundo gráfico (o das correlações), nos mostra que ainda existe uma correlação considerável entre os valores gerados, apesar de ter sido adotado um processo de seleção da amostra.
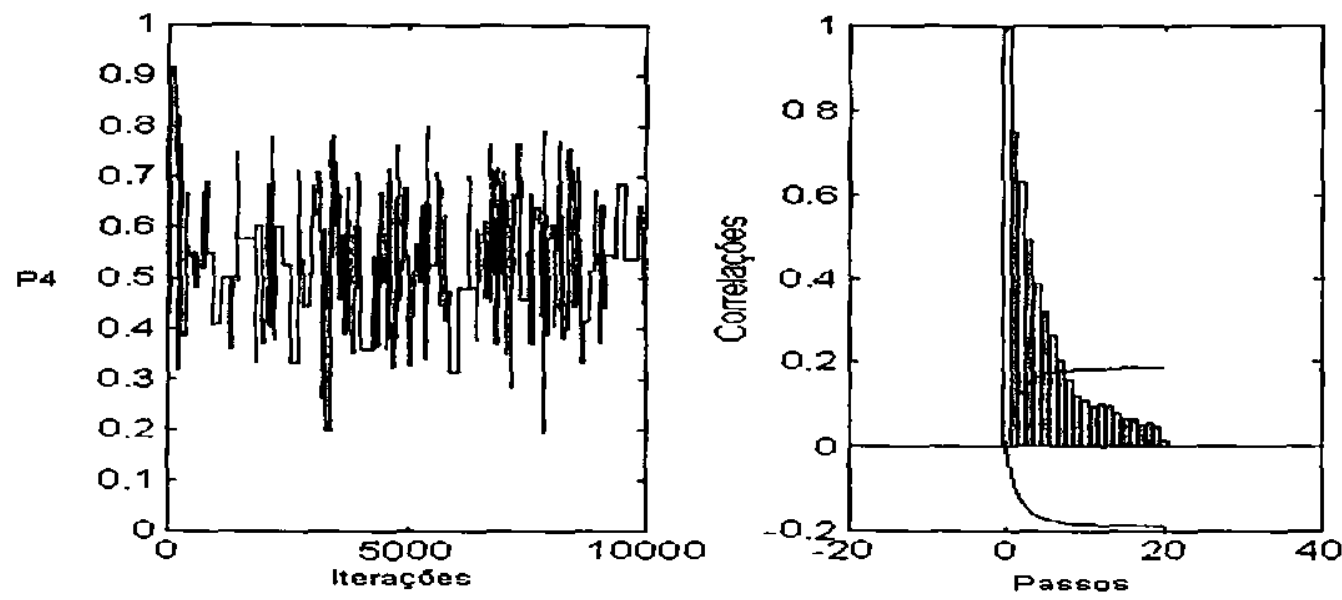

Figura 6.2: Gráficos da seqüência de itcrações $\mathrm{c}$ da corrclação da amostra sciccionada do parâmetro $\mathrm{p}_{4}$ 
As figuras (6.3 e 6.4) a seguir nos mostra a análise gráfica dos resultados simulados para $o$ parâmetro $\lambda_{1}$.
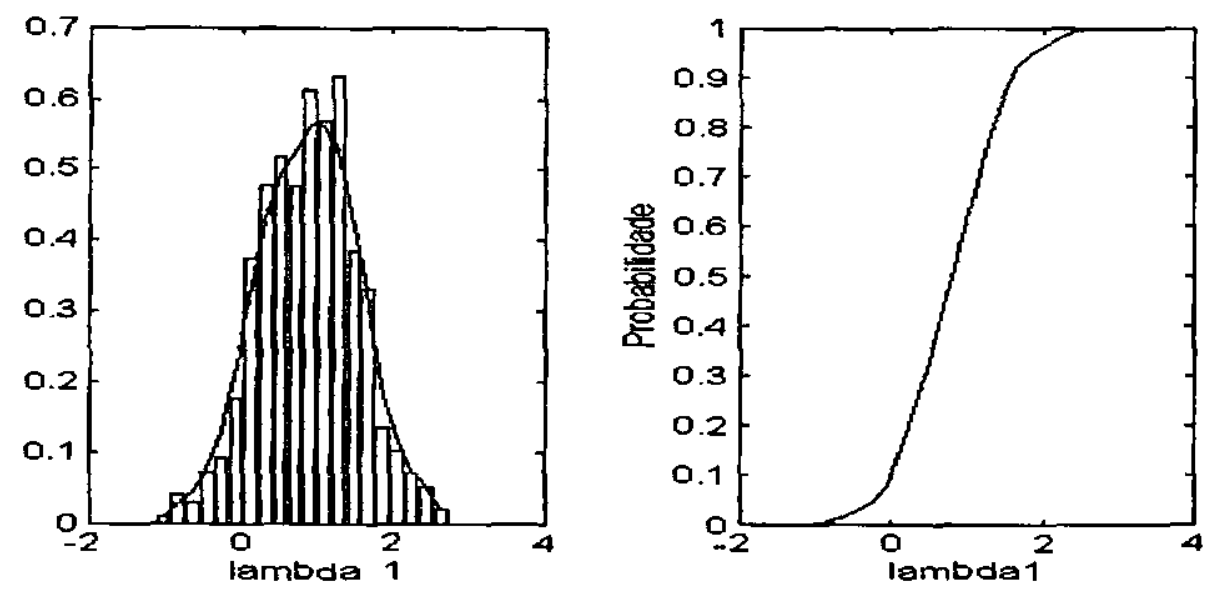

Figura 6.3: Histograma e gráfico da distribuição acumulada do parâmetro $\lambda_{1}$

Como podemos observar, a seqüencia de valores gerados convergiu sem maiores problemas para uma distribuição normal como sugerido no problema.

A figura (6.4) a seguir nos mostra o gráfico das correlações e a sequiência de iterações dos valores gerados para parâmetro $\lambda_{1}$. Podemos observar (no gráfico à direita) que, entre os valores gerados existe uma baixa correlação.
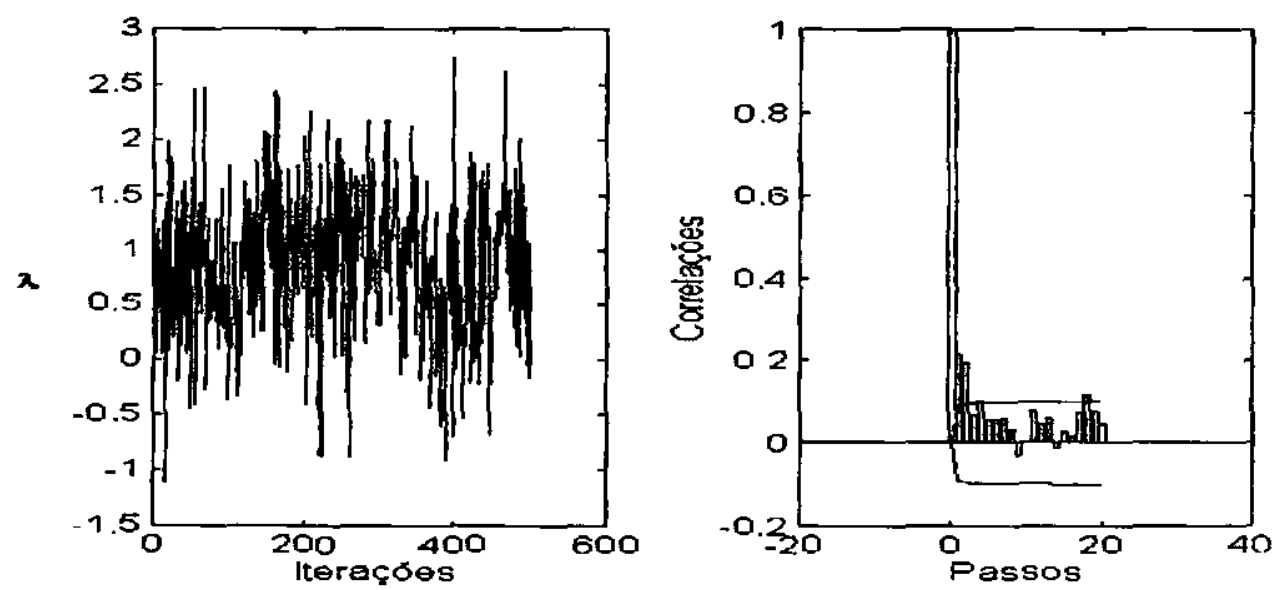

Figura 6.4: Gráficos da seqüuência de iteraç̃̃es $e$ da correlação da amostra selecionada do parâmetro $\lambda_{1}$

As tabelas 6.3, 6.4, 6.5 e 6.6 a seguir, apresentam uma análise das cadeias simuladas com 5000,7500 e 10000 iterações. Em cada caso foram selecionadas amostras de tamanho 500 após o periodo de aquecimento. Para avaliar o erro nas estimativas de cada parâmetro, calculamos a 
diferença entre as médias de cada caso; por exemplo $\mathbf{M}_{1}-\mathrm{M}_{2}$ corresponde a diferença entre as médias dos parâmetros obtida entre as cadeias com $5000\left(\mathrm{M}_{1}\right)$ e $7500\left(\mathrm{M}_{2}\right)$ iterações e $\mathrm{M}_{2}-\mathrm{M}_{3}$ é a diferença entre as médias obtidas entre as cadeias com $7500\left(\mathrm{M}_{1}\right)$ e $10000\left(\mathrm{M}_{3}\right)$. Para avaliar essas diferenças calculamos o erro de estimativa (ou erro amostral) dado por:

$$
\text { Erro }=2 \sqrt{\frac{S_{1}^{2}+S_{2}^{2}}{n}}
$$

onde $S_{1}^{2}$ e $S_{2}^{2}$ são as variâncias amostrais das duas cadeias consecutivas ( por exemplo, $S_{1}^{2}$ pode representar a variância amostral de um parâmetro quando foram realizadas 5000 iterações e $S_{2}^{2}$ a variância desse mesmo parâmetro quando foram realizadas 7500 iterações).

\begin{tabular}{l|c|c|c|c|c|c|c}
\hline \multirow{2}{*}{$\begin{array}{l}\text { Medidas } \\
\text { Estatísticas }\end{array}$} & $\mathrm{p}_{1}$ & $\mathrm{p}_{2}$ & $\mathrm{p}_{3}$ & $\mathrm{p}_{4}$ & $\mathrm{p}_{5}$ & $\lambda_{1}$ & $\lambda_{2}$ \\
\hline Média & 0.867 & 0.873 & 0.776 & 0.488 & 0.781 & 0.771 & 1.176 \\
Desv. Pad. & 0.137 & 0.095 & 0.099 & 0.138 & 0.079 & 0.772 & 0.873 \\
\hline Int.Credib & 0.4485 & 0.6204 & 0.5332 & 0.1951 & 0.5754 & -0.6435 & -0.3568 \\
& 0.9996 & 0.9948 & 0.9160 & 0.7085 & 0.9270 & 2.0064 & 3.0940 \\
\hline
\end{tabular}

Tabela 6.3: Medidas estalísticas dos parâmetros $p_{i}$ 's $c \lambda_{i}$ 's para uma cadeia tananho $5000\left(\mathrm{M}_{1}\right)$ c uma amostra tamanho 500 .

\begin{tabular}{l|c|c|c|c|c|c|c}
\hline \multirow{2}{*}{$\begin{array}{l}\text { Medidas } \\
\text { Estatisticas }\end{array}$} & $\mathrm{p}_{1}$ & $\mathrm{p}_{2}$ & $\mathrm{p}_{3}$ & $\mathrm{p}_{4}$ & $\mathrm{p}_{5}$ & $\lambda_{1}$ & $\lambda_{2}$ \\
\hline Média & 0.8915 & 0.8358 & 0.7959 & 0.5362 & 0.7986 & 0.8586 & 1.2801 \\
Desv. Pad. & 0.0700 & 0.0789 & 0.0777 & 0.1127 & 0.0615 & 0.6000 & 0.9422 \\
\hline Int.Credib & 0.7347 & 0.6634 & 0.6342 & 0.2444 & 0.6620 & -0.4725 & -0.3870 \\
& 0.9781 & 0.9859 & 0.8984 & 0.6497 & 0.8864 & 1.8573 & 3.1545 \\
\hline
\end{tabular}

Tabela 6.4: Medidas estatísticas dos parâmctros $p_{i}$ 's $c \lambda_{i}$ 's para uma cadeia lamanho $7500\left(\mathrm{M}_{2}\right) \mathrm{c}$ uma amostra tamanho 500 . 


\begin{tabular}{l|c|c|c|c|c|c|c}
\hline \multirow{2}{*}{\begin{tabular}{l} 
Medidas \\
\cline { 2 - 7 }
\end{tabular}} & \multicolumn{7}{|c|}{ Parâmetros } \\
\cline { 2 - 7 } & $\mathrm{p}_{1}$ & $\mathrm{p}_{2}$ & $\mathrm{p}_{3}$ & $\mathrm{p}_{4}$ & $\mathrm{p}_{5}$ & $\lambda_{1}$ & $\lambda_{2}$ \\
\hline Média & 0.8950 & 0.8393 & 0.7924 & 0.5547 & 0.7804 & 0.8128 & 1.1363 \\
Desv. Pad. & 0.1041 & 0.0810 & 0.0860 & 0.0847 & 0.0658 & 0.6847 & 0.8115 \\
\hline Int.Credib & 0.7035 & 0.6243 & 0.5746 & 0.3174 & 0.6488 & -0.5225 & -0.4790 \\
& 0.9958 & 0.9716 & 0.8848 & 0.7212 & 0.9331 & 2.0562 & 2.7240 \\
\hline
\end{tabular}

Tabela 6.5: Medidas estatísticas dos parâmetros $p_{i}$ 's e $\lambda_{i}$ 's para uma cadeia tamanho $10000\left(M_{3}\right)$ e uma amostra tamanho 500 .

\begin{tabular}{c|c|c|c|c|c|c|c}
\hline \multirow{2}{*}{\begin{tabular}{c} 
Diferenças \\
\cline { 2 - 7 }
\end{tabular}} & \multicolumn{7}{|c|}{ Parâmetros } \\
\cline { 2 - 8 } & $\mathrm{p}_{1}$ & $\mathrm{p}_{2}$ & $\mathrm{p}_{3}$ & $\mathrm{p}_{4}$ & $\mathrm{p}_{5}$ & $\lambda_{1}$ & $\lambda_{2}$ \\
\hline $\mathbf{M}_{1}-\mathrm{M}_{2}$ & 0.0248 & 0.0376 & 0.0189 & 0.0473 & 0.0170 & 0.0873 & 0.1041 \\
\&rro 1-2 & 0.0138 & 0.0111 & 0.0113 & 0.0160 & 0.0090 & 0.0875 & 0.1149 \\
$\mathbf{M}_{2}-\mathrm{M}_{3}$ & 0.0035 & 0.0035 & 0.0035 & 0.0185 & 0.0183 & 0.0458 & 0.1408 \\
Erro 2-3 & 0.0112 & 0.0101 & 0.0104 & 0.0126 & 0.0081 & 0.0814 & 0.1112 \\
\hline Gelm\&Rub & 1.0872 & 1.0561 & 1.0198 & 1.1090 & 1.0234 & 1.0121 & 1.0078 \\
\hline
\end{tabular}

Tabeia 6.6: Diferenças das médias dos parâmetros $p_{i}$ 's e $\lambda_{i}$ 's para as cadeias de tamanho $5000\left(\mathrm{M}_{1}\right), 7500\left(\mathrm{M}_{2}\right)$. $10000\left(\mathrm{M}_{3}\right), o$ crro das cstimativas cos resultados do diagnóstico de Gelman\&Rubin

Devemos esperar que, sob hipótese de convergência, as diferenças entre as médias devam ser menores que os erros de estimativa com um grau de confiança da ordem de $95 \%$. No entanto, notamos que nem sempre esse resultado esperado ocorre (observe que as diferenças de médias entre as cadeias $M_{1}-M_{2}$, para a maioria dos parâmetros, são maiores que os erros entre estas cadeias), porém, se somente o critério de diagnóstico de convergência de Gelman \& Rubin for adotado qualquer um dos casos $(5000,7500$ e 10000$)$ pode ser diagnosticado como convergente. Neste caso chamamos a atenção para a importância do uso de outros métodos de análise (gráficos, coleta de amostra aleatorizada, diferenças entre as médias do parâmetro de cadeias consecutivas, etc), no diagnóstico da convergência. 


\subsection{O Segundo Problema}

No segundo exemplo consideramos $k=2$ populações independentes e normalmente distribuidas, $N\left(\theta, \tau_{i}^{-1}\right)$ para $i=1,2$ onde $\theta$ é uma média comum desconhecida e as variâncias são diferentes e desconhecidas, ou seja, os parâmetros, $\tau_{1}, \tau_{2}$ são desconhecidos. Suponha que $X_{i j}$ representa o conjunto de observações das 2 amostras independentes e $j=1,2, \ldots, n_{i}$. Então a densidade conjunta da variável amostral é dada pela equação (1.10) como abaixo:

$$
f\left(X_{i j} \mid \theta, \tau_{1}, \tau_{2}\right) \propto \prod_{i=1}^{2} \tau_{i}^{n / 2} \exp \left\{\frac{-\tau_{i}}{2}\left[\left(n_{i}-1\right) S_{i}^{2}+n_{i}\left(\theta-\bar{X}_{i}\right)^{2}\right]\right\} .
$$

A densidade a priori para os parâmetros foi dada pela equação (1.11) como segue:

$$
\pi\left(\theta, \tau_{1}, \tau_{2}\right) \propto \prod_{i=1}^{2} 1 / \tau_{i}, \quad \theta \in \Re \quad e \quad \tau_{i}>0
$$

E a partir do produto das equações (1.10) e (1.11) obtemos a distribuição a posteriori conjunta dos parâmetros de acordo com a equação a seguir

$$
\pi\left(\theta, \tau_{1}, \tau_{2} \mid X_{i j}\right) \propto \prod_{i=1}^{2} \tau_{i}^{\left(n_{i} / 2\right)-1} \exp \left\{\frac{-\tau_{i}}{2}\left[\left(n_{i}-1\right) S_{i}^{2}+\left(\theta-\bar{X}_{i}\right)^{2}\right]\right\}
$$

Construimos então as distribuições condicionais como segue:

$$
\begin{aligned}
& \pi\left(\theta \mid \tau_{1}, \tau_{2}\right) \sim N\left[\left(\sum_{i=1}^{2} n_{i} \tau_{i} \bar{X}_{i} / \sum_{i=1}^{2} n_{i} \tau_{i}\right),\left(\sum_{i=1}^{2} n_{i} \tau_{i}\right)^{-1}\right], i=1,2 \\
& \pi\left(\tau_{i} \mid \theta\right) \sim \operatorname{Gama}\left[n_{i} / 2 ;\left(\left(n_{i}-1\right) S_{i}^{2}+n_{i}\left(\theta-\bar{X}_{i}\right)^{2}\right) / 2\right], \quad i=1,2 .
\end{aligned}
$$


Diferente do primeiro exemplo, aqui nós conhecemos a distribuição das condicionais completas e por isso simularemos as amostras a partir do algoritmo amostrador de Gibbs. Nosso objetivo neste exemplo é estimar a média comum das populações normais com variâncias diferentes. Observaremos que, o fato de selecionarmos ou não a amostra, não influencia no valor dos estimadores quando usamos apenas o algoritmo amostrador de Gibbs. Podemos verificar ainda que o método de estimação é de importante relevância na precisão dos estimadores.

\subsubsection{O Algoritmo}

$1^{2}$ Passo: Inicializamos o contador de iterações $j \leftarrow 1$ e arbitraremos valores iniciais para os parâmetros $\left(\theta^{(0)}, \tau_{1}^{(0)}, \tau_{2}^{(0)}\right)$.

$$
\tau_{1}^{(0)}=1 / S_{1}^{2} \quad, \quad \tau_{2}^{(0)}=1 / S_{2}^{2} \quad \text { e } \quad \theta^{(0)}=n_{1} \bar{x}_{1}+n_{2} \bar{x}_{2} / n_{1}+n_{2}
$$

$2^{\underline{0}}$ Passo: Geramos um novo valor para os parâmetros $\left(\theta^{(j)}, \tau_{1}^{(j)}, \tau_{2}^{(j)}\right)$ de acordo com suas respectivas condicionais:

$$
\begin{aligned}
& \pi\left(\theta^{(j)} \mid \tau_{i}^{(j-1)}\right) \sim N\left[\left(\sum_{i=1}^{2} n_{i} \tau_{i}^{(j-1)} \bar{X}_{i} / \sum_{i=1}^{2} n_{i} \tau_{i}^{(j-1)}\right),\left(\sum_{i=1}^{2} n_{i} \tau_{i}^{(j-1)}\right)^{-1}\right], i=1,2 . \\
& \pi\left(\tau_{i}^{(j)} \mid \theta\right) \sim \operatorname{Gama}\left[n_{i} / 2 ;\left(\left(n_{i}-1\right) S_{i}^{2}+n_{i}\left(\theta^{(j)}-\bar{X}\right)^{2}\right) / 2\right], i=1,2 .
\end{aligned}
$$

30 Passo: Atualizamos o contador de iteraçðes $(j \leftarrow j+1)$ e voltamos a o passo 2 até diagnosticada a convergência do processo. 


\subsubsection{A llustração do Algoritmo}

Para ilustrar o uso deste algoritmo utilizamos o seguinte procedimento: geramos a partir do algoritmo amostrador de Gibbs 3 cadeias: $M_{1}$ de tamanho 2000, $M_{2}$ de tamanho 5000 e $M_{3}$ de tamanho 10000 . Para cada uma destas cadeias usamos 5 condições iniciais diferentes para cada um dos parâmetros, de acordo com a tabela abaixo:

\begin{tabular}{l|c|c|c}
\hline \multirow{2}{*}{ Condições } & \multicolumn{3}{|c}{ Parâmetros } \\
\cline { 2 - 4 } & Theta & Tau1 & Tau2 \\
\hline $1^{\mathrm{a}}$ Condição & 107,50 & 9,0 & 12,0 \\
$2^{\mathrm{a}}$ Condição & 108,00 & 9,5 & 12,5 \\
$3^{\mathrm{a}}$ Condição & 108,27 & 10,0 & 13,0 \\
$4^{\mathrm{a}}$ Condição & 109,00 & 10,5 & 13,5 \\
$5^{\mathrm{a}}$ Condição & 109,50 & 11,0 & 14,0 \\
\hline
\end{tabular}

Tabela 6.7: Conjunto de condiç̃es iniciais usadas para cada uma das três cadeias geradas para os três parâmetros

Neste exemplo, destacamos ainda a utilização dos estimadores de Rao-Blackwell, o qual tem variância menor que o estimador de Monte Carlo. Para calcularmos este estimador para $\theta \quad$ e $\tau=\left(\tau_{1}, \tau_{2}\right)$ respectivamente, temos que:

$$
E(\theta)=E_{\tau}(E(\theta \mid \tau)) \quad \text { e } \quad E\left(\tau_{i}\right)=E_{o}\left(E\left(\tau_{i} \mid \theta\right)\right)
$$

onde,

$$
E(\theta \mid \tau)=E\left[\frac{n_{1} \tau_{1} \bar{x}_{1}+n_{2} \tau_{2} \bar{x}_{2}}{n_{1} \tau_{1}+n_{2} \tau_{2}}\right] \quad \text { e } \quad E\left(\tau_{i} \mid \theta\right)=\frac{n_{i}}{\left(n_{i}-1\right) S_{i}^{2}+n_{i}\left(\theta-\bar{x}_{i}\right)^{2}}
$$

Logo os estimadores de Rao-Blackwell para $\theta$ e $\tau_{i}$ respectivamente são dados por:

$$
\hat{\theta}=\frac{1}{M} \sum_{i=1}^{M} \frac{n_{1} \tau_{1}^{(i)} \bar{x}_{1}+n_{2} \tau_{2}^{(i)} \bar{x}_{2}}{n_{1} \tau_{1}^{(i)}+n_{2} \tau_{2}^{(i)}} \quad \text { e } \quad \bar{\tau}_{i}=\frac{1}{M} \sum_{i=1}^{M} \frac{n_{i}}{\left(n_{i}-1\right) S_{i}^{2}+n_{i}\left(\theta^{(j)}-\bar{x}_{i}\right)^{2}}
$$


A tabela 6.8 a seguir nos fornece o resumo das estimativas dos parâmetros $\theta$ e $\tau=\left(\tau_{1}, \tau_{2}\right)$ para as cadeias $\mathrm{M}_{1}, \mathrm{M}_{2}$ e $\mathrm{M}_{3}$ geradas a partir da $2^{\mathrm{a}}$ condição inicial. As tabelas de resumo das estimativas com as demais condiç̃̃es podem ser vistas nos anexos.

\begin{tabular}{l|ccc|c|c|c|c}
\hline Parâmet & \multicolumn{5}{|c|}{ Estatísticas } & N \\
\cline { 2 - 5 } & Média & D.padrão & Interv. Cred. & Estimador & Tam.Amostr \\
Iteraç.
\end{tabular}

Tabela 6.8: Resumo de cstimativas dos parâmetros $\theta$ e $\quad \tau=\left(\tau_{1}, \tau_{2}\right)$ para as cadeias $\mathrm{M}_{1}, \mathrm{M}_{2}$ e $\mathrm{M}_{3}$ geradas a partir da $2^{\mathrm{g}}$ condição inicial. 
É importante observamos na tabela 6.8 que embora as estimativas de Monte Carlo e RaoBlackwell sejam bem próximas (ou as mesmas), as variâncias dos estimadores de Rao-Blackwell são bem menores que as variâncias dos estimadores de Monte Carlo, garantindo assim uma maior precisão e confiança nos seus valores. Podemos observar ainda que não existe praticamente diferença entre os valores estimados da amostra selecionada e não selecionada para uma mesma cadeia.

Na Tabela 6.9 abaixo podemos observar que os valores do critério de Gelman\&Rubin indicam que o processo converge com melhores resultados quando não selecionamos a amostra.

\begin{tabular}{l|c|c|c|c}
\hline \multirow{2}{*}{ Parâm. } & \multicolumn{3}{|c|}{ Número de Iteracões } & Tam. da \\
\cline { 2 - 4 } & $\mathbf{M}_{1}(2000)$ & $\mathbf{M}_{2}(5000)$ & $\mathbf{M}_{3}(10000)$ & \\
amostra \\
\hline Theta & 1,0020 & 0,9999 & 1,0044 & \\
Tau 1 & 0,9991 & 0,9981 & 1,0090 & selecionada \\
Tau 2 & 1,0030 & 0,9976 & 1,0030 & \\
\hline Theta & 1,0020 & 1 & 1 & não \\
Tau 1 & 0,9996 & 1 & 1 & selecionada \\
Tau 2 & 0,9999 & 1 & 1 & \\
\hline
\end{tabular}

Tabela 6.9: Resumo do Critério de Gelman \& Rubin dos parâmetros $\theta$ e $\tau=\left(\tau_{1}, \tau_{2}\right)$ para as cadeias $M_{1}, M_{2} \in M_{3}$ e arnostra selecionada e não selecionada

As Figuras 6.5, 6.6 e 6.7 a seguir nos mostram o comportamento dos histogramas e FAC's (Funções de Autocorrelação) para a cadeia $M_{3}$ (10000) das amostras selecionada e não selecionada dos parâmetros $\theta \quad e \quad \tau_{1}$
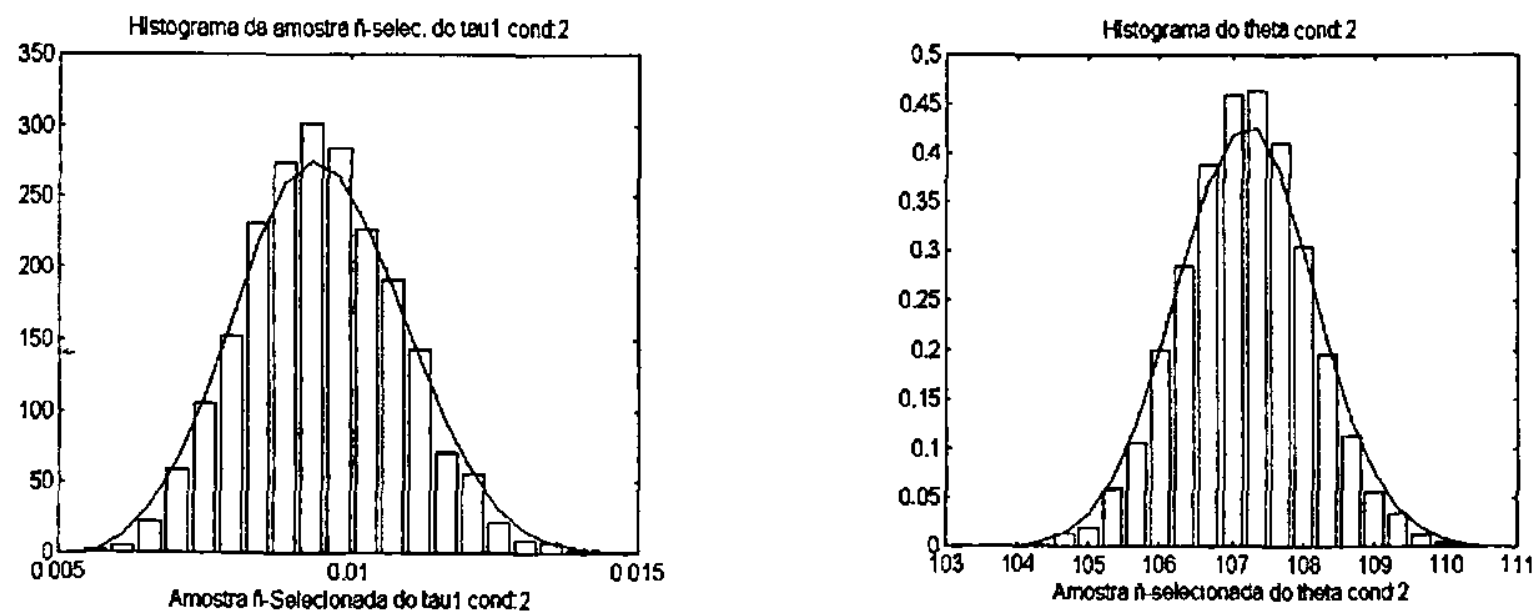

Figura 6.5: Conjunto de histogramas para os parâmetros $\theta \quad e \quad \tau_{1}$ da amostra não selecionada obtidas da cadeia $M_{3}$ (10000) gerada a partir da condição 02. 

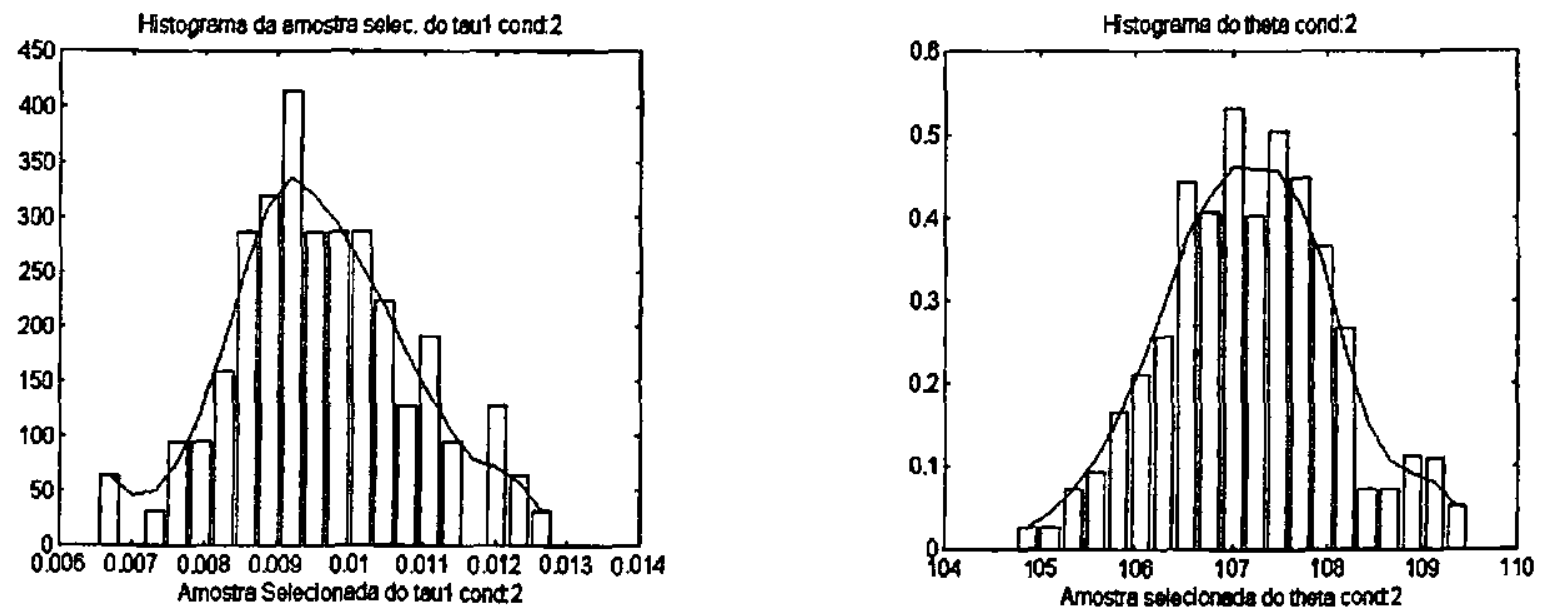

Figura 6.6: Conjunto de histogramas para os parâmetros $\theta \quad e \quad \tau_{1}$ da amostra selecionada obtidas da cadeia $\mathrm{M}_{3}$ (10000) gerada a partir da condiçajo 02.

Observe que, os histogramas para a amostra não selecionada de ambos os parâmetros comportam-se de forma mais suavizada e simétrica que o histograma da amostra selecionada.
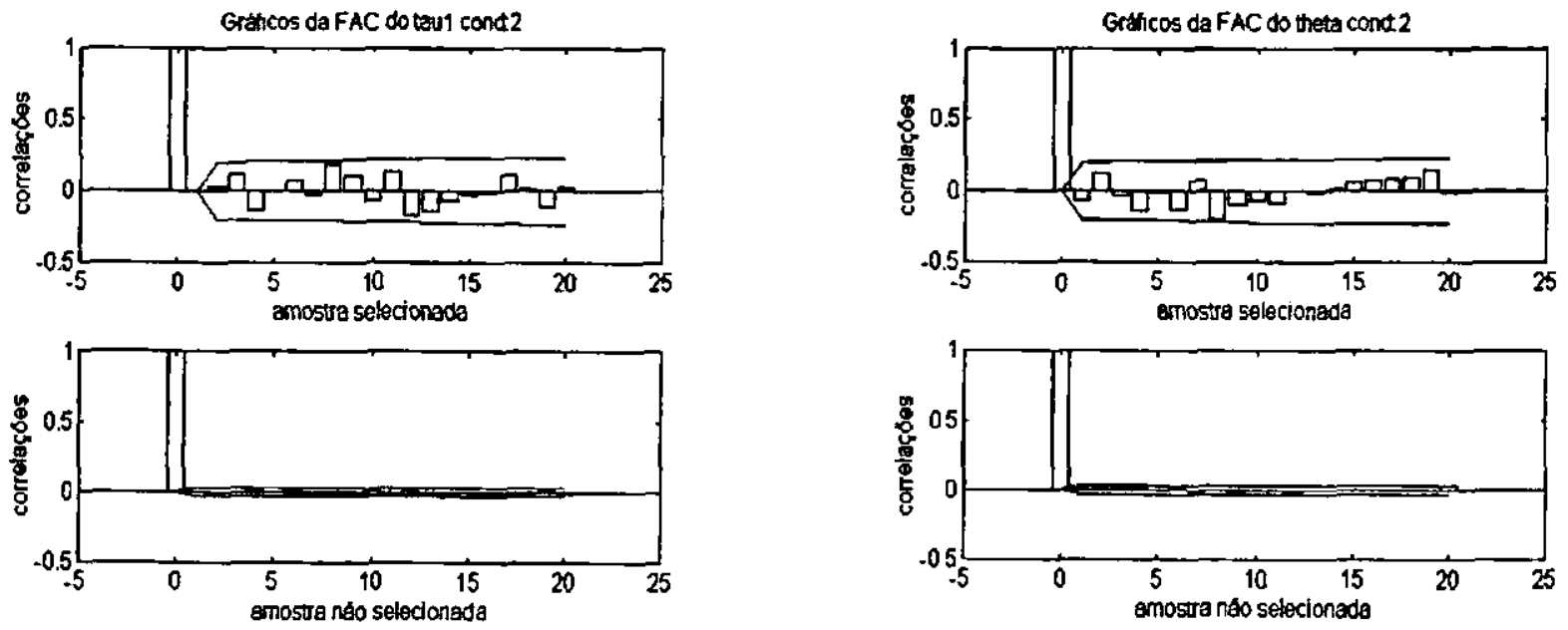

Figura 6.7:Conjunlo de gráficos da FAC (Função de Autocorrelação) para os parâmetros $\theta$ ell $\tau_{1}$ das amostras selecionada e não sclecionada obtidas da cadeia $\mathrm{M}_{3}(10000)$ gerada a partir da condição 02.

Note na figura 6.7, que nos gráficos da FAC (Função de Autocorrelação) para a amostra não selecionada, as correlações sāo baixíssimas para ambos os parâmetros e quando selecionamos a amostra, essas correlaçðes aumentam. Portanto, quando usamos apenas o algoritmo amostrador de Gibbs num processo de simulação, não é aconselhável selecionarmos a amostra. 


\section{CAPÍTULO 7 \\ Conclusões e \\ Propostas Futuras}

\subsection{O Amostrador de Gibbs}

De acordo com o exemplo 6.2 visto anteriormente, onde usamos apenas o algoritmo amostrador de Gibbs no processo de simulação da amostra, constatamos que:

1. É um desperdício usar o processo de seleção aleatório da amostra após o período de aquecimento;

2. Devemos usar os estimadores de Rao-Blackwell para garantirmos uma baixa variância e consequentemente uma maior precisão nas estimativas dos parâmetros;

3. É aconselhável gerar uma única e longa cadeia, evitando assim o desperdicio de informações (valores gerados) e lembrando ainda que, para este algoritmo, podemos usar os critérios de convergência, os quais necessitam de apenas uma cadeia, tais como o Zellner \& Min ou Geweke;

4. Condições iniciais diferentes não alteram a convergência do processo.

Ou seja, quando usamos apenas o algoritmo amostrador de Gibbs, é necessário processarmos apenas uma única e longa cadeia, utilizarmos um critério de convergência do tipo que utiliza apenas uma cadeia e calcularmos as estimativas através do estimador de RaoBlackwell.

\subsection{O Amostrador de Metropolis-Hastings}

De acordo com o exemplo 6.1 visto anteriormente, onde usamos apenas o algoritmo amostrador de $\mathrm{M}-\mathrm{H}$ no processo de simulação da amostra, constatamos que: 
1. Quando possivel devemos verificar teoricamente a ergodicidade uniformemente geométrica, garantindo assim a convergência do processo para a distribuição alvo verdadeira;

2. Quando essa verificação não for possível, devemos gerar várias cadeias com condições iniciais diferentes e utilizar o diagnóstico de critério de convergência do Gelman \& Rubin sem esquecer de verificar o comportamento dos valores gerados, comparando as diferenças das estimativas (médias amostrais) com seu erro padrão;

3. É imprescindível que se faça uma seleção aleatória prévia da amostra gerada para diminuir a correlação entre os valores. Este procedimento exige, em geral, que se gere cadeias muito longas e que valores sejam descartados;

4. Um dos aspectos mais dificeis do uso do $\mathrm{M}-\mathrm{H}$ é a escolha do núcleo gerador de candidatos, quando esse não aparece juntamente com as densidades a posteriori. A escolha inadequada de um núcleo, pode afetar as estimativas e a convergência devido a alta taxa de rejeição que esta escolha inadequada pode provocar.

Este estudo não pretende ser conclusivo, até porque, cada problema tem suas características individuais e é praticamente impossivel se chegar a resultados conclusivos sobre o uso de técnicas de simulação, somente através de resultados teóricos, ou exclusivamente através de exemplos experimentais, por exemplo, verificar ergodicidade uniformemente geométrica para certos problemas pode ser uma tarefa muito dificil. No entanto, muitos problemas reais podem ser resolvidos e neste caso, não resta outra saída, se não utilizar a experiência adquirida na solução de outros problemas, mesmo sabendo que estas experiências nunca serão suficientes por si só. Sendo assim fica como proposta futura deste trabalho a análise de vários aspectos presentes em problemas de inferência Bayesiana, tais como, a escolha da priori, a adequação do modelo, o uso de reparametrização, o uso de variáveis latente. Todos esses, podem influenciar de forma bastante significativa nos resultados da simulação. 


\section{Referências}

ALBERT, J. (1996). A MCMC Algorithm to Fit a General Exchangeable Model. Commun Statist.- Simula., 25(3), 573-592, State University.

ATHEYA, K. B; DOSS, H. \& SETHURAMAN, J. (1992). A Proof of convergence of the Markov Chain simulation method. Technical Report 868, Department of Statistics, Florida State University.

BARKER, A. A (1965). Monte Carlo calculation of the radial distribution functions for $a$ protonelectron plasma. Aust. J. Phys., 18, 119-133.

BRATLEY, P.; FOX, B. L., \& SCHRAGE, L. E. (1987). A Guide to Simulation. New York, NY: Springer, second edition.

CASELLA, G. \& GEORGE, E. (1992), Explaining the Gibbs sampler. The American Statistician, 46, 167-174.

CHAN, K. S. (1989). A Note on the geometric ergodicity of a Markov chain. Adv. Appl. Prob., 21, 702-704.

CHAN, K. S. (1993). Asymptotic behavoir of the Gibbs sampler. J. Amer. Statist. Assoc., 88 , a publicar.

CHIB, S. \& GREENBERG, E. (1995). Understanding the Metropolis-Hastings algorithm. American Statistician, 49, 327-335.

COGBURN, R. (1970). The Central limit theorem for Markov processes. In Proc. Sixth Berkeley Sympos. Math. Statist. Prob., Vol. 2, 485-512. Berkeley, University of California.

GARREN, S. T. \& SMITH, R. L. (1993). Convergence diagnósticsfor Markov Chain samplers. Tecnical report, University of North Carolina, Dept. of Statistics.

GELFAND, A. E. \& SMITH, A. F. M. (1990). Sampling-Based approaches to calculating marginal densities. Journal of the American Statistical Association, 85, 398-409.

GELMAN, A. (1995). Inference and monitoring convergence". Em Markov Chain Monte Carlo in Pratice, ed.:W.K. Gilks, S. Richardson and D.J. Spiegelhalter, cap. 8. New York: Chapman and Hall.

GEMAN, S. \& GEMAN, D. (1984). Stochastic relaxation, Gibbs distributions and the bayesian restoration of images. IEEE Transactions on Pattern Analysis and Machine Intelligence, PAMI-6, 721-741.00.GELMAN, A. \& RUBIN, D. R. (1992a). A Single series from the Gibbs 
sampler provides a false sense of security. Em Bayesian Statistics 4, eds.: J. M. Bernardo et al, Oxford: University Press, pp. 625-631.

GELMAN, A. \& RUBIN, D. R. (1992b). Inference from interative simulation using multiple sequences. (with dicussion), Statistial Science, 7, 457-511.

GEWEKE, J. (1992). Evaluating the accuracy of sampling-based approaches to the calculation of posterior moments. In Bayesian Statistics 4, eds.: J. M. Bernardo et al. Oxford, U. K.: Oxford University Press, pp. 169-193.

GEYER, C. J. (1991). Monte Carlo maximum likelihood for dependent data. In Keramidas, E. M., ed., Computer Science and Statistics: 23rd Symposium on the Interface. 156-163.

GREGURICH, M. A. (1997). A Bayesian analysis for estimating the common mean of independent normal populations using the Gibbs sampler. Commun Statist.- Simula., 26(1), 35-51, State University.

HASTINGS, W. K. (1970). Monte Carlo sampling methods using Markov Chains and their applications. Biometrika, 57, 97-109.

JOHNSON, V. E. (1994). Studying convergence of Markov chain Monte Carlo algorithms using coupeled sampler paths". Journal of the American Statistical Association, 91, 154-166.

KIRKPATRICK, S.; GELLAT, Jr., C. D. \& VECCHI, M. P. (1983). Optimization by simulated annealing. Science, 220, 671-680.

KIPNIS, C. \& VARADHAN, S. R. S. (1986). Central Limit theorem for additive functionals of reversible Markov process and applications to simple exclusions. Communications in Mathematical Physics, 104, 1-19.

LIU, C; LIU, J. \& RUBIN, D. B. (1992). A Variational control variable for assessing the convergence of the Gibbs sampler. In Proceedings of the American Statistical Association, Statistical Computing Section, pp. 74-78.

LIU, J.; WONG, W. H. \& KONG, A. (1991). Correlation structure and convergence rate of the Gibbs sampler: Applications to the comparisons of estimators and augmentation schemes. Technical Report 299, Department of Statistics, University of Chicago.

METROPOLIS, N. ; ROSENBLUTH, A. W.; ROSENBLUTH, M. N. ; TELLER, A. H. \& TELLER, E. (1953). Equations of state calculatuions by fast computing machines. Journal of Chemical Physics, 21, 1087-1091.

MYKLAND, P.; TIERNEY, L. \& YU,B. (1995). Regeneration in Markov chain samplers. Journal of the American Statistical Association, 90, 233-241. 
MÜLLER, P. (1991). A Generic approach to posterior integration and Gibbs sampling. Technical Report 91-09, Department of Statistics, Purdue University.

NUMMELIN, E. (1984). "General Irreducible Markov Chains and Non-Negative Operators". Cambridge: Cambridge University Press $60,607-612$.

PESKUN, P. H. (1973). Optimum Monte Carlo sampling using Markov chains. Biometrika,

RAFTERY, A. E. \& LEWIS,S., (1992). How many iterations in Gibbs sampling ?. In Bayesian Statistics 4, eds.: J. M. Bernardo et al, Oxford, U. K.: Oxford University Press, pp. 763773.

REVUZ, D. (1975). Markov Chains. Amsterdam: North-Holland.

RIPLEY, B. D. (1987). Stochastic Simulation. New York, NY: Wiley.

RITTER, C. \& TANNER, M. A. (1992). Facilitating the Gibbs sampler: The Gibbs stopper and the griddy-Gibbs sampler. Journal of the American Statistical Association, 87, 861-868.

ROBERTS, G. O. (1992), Convergence diagnostics of the Gibbs sampler. In Bayesian Statistics 4, eds.: J. M. Bernardo et al, Oxford, U. K.: Oxford University Press, pp.775-782.

ROBERTS, G. O. (1996), A Note on acceptance rate criteria for CLTs for HastingsMetropolis algorithms. Preprint.

ROBERTS, G. O. (1997), Optimal Metropolis algorithms for product measures on the vertices of a hypercube. Preprint.

ROBERTS, G. \& POLSON, N. (1990). A Note on the geometric convergence of the Gibbs sampler. Submetido à publicação.

ROBERTS, G. O. \& ROSENTHAL, J. S. (1997a), Geometric ergodicity and hybrid Markov chains, 2, paper 2

ROBERTS, G. O. \& SMITH, A. F. M. (1994), Simple conditions for the convergence of the Gibbs sampler and Metropolis Hastings algorithms. Stoch. Process. Applic., 49, 207-216.

SCHMEISER, B. \& CHEN, M. H. (1991). On Randon-direction Monte Carlo sampling for evaluating integrals. Technical Report SMS91-1, School of Industrial Engineering, Purdue University.

SMITH, A. F. M. \& TIERNEY, L. (1996), Exact transition probabilities for the independence Metropolis sampler. Technical Report. University of Cambrige, Cambrige 
SMITH, A. F. M. \& ROBERTS, G. O. (1993), Bayesian computational via Gibbs sampler and related Markov chain Monte Carlo methods. J. Roy. Statist. Soc. Ser. B, 55, 3-24.

SMITH, A. F. M. (1991), Bayesian c omputational methods. Phil. Trans. R. Soc. Lond. A, 337, 369-386.

TIERNEY, L. (1994). Markov Chains for exploring posterior distributions. Ann. Statist., 22, State University.

YU, B. (1994). Monitoring the convergence of Markov samplers based on estimated $L^{l}$ error. Technical Report 409, University of California at Berkeley, Dept of Statistics.

YU, B. \& MYKLAND, P. (1994). Looking at Markov samplers through cusum path plots: A Simple diagnostic idea. Technical Report 413, University of California at Berkeley, Dept of Statistics.

ZELLNER, A. \& MIN, C. K. (1995). Gibbs Sampler convergence criteria. Journal of the American Statistical Association, 90, 921-927. 
ANEXOS 
Tabela 6.10: Resumo de estimativas dos parâmetros $\theta$ e $\quad \tau=\left(\tau_{1}, \tau_{2}\right)$ para as cadeias $M_{1}, M_{2}$ e $M_{3}$ geradas a partir da $1^{2}$ condição inicial, para o exemplo 6.2 .

\begin{tabular}{|c|c|c|c|c|c|c|}
\hline \multirow[t]{2}{*}{ Parâmet } & \multicolumn{5}{|c|}{ Estatisticas } & \multirow{2}{*}{$\begin{array}{l}\mathrm{N}^{0} \mathrm{de} \\
\text { Iteraç. }\end{array}$} \\
\hline & Média & D. padrāo & Interv. Cred. & Estimador & Tam.Amost. & \\
\hline $\begin{array}{l}\text { Theta } \\
\text { Tau } 1 \\
\text { Tau } 2\end{array}$ & $\begin{array}{l}107,2000 \\
0,009518 \\
0,003442 \\
\end{array}$ & $\begin{array}{l}0,040860 \\
0,000109 \\
0,000022 \\
\end{array}$ & -- & Rao-Black & \multirow{2}{*}{$\begin{array}{c}100 \\
\text { (selecionada) }\end{array}$} & \multirow{4}{*}{$\begin{array}{l}2000 \\
\left(\mathrm{M}_{1}\right)\end{array}$} \\
\hline $\begin{array}{l}\text { Theta } \\
\text { Tau } 1 \\
\text { Tau } 2\end{array}$ & $\begin{array}{l}107,2000 \\
0,009510 \\
0,003433\end{array}$ & $\begin{array}{l}0,966100 \\
0,001381 \\
0,000451\end{array}$ & $\begin{array}{l}105,400: 109,000 \\
0,00697: 0,01276 \\
0,00251: 0,00435\end{array}$ & Mont-Carl & & \\
\hline $\begin{array}{l}\text { Theta } \\
\text { Tau } 1 \\
\text { Tau } 2 \\
\end{array}$ & $\begin{array}{l}107,2000 \\
0,009528 \\
0,003445 \\
\end{array}$ & $\begin{array}{l}0,042320 \\
0,000109 \\
0,000022\end{array}$ & $\cdots$ & Rao-Black & \multirow{2}{*}{$\begin{array}{c}1000 \\
\text { (ñ-selecion.) }\end{array}$} & \\
\hline $\begin{array}{l}\text { Theta } \\
\text { Tau } 1 \\
\text { Tau } 2\end{array}$ & $\begin{array}{l}107,2000 \\
0,009501 \\
0,003448 \\
\end{array}$ & $\begin{array}{l}0,887400 \\
0,001373 \\
0,000478\end{array}$ & $\begin{array}{l}105,000: 109,000 \\
0,00707: 0,01234 \\
0,00257: 0,00444\end{array}$ & Mont-Carl & & \\
\hline $\begin{array}{l}\text { Theta } \\
\text { Tau } 1 \\
\text { Tau } 2\end{array}$ & $\begin{array}{c}107,2 \\
0,009546 \\
0,003446 \\
\end{array}$ & $\begin{array}{l}0,042520 \\
0,000085 \\
0,000017 \\
\end{array}$ & -..- & Rao-Black & 100 & \multirow{4}{*}{$\begin{array}{l}5000 \\
\left(\mathrm{M}_{2}\right)\end{array}$} \\
\hline $\begin{array}{l}\text { Theta } \\
\text { Tau } 1 \\
\text { Tau } 2 \\
\end{array}$ & $\begin{array}{c}107,2 \\
0,009578 \\
0,003470 \\
\end{array}$ & $\begin{array}{l}0,777100 \\
0,001284 \\
0,000475 \\
\end{array}$ & $\begin{array}{l}105,700: 108,600 \\
0,00732: 0,01236 \\
0,00270: 0,00448\end{array}$ & Mont-Carl & (selecionada) & \\
\hline $\begin{array}{l}\text { Theta } \\
\text { Tau } 1 \\
\text { Tau } 2\end{array}$ & $\begin{array}{c}107,2 \\
0,009533 \\
0,003446 \\
\end{array}$ & $\begin{array}{l}0,041605 \\
0,000073 \\
0,000019 \\
\end{array}$ & $-\cdots$ & Rao-Black & \multirow{2}{*}{ 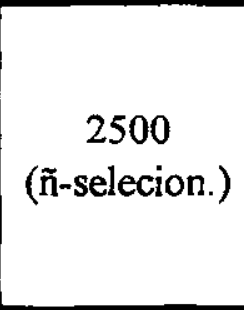 } & \\
\hline $\begin{array}{l}\text { Theta } \\
\text { Tau } 1 \\
\text { Tau } 2 \\
\end{array}$ & $\begin{array}{c}107,2 \\
0,009522 \\
0,003439 \\
\end{array}$ & $\begin{array}{l}0,854200 \\
0,001323 \\
0,000472\end{array}$ & $\begin{array}{l}105,500: 108,800 \\
0,00710: 0,01233 \\
0,00257: 0,00444\end{array}$ & Mont-Carl & & \\
\hline $\begin{array}{l}\text { Theta } \\
\text { Tau } 1 \\
\text { Tau } 2\end{array}$ & $\begin{array}{c}107,2 \\
0,009518 \\
0,003444\end{array}$ & $\begin{array}{l}0,044564 \\
0,000120 \\
0,000021\end{array}$ & -- & Rao-Black & 100 & \multirow{4}{*}{$\begin{array}{c}10000 \\
\left(\mathrm{M}_{3}\right)\end{array}$} \\
\hline $\begin{array}{l}\text { Theta } \\
\text { Tau } 1 \\
\text { Tau } 2\end{array}$ & $\begin{array}{c}107,2 \\
0,009693 \\
0,003435\end{array}$ & $\begin{array}{l}0,949900 \\
0,001304 \\
0,000487\end{array}$ & $\begin{array}{l}105,300: 109,100 \\
0,00775: 0,01245 \\
0,00254: 0,00416\end{array}$ & Mont-Carl & (selecionada) & \\
\hline $\begin{array}{l}\text { Theta } \\
\text { Tau } 1 \\
\text { Tau } 2 \\
\end{array}$ & $\begin{array}{c}107,2 \\
0,009526 \\
0,003445 \\
\end{array}$ & $\begin{array}{l}0,042497 \\
0,000120 \\
0,000021 \\
\end{array}$ & -- & Rao-Black & \multirow{2}{*}{ 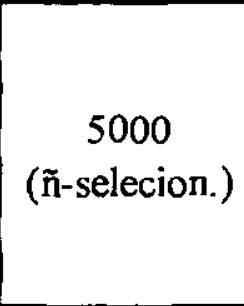 } & \\
\hline $\begin{array}{l}\text { Theta } \\
\text { Tau } 1 \\
\text { Tau } 2\end{array}$ & $\begin{array}{c}107,2 \\
0,009513 \\
0,003447\end{array}$ & $\begin{array}{l}0,895700 \\
0,001343 \\
0,000481\end{array}$ & $\begin{array}{l}105,400: 109,000 \\
0,00708: 0,01230 \\
0,00256: 0,00444\end{array}$ & Mont-Carl & & \\
\hline
\end{tabular}


Tabela 6.11: Resumo de estimativas dos parâmetros $\theta$ e $\tau=\left(\tau_{1}, \tau_{2}\right)$ para as cadeias $\mathbf{M}_{1}, \mathbf{M}_{2}$ e $\mathbf{M}_{3}$ geradas a partir da $2^{2}$ condição inicial, para o exemplo 6.2 .

\begin{tabular}{|c|c|c|c|c|c|c|}
\hline \multirow[t]{2}{*}{ Parâmet } & \multicolumn{5}{|c|}{ Estatísticas } & \multirow{2}{*}{$\begin{array}{l}\mathrm{N} \underline{0} \mathrm{de} \\
\text { Iteraç. }\end{array}$} \\
\hline & Média & D.padrão & Interv. Cred. & Estimador & Tam. Amost. & \\
\hline $\begin{array}{l}\text { Theta } \\
\text { Tau } 1 \\
\text { Tau } 2\end{array}$ & $\begin{array}{l}107,200 \\
0,00952 \\
0,00344\end{array}$ & $\begin{array}{l}0,040963 \\
0,000106 \\
0,000023 \\
\end{array}$ & - & Rao-Black & \multirow{2}{*}{$\begin{array}{c}100 \\
\text { (selecionada) }\end{array}$} & \multirow{4}{*}{$\begin{array}{l}2000 \\
\left(M_{1}\right)\end{array}$} \\
\hline $\begin{array}{l}\text { Theta } \\
\text { Tau } 1 \\
\text { Tau } 2\end{array}$ & $\begin{array}{l}107,300 \\
0,00956 \\
0,00350\end{array}$ & $\begin{array}{l}0.914100 \\
0,001368 \\
0,000446\end{array}$ & $\begin{array}{l}105,400: 109,200 \\
0,00719: 0,12550 \\
0,00262: 0,00448\end{array}$ & Mont-Carl & & \\
\hline $\begin{array}{l}\text { Theta } \\
\text { Tau } 1 \\
\text { Tau } 2\end{array}$ & $\begin{array}{l}107,200 \\
0,00953 \\
0,00344 \\
\end{array}$ & $\begin{array}{l}0,041560 \\
0,000106 \\
0,000019\end{array}$ & $-\infty$ & Rao-Black & \multirow{2}{*}{ 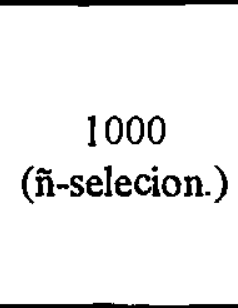 } & \\
\hline $\begin{array}{l}\text { Theta } \\
\text { Tau 1 } \\
\text { Tau } 2\end{array}$ & $\begin{array}{l}107,200 \\
0,00952 \\
0,00345\end{array}$ & $\begin{array}{l}0,844700 \\
0,001339 \\
0,000458\end{array}$ & $\begin{array}{l}105,500: 108,800 \\
0,00705: 0,01239 \\
0,00258: 0,00438\end{array}$ & Mont-Carl & & \\
\hline $\begin{array}{l}\text { Theta } \\
\text { Tau } 1 \\
\text { Tau } 2\end{array}$ & $\begin{array}{l}107,200 \\
0,00951 \\
0,00344 \\
\end{array}$ & $\begin{array}{l}0,043011 \\
0,000094 \\
0,000024 \\
\end{array}$ & - & Rao-Black & 100 & \multirow{4}{*}{$\begin{array}{l}5000 \\
\left(\mathrm{M}_{2}\right)\end{array}$} \\
\hline $\begin{array}{l}\text { Theta } \\
\text { Tau } 1 \\
\text { Tau } 2 \\
\end{array}$ & $\begin{array}{l}107,200 \\
0,00952 \\
0,00352 \\
\end{array}$ & $\begin{array}{l}0,972100 \\
0,001299 \\
0,000491\end{array}$ & $\begin{array}{l}105,600: 109,200 \\
0,00733: 0,01207 \\
0,00250: 0,00445\end{array}$ & Mont-Carl & (selecionada) & \\
\hline $\begin{array}{l}\text { Theta } \\
\text { Tau } 1 \\
\text { Tau } 2\end{array}$ & $\begin{array}{l}107,200 \\
0,00952 \\
0,00344 \\
\end{array}$ & $\begin{array}{l}0,042485 \\
0,000094 \\
0,000021 \\
\end{array}$ & $--\infty$ & Rao-Black & \multirow{2}{*}{$\begin{array}{c}2500 \\
\text { (ñ-selecion.) }\end{array}$} & \\
\hline $\begin{array}{l}\text { Theta } \\
\text { Tau 1 } \\
\text { Tau } 2\end{array}$ & $\begin{array}{l}107,200 \\
0,00953 \\
0,00344 \\
\end{array}$ & $\begin{array}{l}0,888600 \\
0,001338 \\
0,000479\end{array}$ & $\begin{array}{l}105,500: 109,000 \\
0,00714: 0,01226 \\
0,00257: 0,00443\end{array}$ & Mont-Carl & & \\
\hline $\begin{array}{l}\text { Theta } \\
\text { Tau } 1 \\
\text { Tau } 2\end{array}$ & $\begin{array}{l}107,200 \\
0,00953 \\
0,00344\end{array}$ & $\begin{array}{l}0,041133 \\
0,000085 \\
0,000020 \\
\end{array}$ & $-\cdots$ & Rao-Black & 100 & \multirow{4}{*}{$\begin{array}{r}10000 \\
\left(\mathrm{M}_{3}\right)\end{array}$} \\
\hline $\begin{array}{l}\text { Theta } \\
\text { Tau } 1 \\
\text { Tau } 2 \\
\end{array}$ & $\begin{array}{l}107,200 \\
0,00960 \\
0,00343 \\
\end{array}$ & $\begin{array}{l}0,818600 \\
0,001245 \\
0,000534 \\
\end{array}$ & $\begin{array}{l}105,700: 109,000 \\
0,00731: 0,01229 \\
0,00242: 0,00440\end{array}$ & Mont-Carl & (selecionada) & \\
\hline $\begin{array}{l}\text { Theta } \\
\text { Tau } 1 \\
\text { Tau } 2 \\
\end{array}$ & $\begin{array}{l}107,200 \\
0,00952 \\
0,00344 \\
\end{array}$ & $\begin{array}{l}0,042825 \\
0,000085 \\
0,000021 \\
\end{array}$ & $-m$ & Rao-Black & \multirow{2}{*}{$\begin{array}{c}5000 \\
\text { (ñ-selecion.) }\end{array}$} & \\
\hline $\begin{array}{l}\text { Theta } \\
\text { Tau } 1 \\
\text { Tau } 2\end{array}$ & $\begin{array}{l}107,200 \\
0,00952 \\
0,00344\end{array}$ & $\begin{array}{l}0,884700 \\
0,001329 \\
0,000491\end{array}$ & $\begin{array}{l}105,500: 109,000 \\
0,00707: 0,01223 \\
0,00251: 0,00444\end{array}$ & Mont-Carl & & \\
\hline
\end{tabular}


Tabela 6.12: Resumo de estimativas dos parâmetros $\theta$ e $\tau=\left(\tau_{1}, \tau_{2}\right)$ para as cadeias $\mathrm{M}_{1}, \mathrm{M}_{2}$ e $\mathrm{M}_{3}$ geradas a partir da $3^{\mathbf{a}}$ condição inicial, para o exemplo 6.2 .

\begin{tabular}{|c|c|c|c|c|c|c|}
\hline \multirow[t]{2}{*}{ Parâmet } & \multicolumn{5}{|c|}{ Estatísticas } & \multirow{2}{*}{$\begin{array}{l}\mathrm{N}^{0} \text { de } \\
\text { Iterac. }\end{array}$} \\
\hline & Média & D.padrão & Interv. Cred. & Estimador & Tam.Amost. & \\
\hline $\begin{array}{l}\text { Theta } \\
\text { Tau } 1 \\
\text { Tau } 2 \\
\end{array}$ & $\begin{array}{l}107,200 \\
0,00952 \\
0,00344 \\
\end{array}$ & $\begin{array}{l}0,045122 \\
0,000109 \\
0,000022 \\
\end{array}$ & --- & Rao-Black & \multirow{2}{*}{$\begin{array}{c}100 \\
\text { (selecionada) }\end{array}$} & \multirow{4}{*}{$\begin{array}{l}2000 \\
\left(M_{1}\right)\end{array}$} \\
\hline $\begin{array}{l}\text { Theta } \\
\text { Tau } 1 \\
\text { Tau } 2 \\
\end{array}$ & $\begin{array}{l}107,200 \\
0,00945 \\
0,00345\end{array}$ & $\begin{array}{l}0,897000 \\
0,001400 \\
0,000485\end{array}$ & $\begin{array}{l}105,500: 109,200 \\
0,00706: 0,01231 \\
0,00251: 0,00436\end{array}$ & Mont-Carl & & \\
\hline $\begin{array}{l}\text { Theta } \\
\text { Tau } 1 \\
\text { Tau } 2 \\
\end{array}$ & $\begin{array}{l}107,200 \\
0,00952 \\
0,00344 \\
\end{array}$ & $\begin{array}{l}0,043116 \\
0,000109 \\
0,000021 \\
\end{array}$ & ---- & Rao-Black & \multirow{2}{*}{$\begin{array}{c}1000 \\
\text { (ñ-selecion.) }\end{array}$} & \\
\hline $\begin{array}{l}\text { Theta } \\
\text { Tau } 1 \\
\text { Tau } 2\end{array}$ & $\begin{array}{l}107,100 \\
0,00951 \\
0,00345\end{array}$ & $\begin{array}{l}0,894000 \\
0,001351 \\
0,000485\end{array}$ & $\begin{array}{l}105,500: 108,900 \\
0,00713: 0,01230 \\
0,00255: 0,00445\end{array}$ & Mont-Carl & & \\
\hline $\begin{array}{l}\text { Theta } \\
\text { Tau } 1 \\
\text { Tau } 2 \\
\end{array}$ & $\begin{array}{l}107,200 \\
0,00953 \\
0,00344 \\
\end{array}$ & $\begin{array}{l}0,048651 \\
0,000089 \\
0,000022 \\
\end{array}$ & --- & Rao-Black & 100 & \multirow{4}{*}{$\begin{array}{l}5000 \\
\left(\mathrm{M}_{2}\right)\end{array}$} \\
\hline $\begin{array}{l}\text { Theta } \\
\text { Tau } 1 \\
\text { Tau } 2\end{array}$ & $\begin{array}{l}107,300 \\
0,00954 \\
0,00344 \\
\end{array}$ & $\begin{array}{l}0,887900 \\
0,001418 \\
0,000509\end{array}$ & $\begin{array}{l}105,600: 109,000 \\
0,00682: 0,01211 \\
0,00267: 0,00487\end{array}$ & Mont-Carl & (selecionada) & \\
\hline $\begin{array}{l}\text { Theta } \\
\text { Tau } 1 \\
\text { Tau } 2\end{array}$ & $\begin{array}{l}107,200 \\
0,00952 \\
0,00344\end{array}$ & $\begin{array}{l}0,043220 \\
0,000089 \\
0,000021\end{array}$ & --- & Rao-Black & \multirow{2}{*}{$\begin{array}{c}2500 \\
\text { (ñ-selecion.) }\end{array}$} & \\
\hline $\begin{array}{l}\text { Theta } \\
\text { Tau } 1 \\
\text { Tau } 2\end{array}$ & $\begin{array}{l}107,200 \\
0,00950 \\
0,00343 \\
\end{array}$ & $\begin{array}{l}0,893700 \\
0,001367 \\
0,000488 \\
\end{array}$ & $\begin{array}{c}105,400 \\
0,00694: 0,01241 \\
0,00252: 0,00446\end{array}$ & Mont-Carl & & \\
\hline $\begin{array}{l}\text { Theta } \\
\text { Tau } 1 \\
\text { Tau } 2 \\
\end{array}$ & $\begin{array}{l}107,200 \\
0,00952 \\
0,00344 \\
\end{array}$ & $\begin{array}{l}0,046658 \\
0,000125 \\
0,000015 \\
\end{array}$ & -- & Rao-Black & 100 & \multirow{4}{*}{$\begin{array}{c}10000 \\
\left(\mathrm{M}_{3}\right)\end{array}$} \\
\hline $\begin{array}{l}\text { Theta } \\
\text { Tau } 1 \\
\text { Tau } 2 \\
\end{array}$ & $\begin{array}{l}107,000 \\
0,00933 \\
0,00352 \\
\end{array}$ & $\begin{array}{l}0,858800 \\
0,001305 \\
0,000522 \\
\end{array}$ & $\begin{array}{l}105,300: 108,800 \\
0,00666: 0,01153 \\
0,00253: 0,00451\end{array}$ & Mont-Carl & (selecionada) & \\
\hline $\begin{array}{l}\text { Theta } \\
\text { Tau } 1 \\
\text { Tau } 2 \\
\end{array}$ & $\begin{array}{l}107,200 \\
0,00952 \\
0,00344 \\
\end{array}$ & $\begin{array}{l}0,042343 \\
0,000125 \\
0,000021 \\
\end{array}$ & --- & Rao-Black & \multirow{2}{*}{$\begin{array}{c}5000 \\
\text { (ñ-selecion.) }\end{array}$} & \\
\hline $\begin{array}{l}\text { Theta } \\
\text { Tau } 1 \\
\text { Tau } 2\end{array}$ & $\begin{array}{l}107,200 \\
0,00952 \\
0,00344\end{array}$ & $\begin{array}{l}0,897800 \\
0,001353 \\
0,000482\end{array}$ & $\begin{array}{l}105,400: 108,900 \\
0,00703: 0,01239 \\
0,00256: 0,00443\end{array}$ & Mont-Carl & & \\
\hline
\end{tabular}


Tabela 6.13: Resumo de estimativas dos parâmetros $\theta$ e $\tau=\left(\tau_{1}, \tau_{2}\right)$ para as cadeias $\mathrm{M}_{1}, \mathrm{M}_{2}$ e $\mathrm{M}_{3}$ geradas a partir da $4^{z}$ condição inicial, para o exemplo 6.2 .

\begin{tabular}{|c|c|c|c|c|c|c|}
\hline \multirow[t]{2}{*}{ Parâmet } & \multicolumn{5}{|c|}{ Estatísticas } & \multirow{2}{*}{$\begin{array}{l}\mathrm{N}^{0} \text { de } \\
\text { Iteraç. }\end{array}$} \\
\hline & Média & D.padrão & Interv. Cred. & Estimador & Tam. Amost. & \\
\hline Theta & 107,200 & 0,043577 & & \multirow{3}{*}{ Rao-Black } & \multirow{6}{*}{$\begin{array}{c}100 \\
\text { (selecionada) }\end{array}$} & \multirow{12}{*}{$\begin{array}{l}2000 \\
\left(M_{1}\right)\end{array}$} \\
\hline Tau 1 & 0,00954 & 0,000102 & --- & & & \\
\hline Tau 2 & 0,00344 & 0,000021 & & & & \\
\hline Theta & 107,300 & 0,814100 & $105,900: 108,700$ & \multirow{3}{*}{ Mont-Carl } & & \\
\hline Tau 1 & 0,00973 & 0,001404 & $0,00739: 0,01240$ & & & \\
\hline Tau 2 & 0,00351 & 0,000538 & $0,00261: 0,00483$ & & & \\
\hline Theta & 107,200 & 0,041928 & & \multirow{3}{*}{ Rao-Black } & \multirow{6}{*}{$\begin{array}{c}1000 \\
\text { (ñ-selecion.) }\end{array}$} & \\
\hline Tau 1 & 0,00953 & 0,000102 & --- & & & \\
\hline Tau 2 & 0,00344 & 0,000022 & & & & \\
\hline Theta & 107,300 & 0,874500 & $105,500: 109,100$ & \multirow{3}{*}{ Mont-Carl } & & \\
\hline Tau 1 & 0,00953 & 0,001322 & $0,00707: 0,01230$ & & & \\
\hline Tau 2 & 0,00345 & 0,000480 & $0,00258: 0,00448$ & & & \\
\hline Theta & 107,200 & 0,043023 & & \multirow{3}{*}{ Rao-Black } & & \multirow{12}{*}{$\begin{array}{l}5000 \\
\left(\mathrm{M}_{2}\right)\end{array}$} \\
\hline Tau 1 & 0,00952 & 0,000012 & -- & & & \\
\hline Tau 2 & 0,00344 & 0,000023 & & & 100 & \\
\hline Theta & 107,300 & 0,953700 & $105,300: 109,200$ & \multirow{3}{*}{ Mont-Carl } & (selecionada) & \\
\hline Tau 1 & 0,00955 & 0,001220 & $0,00723: 0,01221$ & & & \\
\hline Tau 2 & 0,00347 & 0,000518 & $0,00249: 0,00432$ & & & \\
\hline Theta & 107,200 & 0,042965 & & \multirow{3}{*}{ Rao-Black } & \multirow{6}{*}{ 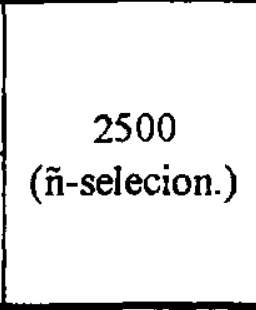 } & \\
\hline Tau 1 & 0,00952 & 0,000123 & $-\infty$ & & & \\
\hline Tau 2 & 0,00344 & 0,000020 & & & & \\
\hline Theta & 107,200 & 0,890900 & $105,400: 109,000$ & \multirow{3}{*}{ Mont-Carl } & & \\
\hline Tau 1 & 0,00951 & 0,001328 & $0,00705: 0,01231$ & & & \\
\hline Tau 2 & 0,00344 & 0,000494 & $0,00249: 0,00446$ & & & \\
\hline Theta & 107,200 & 0,043046 & & \multirow{3}{*}{ Rao-Black } & & \multirow{12}{*}{$\begin{array}{c}10000 \\
\left(\mathrm{M}_{3}\right)\end{array}$} \\
\hline Tau 1 & 0,00954 & 0,000088 & $\cdots$ & & & \\
\hline Tau 2 & 0,00344 & 0,000019 & & & 100 & \\
\hline Theta & 107,200 & 0,815500 & $105,400: 108,800$ & \multirow{3}{*}{ Mont-Carl } & (selecionada) & \\
\hline Tau 1 & 0,00933 & 0,001320 & $0,00702: 0,01194$ & & & \\
\hline Tau 2 & 0,00343 & 0,000497 & $0,00246: 0,00438$ & & & \\
\hline Theta & 107,200 & 0,042485 & \multirow{3}{*}{$\cdots$} & \multirow{3}{*}{ Rao-Black } & \multirow{6}{*}{$\begin{array}{c}5000 \\
\text { (ñ-selecion.) }\end{array}$} & \\
\hline Tau 1 & 0,00952 & 0,000088 & & & & \\
\hline Tau 2 & 0,00344 & 0,000020 & & & & \\
\hline Theta & 107,200 & 0,878300 & $105,400: 108,900$ & \multirow{3}{*}{ Mont-Carl } & & \\
\hline Tau 1 & 0,00953 & 0,001373 & $0,00703: 0,01243$ & & & \\
\hline Tau 2 & 0,00343 & 0,000489 & $0,00256: 0,00445$ & & & \\
\hline
\end{tabular}

